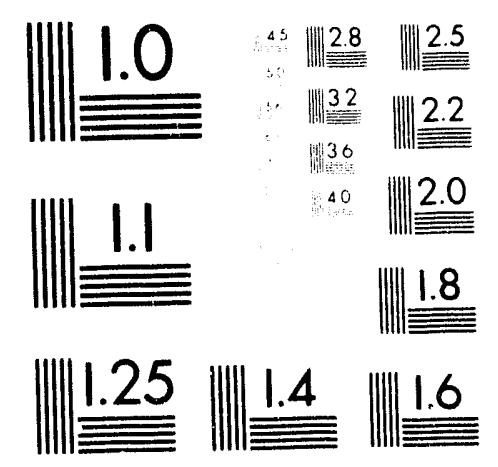



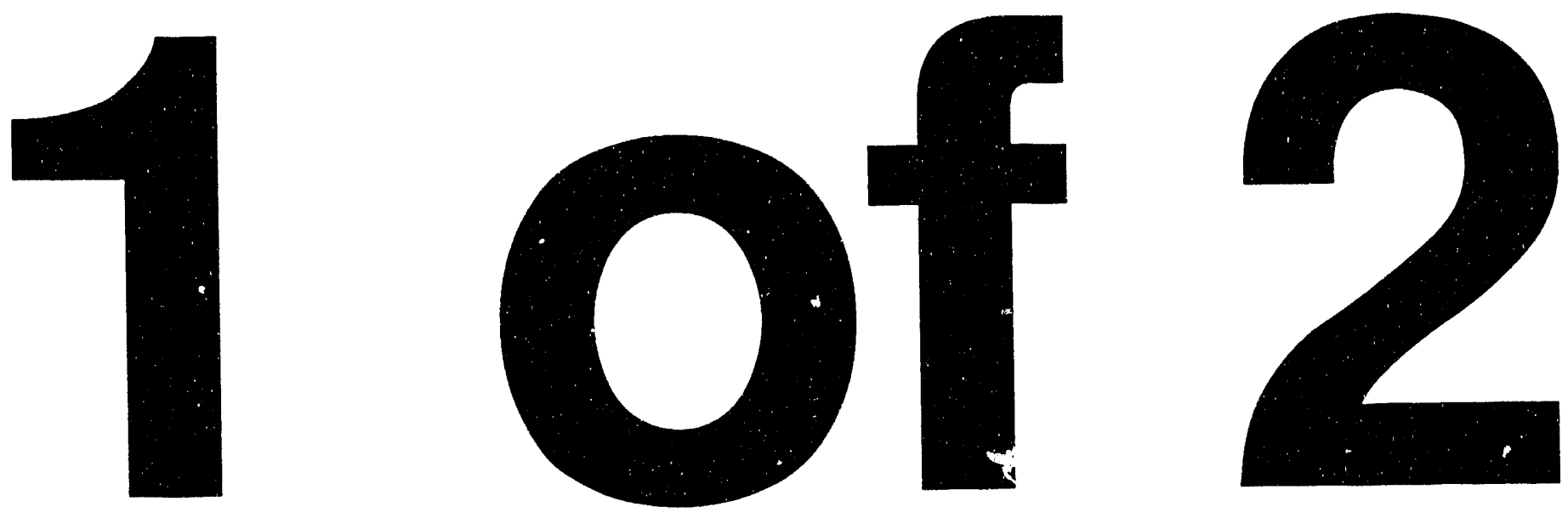


\title{
Review of Consolidated Edison's Integrated Resource Bidding Program
}

Charles A. Goldman, John F. Busch, Edward P. Kahn, Ross Baldick, Adele Milne

\author{
Energy \& Environment Division \\ Lawrence Berkeley Laboratory \\ University of California \\ Berkeley, CA 94720
}

July 1993

The work described in this report was funded by the Assistant Secretary for Conservation and Renewable Energy, Office of Utility Technologies, Office of Energy Manageraent of the U.S. Department of Energy under Contract No. DE-AC03-76SF00098 and by NYSERDA, under Contract No. 1515-EEED-BES-91. 


\section{Table of Contents}

Executive Summary $\ldots \ldots \ldots \ldots \ldots \ldots \ldots \ldots \ldots \ldots$

Chapter 1

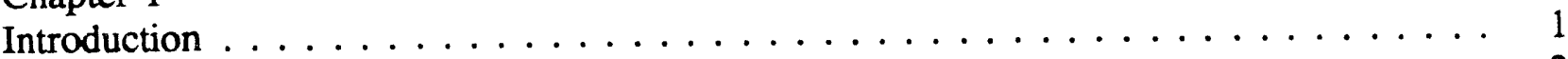

Organization of the Study $\ldots \ldots \ldots \ldots \ldots \ldots$

Chapter 2

Development of Competitive Bidding at Consolidated Edison . . . . . . . . . . 3

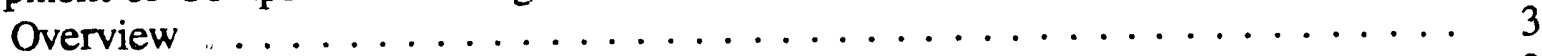

Electricity Situation in New York .................. 3

Regulatory Initiatives ...................... 6

Chapter 3

Design of the Bidding Program $\ldots \ldots \ldots \ldots \ldots \ldots \ldots \ldots \ldots$

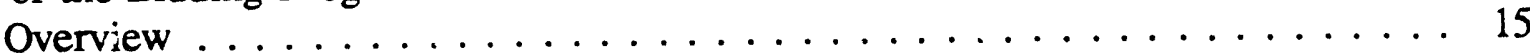

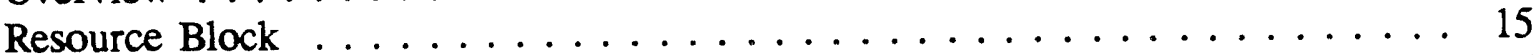

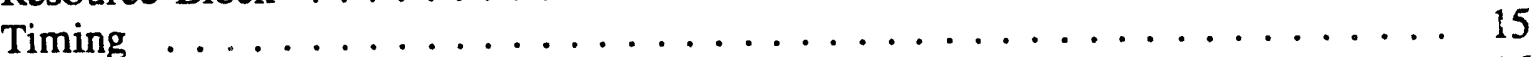

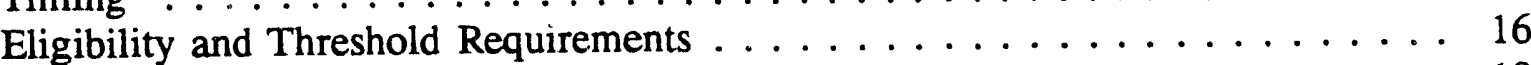

Scoring System $\ldots \ldots \ldots \ldots \ldots \ldots \ldots \ldots$

Chapter 4

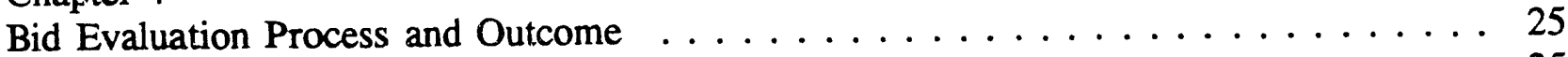

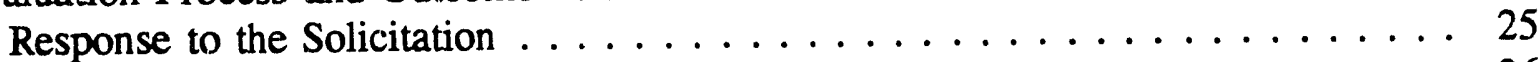

Con Edison's Bid Evaluation Process . . . . . . . . . . . . . . . 26

Preliminary Contract Award Group . . . . . . . . . . . . . . . . . . 27

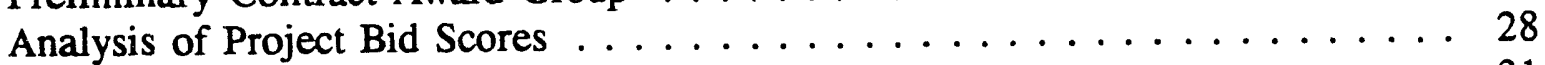

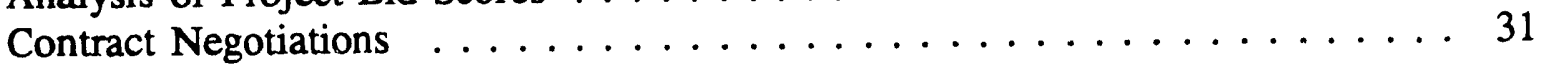

Chapter 5

Issues in the Bidding Program $\ldots \ldots \ldots \ldots \ldots \ldots \ldots \ldots \ldots \ldots$

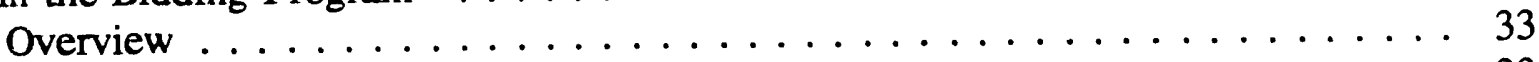

Lack of Participation by DSM Providers . . . . . . . . . . . . . 33

Incentives in the Scoring System . . . . . . . . . . . . . . . . 36

The Importance of Transmission and Distribution Impacts . . . . . . . . . . 44

Project Viability Issues $\ldots \ldots \ldots \ldots \ldots \ldots$ 


\section{Table of Contents (continued)}

Chapter 6

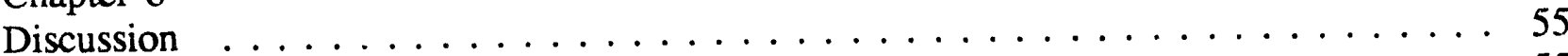

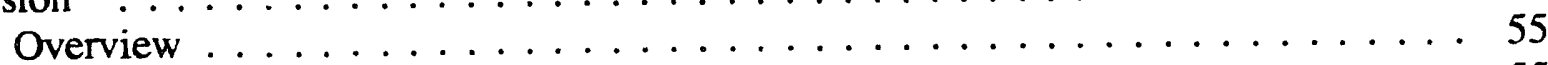

Indicators of Success $\ldots \ldots \ldots \ldots \ldots \ldots$

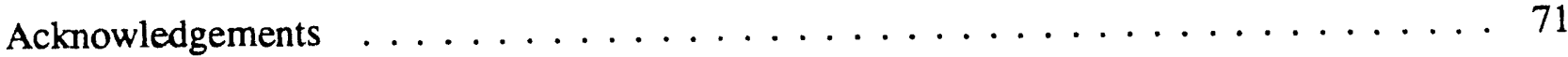

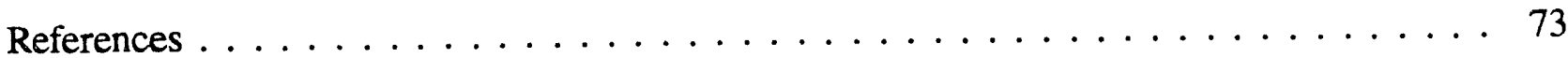

Appendix A

Reactions to Consolidated Edison's DSM Bidding Program . . . . . . . . . . . . 77

Appendix B

Survey of DSM Bidders $\ldots \ldots \ldots \ldots \ldots \ldots \ldots$

Appendix C

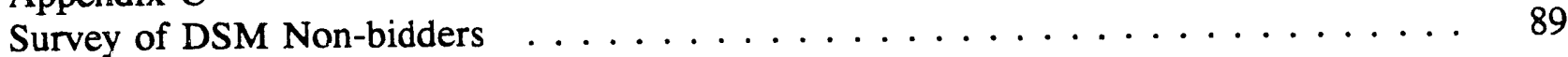

Appendix D

Questionnaire to Con Edison Staff Involved in Bidding Program . . . . . . . . . . 91

Appendix E

Impact of Fuel Escalation Rate on Bid Price 


\section{List of Tables}

Table 2-1. NYPP Load Growth and Reserve Margin . . . . . . . . . . . . . . 4

Table 2-2. $\quad$ Summary of Utility Summer Period Reserve Margin Deficiency

Dates and Amount of Capacity Surplus or Deficiency . . . . . . . . . . 5

Table 2-3. Origins of DSM Bidding in New York . . . . . . . . . . . . . 7

Table 2-4. NYPSC Guidelines on Bidding ................ 8

Table 2-5a. Public Comments and PSC Decision on Con Edison Bidding Program . . 10

Table 2-5b. Public Comments and PSC Decision on Con Edison Bidding Program (continued) ........................ 11

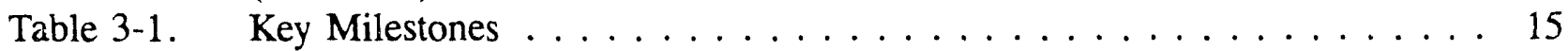

Table 3-2. Key Eligibility and Threshold Requirements . . . . . . . . . . . 16

Table 4-1. Profile of Supply Bids Submitted . . . . . . . . . . . . . . . . 25

Table 4-2. Preliminary Contract Award Group . . . . . . . . . . . . . . . 26

Table 4-3. Summary of Bid Scoring in Con Edison Solicitation . . . . . . . . . . . . 29

Table 5-1. Principal Reasons for Non-Participation . . . . . . . . . . . . . . . 34

Table 5-2. Ceiling Prices for DSM Measures $(\$ / \mathrm{kW}) \ldots \ldots \ldots \ldots$

Table 5-3. Example of Make-up Energy Adjustment's Effect on Choice

Between Two Hypothetical Bids . . . . . . . . . . . . . . . . . . 39

Table 5-4. Non-price Points Related to T\&D for Two Hypothetical Bids . . . . . . . 43

Table 5-5. Share of Transmission in Total Assets of Selected

Investor-Owned Electric Utilities . . . . . . . . . . . . . . . . . . 45

Table 5-6. T\&D Circuit Miles . . . . . . . . . . . . . . . . 46

Table 5-7. Implied Gas Premium . . . . . . . . . . . . . . . . . 51

Table 6-1. Market Response in Small vs. Large Bidding Programs . . . . . . . . . 57

Table 6-2. Development Status of Winning Projects in Niagara Mohawk and Con Edison Bidding Programs . . . . . . . . . . . . . . . 60

Table 6-3. Cost-Effectiveness of NMPC and Con Edison Bids with Signed

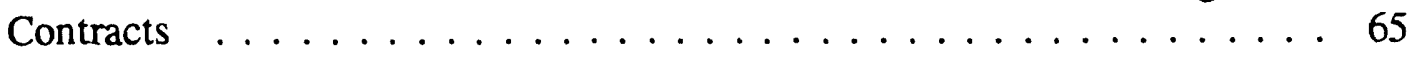

Table A-1. Principal Reasons for Non-Participation . . . . . . . . . . . . . . 78

Table E-1. Comparison of Different Gas Price Escalation Assumptions on the Bid Prices for the Brooklyn Navy Yard Projects . . . . . . . . . . 93

Table E-2. Brooklyn Navy Yard A as Bid . . . . . . . . . . . . . . . . . . 94

Table E-3. Brooklyn Navy Yard A Using Con Edison Fuel Price Escalator . . . . . . 95 
$\mid$
-
$=$
$=$
$=$
$=$
$\overline{-}$
$=$
$=$
$=$
$=$
$=$
$\overline{=}$

$-$

$=$

$\stackrel{-}{=}$

$=$

$=$
$=$
$=$

$\overline{\overline{-}}$

$-$

$=$

$\underline{\equiv}$ 
Figure 2-1. Chronology of New York Regulatory and Utility Actions . . . . . . . . . 6

Figure 3-1. Long-run Avoided Costs for Con Edison (1989) . . . . . . . . . . . . 19

Figure $3-2$. Estimating Make-up Energy . . . . . . . . . . . . . . 21

Figure 6-1. Status of Projects Awarded Thr ugh Bidding . . . . . . . . . . . . 59

Figure 6-2. Effect of Changed Market Conditions on Estimating Benefits of

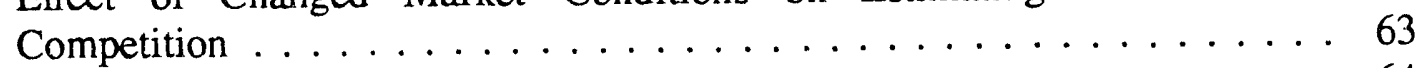

Figure $6-3$. Utility Payments to DSM Bidders . . . . . . . . . . . . . . 64 
Competitive bidding has emerged as the dominant method for procuring new resources by U.S. utilities. In New York, the Public Service Commission (NYPSC) ordered the state's seven investor-owned utilities to develop bidding programs to acquire supply and DSM resource options. Utilities were allowed significant discretion in program design in order to encourage experimentation. Competitive bidding programs pose formidable policy, design, and management challenges for utilities and their regulators. Yet, there have been few detailed case studies of bidding programs, particularly of those utilities that take on the additional challenge of having supply and DSM resources compete head-to-head for a designated block of capacity. To address that need, the New York State Energy Research \& Development Authority (NYSERDA), the New York Department of Public Service, and the Department of Energy's Integrated Resource Planning program asked Lawrence Berkeley Laboratory (LBL) to review the bidding programs of two utilities that tested the integrated, "all-sources" approach. This study focuses primarily on Consolidated Edison Company of New York's (Con Edison) bidding program; an earlier report discusses our review of Niagara Mohawk's program (Goldman et al 1992). We reviewed relevant Commission decisions, utility filings and signed contracts, interviewed utility and regulatory staff, surveyed DSM bidders and a selected sample of DSM non-bidders, and analyzed the bid evaluation system used in ranking bids based on detailed scoring information on individual bids provided by Con Edison.

Con Edison issued a Request for Proposals (RFP) in February 1990 requesting 200 MW of resources by May 1994. In the design of its RFP, Con Edison developed relatively stringent threshold requirements for both supply and DSM projects to assure reliable, acceptable resources and relied on a price-oriented scoring system. The market response by private power producers was impressive ( 35 unique supply sites offering $2976 \mathrm{MW}$ ), although relatively few bids were received from customers or energy service companies (five DSM bids representing about 12 MW). Con Edison ranked eligible supply and demand-side bids that met threshold and eligibility requirements using the following criteria: (1) price factor - the project sponsor's bid price which was adjusted for various factors (e.g., differences in energy output, contract term, plant availability, and transmission and distribution cost impacts) so that bids were evaluated on a comparable basis and (2) several non-price factors (e.g., environmental characteristics, project viability and level of risk, and project's ability to diversify the utility's fuel mix). Con Edison used an objective scoring system that ultimately ranked all bids in terms of an adjusted bid price ( $\$ / \mathrm{kW}$ on a net present value basis). In January 1991, Con Edison announced a Preliminary Contract Award Group of four DSM bids offering 10.5 MW of savings and five supply projects representing 204 MW. As of June 1993, Con Edison had signed contracts with two DSM bidders and three supply-side projects. 
The major findings from our review of Con Edison's bidding program are:

(1) The market response to Con Edison's bidding program by customers and energy service companies (ESCOs) was disappointing compared to the bidding programs of other utilities. The utility's threshold and eligibility requirements were the major barriers to participation by ESCOs.

Con Edison received only four DSM bids for $12 \mathrm{MW}$, even though the company had received 36 Notices of Intent from potential DSM bidders. Among customers, the principal barriers to participation appear to be: (1) high upfront bid preparation costs and (2) the perception that the risks and rewards of this bidding program were not particularly attractive compared to the utility's existing DSN' rebate programs. Among ESCOs, the major barriers to participation were: (1) various threshold and eligibility requirements that were perceived to be onerous, (2) limited number of eligible measures, and (3) perceived difficulties and uncertainties associated with marketing a project because Con Edison had proposed significantly higher rebates in its existing DSM programs for most eligible measures after the bidding RFP had been issued.

(2) We are critical of Con Edison's treatment and assessment of project viability issues. On the demand-side, the utility's approach contributed to the poor market response by DSM bidders. On the supply-side, the company's bid evaluation process had some limitations which made it more difficult to detect financial difficulties of several winning supply-side projects.

With respect to DSM resources, the design of the Con Edison bidding program discouraged most third-party DSM providers from even participating. Con Edison over-reacted in its concerns about potential project viability problems among ESCOs by establishing overly stringent threshold requirements. For example, Con Edison required that ESCOs obtain a letter of intent from each participating customer, which specified measures to be installed and the estimated demand reduction. Moreover, a winning ESCO was not allowed to substitute a project after a contract was signed with the utility if one of the customers with a letter of intent withdrew. Con Edison insisted that this threshold requirement was necessary to ensure the reliability of the size of the bid and to minimize the possibility of "double-counting" of savings by ESCOs that were marketing the same customers. This requirement was seen as onerous and unreasonable by potential DSM bidders based on our interviews and was given as a principal reason for nonparticipation by 14 of 23 respondents.

On the supply-side, one of the most unusual results of the Con Edison bidding program was the near coilapse and subsequent resuscitation of the developmeit firm which was awarded the vast majority of the contractual capacity rights. York Research was the managing partner or responsible agent for four separate projects which accounted for almost $90 \%$ of the total capacity in the Preliminary Contract Award Group (186 MW out of $215 \mathrm{MW}$ ). York ran into a number of difficulties with vendors and financial backers that called the viability of its projects into doubt. York's problems might have been identified if the RFP had included requirements regarding the financial viability of proposals (e.g., minimum debt service coverage ratios). Con 
Edison proposed such a measure in its draft RFP. However, several parties objected, including the PSC staff, and the Company withdrew this requirement in favor of a statement from a reputable financial institution that a project is financeable. Subsequently, York entered into an agreement with Mission Energy to develop the Con Edison projects. York Research proposed three gas-fired projects, which were based at the Brooklyn Navy Yard, with a pricing arrangement in which the variable costs of production escalated over the 30-year contract term at the rate of the GNP deflator rather than at a rate tied to natural gas prices. This type of indexation mechanism is quite unusual for gas-fired private power projects, particularly for such a long-term. Typically, developers attempt to link changes in gas costs to changes in revenues. The York projects illustrate one of the fundamental dilemmas of competitive bidding: when is an innovative and attractive offer too good to be true, and when is it a good deal? It is difficult to tell whether the unusual fuel pricing arrangements were an indicator of the subsequent problems experienced by the York projects. However, it appears that Con Edison had no procedure for evaluating non-standard offers in the fuel pricing area. We developed a simple method to assess the York project's gas pricing. Our analysis is not cefinitive but suggests that the York bid's fuel pricing arrarngements might have been interpreted as a signal of "nonviability" based on the unusually long term over which fuel price stability was being offered. However, given the difficulty faced by a utility in challenging innovative arrangements in gas supply contracting, anciher approach to the viability problem which might prove more feasible is to rely on portfolio diversification criteria in which the utility would seek to avoid a concentration of ownership among a set of winning bidders.

(3) Bid price and the transmission and distribution (T\&D) scoring adjustment, which was designed to reflect incremental (and opportunity) costs of additional T\&D capacity, were especially importaut in determining the outcome of Con Edison's solicitation.

Adjusted bid prices of winning bidders were $\$ 2200 / \mathrm{kW}$ lower on average than losing bidders. Differences in this initial unadjusted bid prices of winning bidders compared to losing bidders accounted for aboui $50 \%$ of this difference. In addition, the T\&D adjustment increased losing bids by $\$ 700 / \mathrm{kW}$ on average more than winning bids. We calculated that the bid evaluation penalty between a hypothetical bid that connected at transmission level compared to a bid that connected at distribution level was about $\$ 1077 / \mathrm{kW}$. Given the characteristics of the Con Edison service territory, this implies that the difference in costs for projects that interconnect at transmission vs. distribution level is valued at about $\$ 21 / \mathrm{kW}$-mile. By comparison, the cost for new overhead transmissioil capacity ranges between $\$ 1-2 / \mathrm{kW}$-mile where right-of-way is not particularly expensive. Con Edison's true incremental interconnection costs at transmission level appear to be quite high and therefore the scoring penalties were not unreasonable. The high interconnection costs favor baseload capacity because such units should produce larger benefits. However, Con Edison's scoring system goes too far in its orientation toward baseload projects by penalizing DSM bids through the "make-up" energy adjustment. 
Non-price factors, particularly environmental factors, turned out to have an insignificant effect in determining the outcome of the solicitation.

The scoring adjustment for environmental factors decreased the prices of winning bids by about $\$ 200 / \mathrm{kW}$ on average more than losing bids, which represents only about $10 \%$ of the difference in bid prices between average winning and losing bids.

Con Edison's competitive bidding process successfully elicited winning supply bids that were significantly lower than the utility's avoided costs; bid prices for winning DSM bids were only slightly below ceiling prices established by Con Edison for individual DSM measures. Development uncertainties associated with the York projects and dramatic changes in market conditions make it more difficult to estimate the benefits of competition.

Levelized costs for the three supply-side projects (170 MW) with signed contracts average about 7.0 cents $/ \mathrm{kWh}(1993 \$)$. However, as indicated earlier, the York projects are still under development. The prices offered by winning supply bids are substantially lower than the 1989 Commission-approved long-run avoided costs (LRACs). However, estimates of Con Edison's avoided costs have decreased significantly during the protracted bid evaluation and contract negotiation stages. Simply comparing winning bid prices to the utility's forecast avoided cost would overstate the benefits of competition. However, the competitive process appears to have worked reasonably well on the supply-side in eliciting market prices. The levelized total resource costs (TRC) for the two DSM projects (representing $7.4 \mathrm{MW}$ ) average 5.6 cents $/ \mathrm{kWh}$. These costs appear comparable to those observed in the bidding programs of other utilities, although data limitations (e.g., some utilities do not report all relevant costs, particularly customer cost contribution) limit our ability to draw definitive conclusions.

In this study, we also discuss methods that can be used to assess the relative benefits and risks of competitive bidding programs. Several "indicators of success" are identified which provide a framework for comparative analysis: (1) market response, (2) project viability (the percentage of projects and MWs with signed contracts that successfully develop), (3) economic benefits to ratepayers compared to alternatives, and (4) processes that are administratively tractable, workable, and perceived to be fair. We draw upon our case studies of the bidding programs of both Con Edison and Niagara Mohawk to illustrate the types of issues that PUCs and utilities should consider as they review results from the first-generation of bidding programs (see Goldman et al. 1992). Compared to most other states, the process and outcomes of the bidding programs of New York utilities have been subject to more public scrutiny and review by third parties. Because there have been few detailed case studies of utility bidding programs, wellestablished evaluation criteria do not exist. Thus, the analysis is not definitive but does suggest that a more comprehensive evaluation framework could be useful to regulators and utilities, but will require refined analytic methods and increased availability and consistent reporting of cost and performance data. 


\section{Chapier 1 \\ Introduction}

Competitive bidding originated as a reform of the Public Utility Regulatory Policies Act (PURPA) which created a process for utilities to purchase power from certain private producers. Since the first Requests for Proposals (RFPs) in 1984, competitive bidding for electric resources has been both prolific and varied. As of February 1993, 70 U.S. utilities in twenty-eight states had instituted over one hundred solicitations requesting over $26 \mathrm{GW}$ of power (Current Competition 1993). In twenty states, bidding has bein restricted to private power producers. Utilities in a number of states have also used bidding as a mechanism to acquire demand-side (DSM) resources, although experimentation has been more limited.

In New York, the Public Service Commission (NYPSC) ordered the state's seven investor-owned utilities to develop competitive bidding programs that were applicable to both supply and DSM resource opitons (NYPSC 1988a). However, utilities were allowed significant discretion in auction design, and had the option of either establishing separate, parallel auctions for supply and DSM resources, or including both supply and demand-side optioins in a single "integrated" auction. The NYPSC wanted to encourage experimentation among utilities in terms of program design, subject to the usual caveat that the utility's bidding program was consistent with Commission decisions and pol.cy guidelines.

Competitive bidding programs pose formidable policy, design, and management challenges for utilities and their regulators. Yet there have been few systematic reviews or detailed case studies of bidding programs, particularly of those utilities that take on the additional challenge of having supply and DSM resources compete head-to-head on an equal footing for a designated blinck of capacity. To address that need, the New York State Energy Research \& Development Authority (NYSERDA), the New York Department of Public Service, and the Department of Energy's Integrated Resource Planning program asked Lawrence Berkeley Laboratory (LBL) to review the bidding programs of Niagara Mohawk Power Company (NMPC) and Consolidated Edison Company of New York (Con Edison). The decision was made to focus on these two utilities, in part because both utilities developed RFPs that tested the integrated, all-source approach in an explicit fashion. This study focuses primarily on the Con Edison bidding program; an earlier report discusses our review of Niagara Mohawk's program (Goldman et al. 1992).

In February 1990, Con Edison issued a Request for Proposals (RFP) that requested offers from potential supply-side and DSM bidders to supply $200 \mathrm{MW}$ of resources by May 1994. The Company indicated that its ranking procedure (i.e., total overall adjusted cost per capacity bid on a net present value basis) would be the only criteria used to rank eligible supply and demandside bids that met threshold and eligibility requirements. Con Edison received 47 bids consisting of four DSM bids representing about $12 \mathrm{MW}$ and 43 supply-side bids. Eight of the supply-side proposals vere alternate bids for the same site, thus there were 35 unique supply sites offering 2976 MW. In January 1991, Con Edison announced that three DSM bids offering 10.5 MW 
of savings and five supply projects representing $204 \mathrm{MW}$ had been selected for the Preliminary Contract Award Group. As of May 1993, Con Edison had signed contracts with two of the DSM firms representing 8.2 MW, while one DSM bidder withdrew its project. Con Edison had signed contracts with three supply-side projects, but as of this writing was still negotiating with two supply project sponsors.

Our analysis builds on and is intended to complement activities of the Bidding Working Group (supply-side and demand-side) being conducted under the direction of the New York Department of Public Service's Office of Regulatory Economics and Office of Energy Efficiency and Environment. In terms of overall approach, we reviewed relevant Commission decisions, utility filings, and testimony offered by various parties during the development of the Con Edison. bidding RFP. Con Edison also provided us with information on its quantitative evaluation and scoring of individual bids (on a confidential basis). We also surveyed DSM bidders and a selected sample of DSM non-bidders and had discussions with regulatory and utility staff.

\subsection{Organization of the Study}

Chapter 2 describes the evolution and context for integrated resource bidding at Con Edison, highlighting those factors that shaped the company's program. Chapter 3 reviews the key features of Con Edison's bidding program. Chapter 4 describes the market response of bidders to the solicitation and examines the way that the ranking system worked in practice in the company's selection of a Preliminary Contract Award Group. Chapter 5 analyzes Con Edison's bid evaluation and scoring system in more detail. Chapter 6 discusses several key policy issues that are raised by Con Edison's bidding experiment. This chapter builds on our previous work which reviewed the Niagara Mohawk integrated bidding prograin as well as the experience and lessons learned from other utilities that are implementing competitive resource procurements. 


\section{Chapter 2 \\ Development of Competitive Bidding at Consolidated Edison}

\subsection{Overview}

This chapter discusses the context in which New York utilities developed competitive bidding programs. In the late 1980s, there was general agreement among New York's utilities and regulatory agencies that additional resources would be needed by the early to mid-1990s. In response, the Public Service Commission (PSC) initiated a proceeding (Case 29409) to examine plans for meeting the state's future electricity needs, which produced a series of orders, including the Commission's rulings on bidding. During this period, the PSC also directed utilities to file long-range DSM plans, offer full-scale, system-wide DSM programs to all customer classes, and suggest ratemaking mechanisms that would overcome financial barriers to promoting energy efficiency options. The PSC consciously chose to implement bidding quickly and recognized that its "learning by doing" approach would inevitably lead to some successes and failures which would be corrected as part of an iterative process. The PSC provided general guidelines on bidding but utilities had significant discretion in program design. The utilities also had primary responsibility for sorting out and ultimately reconciling the consequences of the PSC's DSM policy initiatives with bidding guidelines that required inclusion of demand-side providers.

\subsection{Electricity Situation in New York}

In its 1988 long-term forecast, the New York Power Pool (NYPP 1988) projected that statewide reserve margins would drop below twenty percent between 1991 and 1996 depending on load growth, without acquisition of additional generating capacity (see Table 2-1). ${ }^{1}$ In the State Energy Plan, the New York State Energy Office (NYSEO 1989) noted that the need for new resources varied significantly among utilities (see Table $2-2) .{ }^{2}$ During this period, the prevailing view was that several of the state's utilities (e.g., Orange and Rockland, Long Island Lighting Company, and Con Edison) were likely to need additional resources by the early-1990s with the principal uncertainties being actual load growth, level of independent power production, achievement of DSM

\footnotetext{
${ }^{1}$ Non-utility sources of supply are not included.

${ }^{2}$ Note that NMPC and New York State Electric and Gas (NYSEG) are winter-peaking utilities.
} 


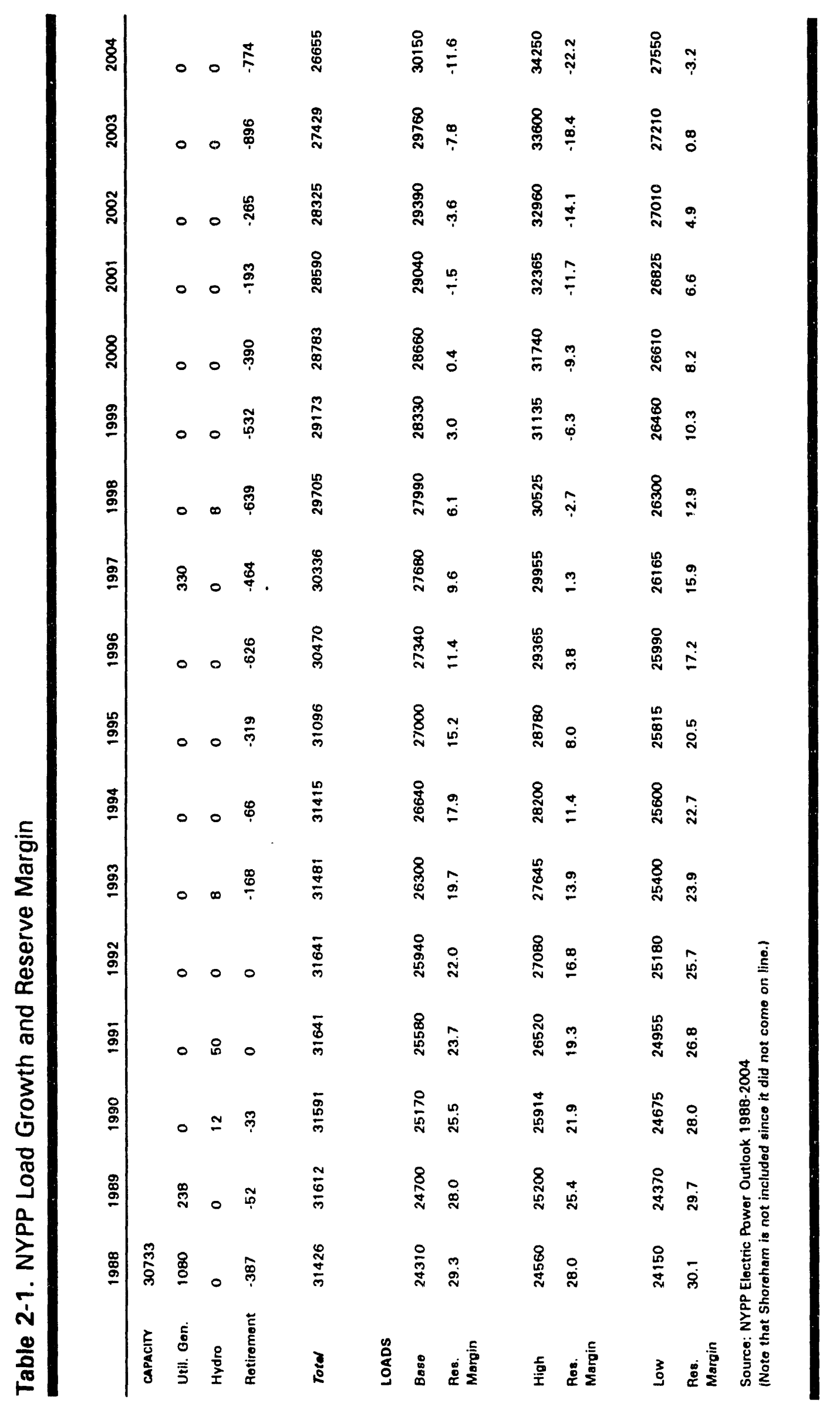


Table 2-2. Summary of Utility Summer Period Reserve Margin Deficiency Dates and Amount of Capacity Surplus or Deficiency

\begin{tabular}{|c|c|c|c|}
\hline Utility & $\begin{array}{l}\text { Date of First } \\
\text { Summer Period } \\
\text { Capacity Deficiency }\end{array}$ & $\begin{array}{l}\text { Reserve Margin } \\
\text { Capacity (MW) } \\
\text { Deficiency in } 1988\end{array}$ & $\begin{array}{l}\text { Reserve Margin } \\
\text { Capacity (MW) } \\
\text { Deficiency in } 2008\end{array}$ \\
\hline Central Hudson & 1997 & -4 & -105 \\
\hline Con Ed & 1991 & -412 & -3432 \\
\hline Long Island Lighting Co. & $1994^{1}$ & -187 & -1920 \\
\hline NYSEG & 1998 & -25 & -827 \\
\hline Niagara Mohawk & 1997 & -196 & -2034 \\
\hline Orange \& Rockland & $1989^{2}$ & -139 & -582 \\
\hline Rochester Gas \& Electric & 1991 & -259 & -784 \\
\hline \multicolumn{4}{|c|}{$\begin{array}{l}\text { A small projected deficiency occurs for two years in } 1990 \text { and } 1991 \text {. Small surpluses occur in } 1992 \text { and } 1993 \text { as a } \\
\text { result of increased DSM, IPPs and planngd purchase of Gilboa capacity from NYPA and completion of Long Island } \\
\text { Sound Cable Project. Deficiencies resume and continue in } 1994 \text {. } \\
2 \text { O\&R has entered into short-term capacity contracts for the next few years. }\end{array}$} \\
\hline
\end{tabular}

savings, and approval of utility plans for life extension of existing oil and coal-fired generating units. $^{3}$

However, the overall resource outlook had changed significantly by 1991 , which is the period when Con Edison was evaluating bids received in its first RFP. Specifically, the need to acquire additional resources was perceived to be less urgent due to a combination of factors. For example, the 1991 update of the State Energy Plan concluded that the state's utilities had adequate capacity to meet anticipated load growth throughout the planning period, primarily because of lower energy demand and aggressive utility DSM programs (NYSEO 1991). This provides the backdrop for regulatory initiatives on integrated resource planning (IRP) and bidding.

\footnotetext{
${ }^{3}$ Con Edison's primary intent in issuing the RFP was to satisfy the PSC's desire to conduct a test of competitive procurement.
} 


\subsection{Regulatory Initiatives}

Figure 2-1. Chronology of New York Regulatory and Utility Actions

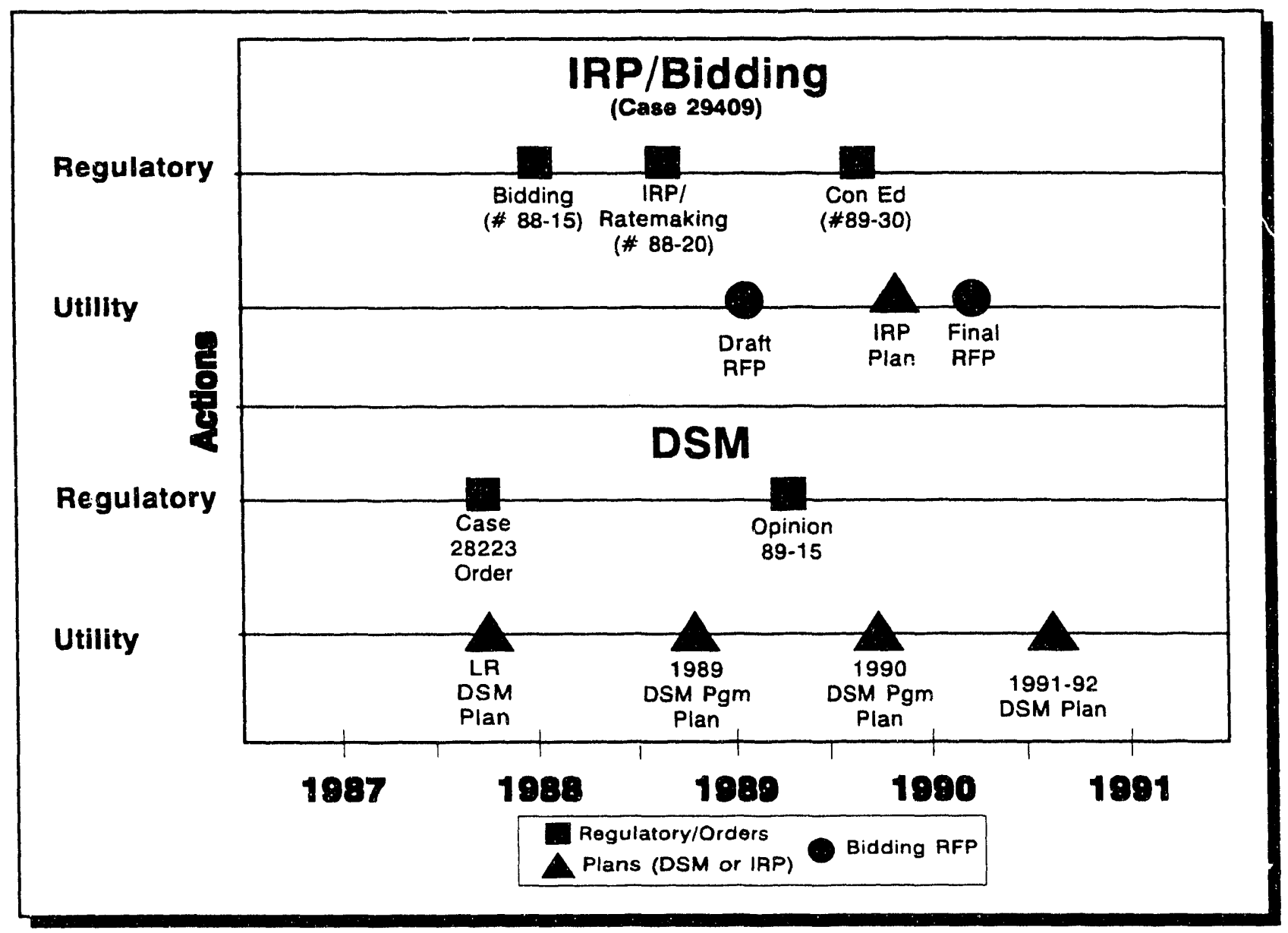

Figure 2-1 provides a chronology of major regulatory decisions in New York on IRP, competitive bidding, and DSM. The New York PSC developed its policies on bidding and DSM in two major proceedings, Case 29409 and Case 28223 (see Goldman et al. 1992 for a more detailed discussion of these regulatory initiatives). 


\subsubsection{Regulatory Guidelines on Bidding}

There were two major phases in the development process of New York's bidding program. In the first phase (of Case 29409), several working groups investigated broad policy issues and developed position papers on various topics. ${ }^{4}$ This phase culminated in the Commission's bidding guidelines and policies issued in June 1988 (NYPSC 1988a).

Table 2-3 provides a summary of key events prior to the Commission's decision and highlights the fact that inclusion of DSMi resource options in bidding was among the more contentious issues. The Bidding Working Group initially focused on issues related to the selection of generation resources. The feasibility and desirability of adding a demand-side component to the bidding program was proposed by New York State Energy Research Development and Authority, NYSEO, and Department of Public Service staff.

Policy and implementation issues associated with DSM bidding were not discussed at nearly the same level of detail as generation options by the Bidding Working Group. The Commission's guidelines on bidding also reflect this basic thrust directed toward supply-side considerations (see Table 2-4). For example, in discussing eligible participants, the Order mentions only QFs and non-QF producers, while demand-side providers are discussed under additional considerations:

Bidders of demand-side management (DSM) projects are not precluded from participating in utilities' auctions... If DSM options are not included alongside supply-side options in a single auction, a system of
Table 2-3. Origins of DSM Bidding in New York

\begin{tabular}{|c|c|}
\hline Date & Activity \\
\hline 1987 & $\begin{array}{l}\text { Working group focuses on supply } \\
\text { issues }\end{array}$ \\
\hline Summer 1987 & $\begin{array}{l}\text { NYSERDA, SEO, and DPS propose } \\
\text { that bidding for DSM resources be } \\
\text { considered }\end{array}$ \\
\hline October 1987 & Conference on bidding held \\
\hline December 1987 & $\begin{array}{l}\text { Bidding Working group identifies } 15 \\
\text { issues for DSM bidding }\end{array}$ \\
\hline December 1987 & $\begin{array}{l}\text { ALJ recommendation on bidding: } \\
\text { proceed with capacity bidding but } \\
\text { DSM resources should not be } \\
\text { included }\end{array}$ \\
\hline Early 1988 & $\begin{array}{l}\text { State agencies and several } \\
\text { intervenors active in working group } \\
\text { file briefs opposing ALJ } \\
\text { recommendation on DSM bidding }\end{array}$ \\
\hline March 1988 & Workshop on DSM Bidding \\
\hline
\end{tabular}


Table 2-4. NYPSC Guidelines on Bidding

\begin{tabular}{|c|c|}
\hline Issue & Guideline \\
\hline Eligible Participants & QF, IPP \\
\hline Bid Process Evaluation and Selection & $\begin{array}{l}\text { RFP should use objective ranking system, but utility is } \\
\text { permitted to exercise subjective judgement }\end{array}$ \\
\hline Ranking Criteria & $\begin{array}{l}\text { RFP should include the following factors and their } \\
\text { weights: price, payment stream, dispatchability, fuel } \\
\text { diversity, location, availability of production, } \\
\text { environmental impacts, likelihood of project } \\
\text { completion }\end{array}$ \\
\hline Ceiling Price & $\begin{array}{l}\text { Cost of utility's own optimal generating plan, } \\
\text { including price and non-price factors }\end{array}$ \\
\hline Performance Security & Required \\
\hline $\begin{array}{l}\text { Participation of } \\
\text { Utility Subsidiaries }\end{array}$ & $\begin{array}{l}\text { Participation allowed with additional procedural } \\
\text { safeguards: } \\
\text { 1) sealed bids opened by independent party } \\
\text { 2) ratemaking adjustment on utility earnings will } \\
\text { be imposed if unfair or abusive practice } \\
\text { is discovered }\end{array}$ \\
\hline $\begin{array}{l}\text { Availability of } \\
\text { Information }\end{array}$ & $\begin{array}{l}\text { Utility must provide information on utility system } \\
\text { planning to IPPs on timely basis and in sufficient } \\
\text { detail }\end{array}$ \\
\hline New Utility Generation & "Supplier of Last Resort" \\
\hline Source: NYPSC 1988a & \\
\hline
\end{tabular}

sfparate, parallel auctions should be established. In designing the details of their specific auction processes, the utilities should set forth proposals for including DSM options in an overall auction process, or if separate auctions are required, set forth the details of the DSM auction and its links to the supply-side auction (NYPSC 1988a).

In the second phase, utilities filed bidding guidelines and an RFP for supply and DSM resources in order to comply with the PSC's decision. In this phase, the focus was more on program design and implementation issues. Con Edison submitted its initial bidding plan in December 1988 and PSC staff and six other interested parties filed comments on Con Edison's proposed RFP and sample contract. ${ }^{5}$ In February 1989, Con Edison filed comments replying to issues raised by the parties and, in some cases, modified its program design (Con Edison 1989).

\footnotetext{
${ }^{s}$ Comments were also filed by New York State Energy Office (NYSEO), Sentinel Energy Savings Corporation (SESCO), Long Lake Energy Corporation, Independent Power Producers of New York (IPPNY), Multiple Intervenors, and City of New York.
} 
Parties then filed comments responding to Con Edison's revisions and a meeting of the parties was held to discuss outstanding issues. The comment and review process was rather protracted because there were many contested issues. In September 1989, the PSC issued a decision which addressed the various issues raised by the parties (NYPSC 1989b). ${ }^{6}$ The Commission typically endorsed the compromises reached by the parties on program design and contract features.

The PSC also had to resolve many contested issues. Table 2-5 provides a summary of the positions of the interested parties on selected key issues and the PSC's ultimate decision. There were major disagreements among the parties on the Company's demonstration of resource need, appropriate threshold and eligibility requirements, and several bid evaluation and scoring criteria. Several parties argued that Con Edison had provided insufficient information on the Company's justification and rationale for $200 \mathrm{MW}$ as an appropriate size for the capacity block to be bid. These parties emphasized the importance of an explicit linkage between the utility's integrated resource plan and its resource acquisition strategies. Con Edison's position was that the $200 \mathrm{MW}$ capacity block was sufficient to provide a test of bidding, although the Company had no explicit need for capacity.

With respect to threshold requirements for DSM bidders, parties criticized Con Edison's program design as too restrictive with respect to eligible measures, market sectors and requiring energy service companies to include letters of intent from each participating customer in order to demonstrate the reliability of proposed demand reductions. Regarding the threshold requirements for supply-side options, several parties argued that Con Edison's proposed availability requirements were too high and inappropriate as a threshold requirement. Con Edison's view was that threshold requirements were no different than required for its own units. The Independent Power Producers of New York (IPPNY) also found Con Edison's request that private producers grant the utility the right of first refusal upon sale during or at the end of the contract to be particularly objectionable. On a number of these threshold requirements, the Commission sided with the PSC staff or other parties and ordered Con Edison to revise its RFP (see Table 2-5). However, the Commission did support Con Edison's position (with some reservations) on the critical issue of requiring ESCOs to have signed letters of intent from all participating customers. The PSC also tended to reaffirm Con Edison's position on most issues related to bid evaluation and scoring, with the important exception of non-price environmental factors. For example, the PSC approved Con Edison's proposal for different ceiling prices for individual DSM measures and its procedures to adjust bid prices (i.e., makeup energy, and contract term adjustments). The PSC gave utility management significant latitude in these areas in the spirit of experimentation, although the Commission expressed some reservations regarding Con Edison's approach.

\footnotetext{
- The PSC resolved several issues presented in petition for re-hearing in an Order issued on January $10,1990$.
} 


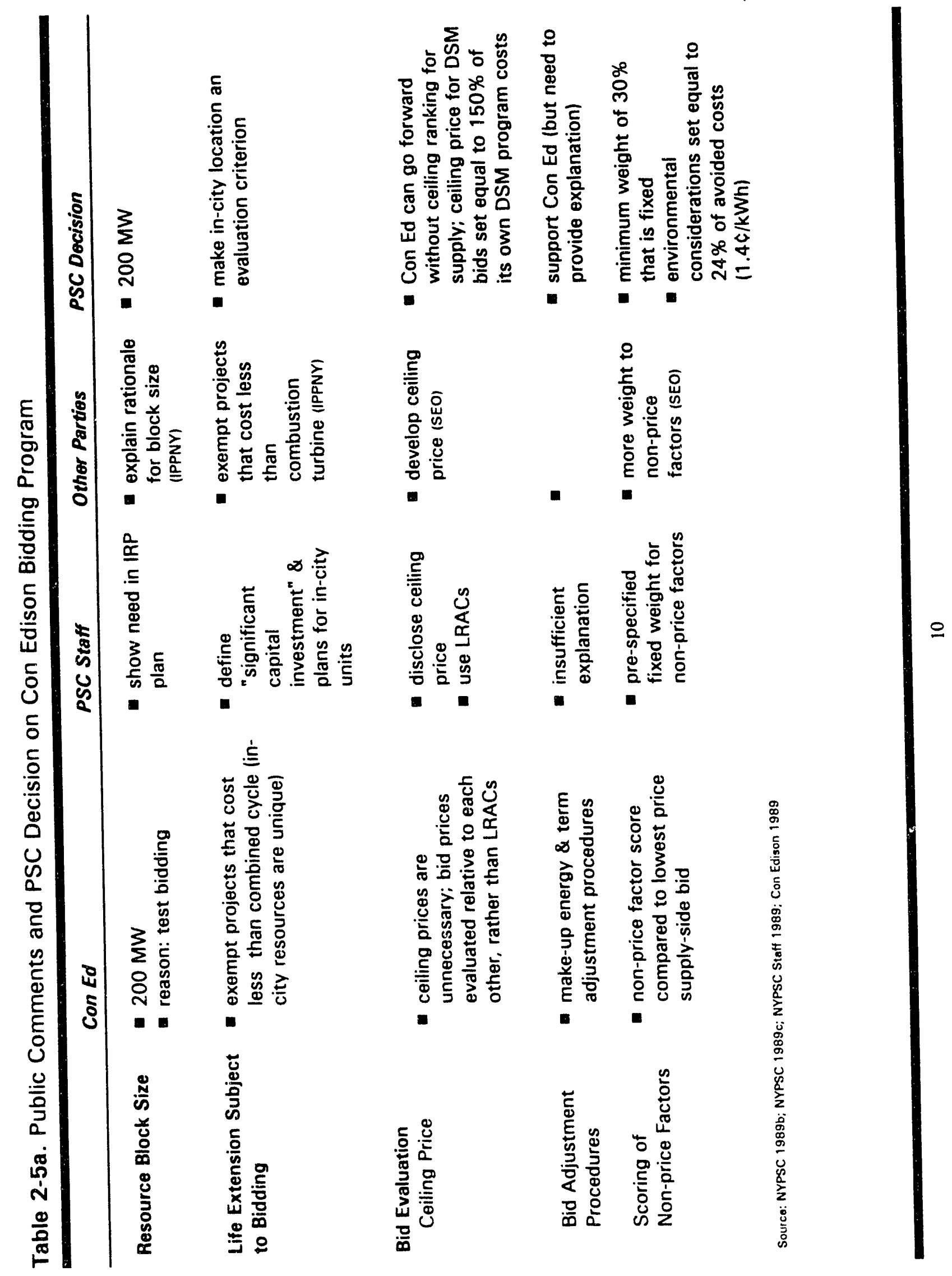




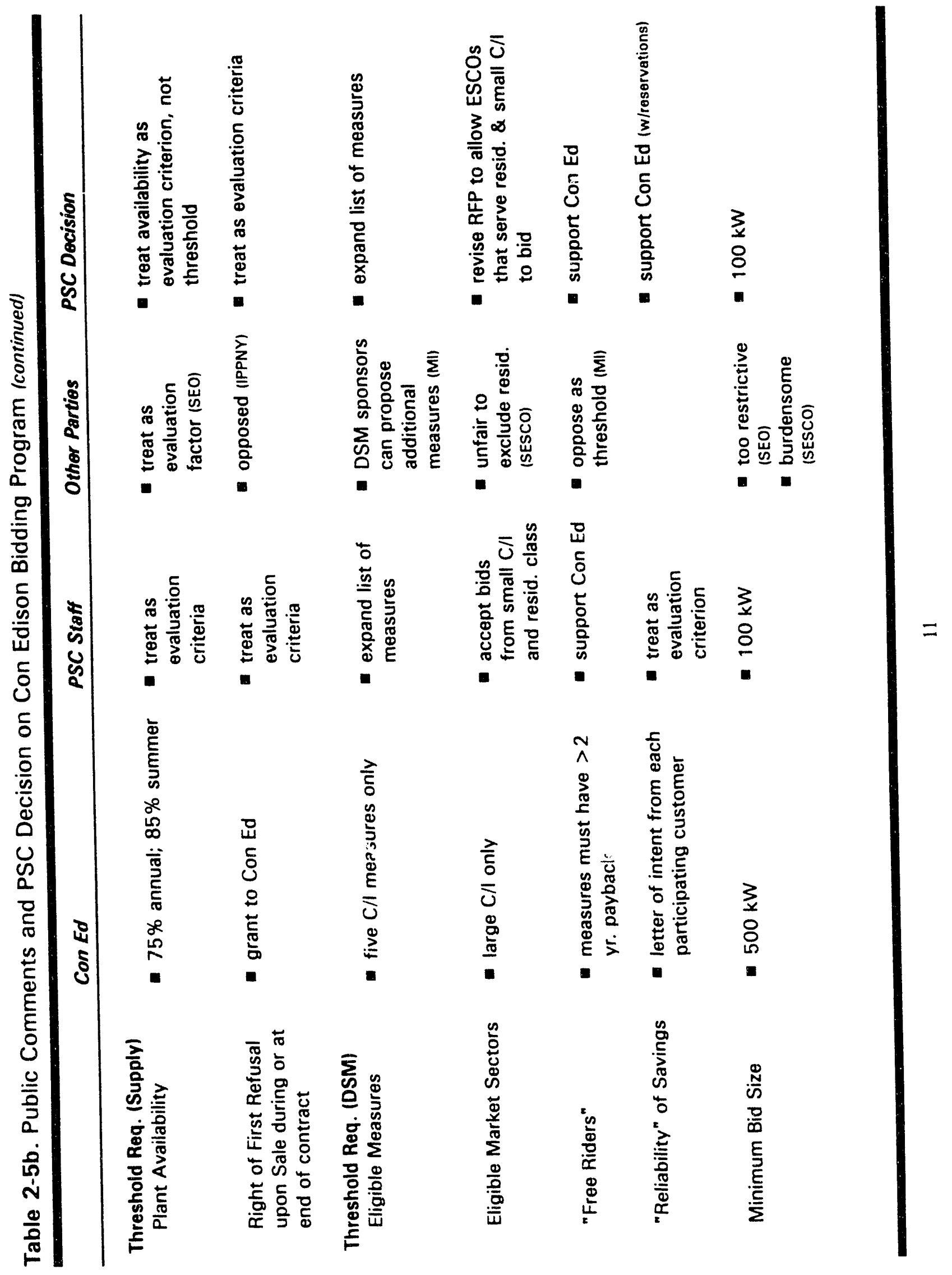




\subsubsection{Evolving Regulatory Policies on DSM}

During this period, the PSC also issued a series of decisions as part of Case 28223 that required utilities to pursue cost-effective demand-side resource options more aggressively (see Figure 21). In September 1987, the PSC directed utilities to submit their first long-range demand-side management plans. In December 1988, based on a review of these initial plans, the PSC ordered utilities statewide to develop and implement eight full-scale programs called the Consumers Energy Efficiency Program (NYPSC 1988b). The program areas were to include:

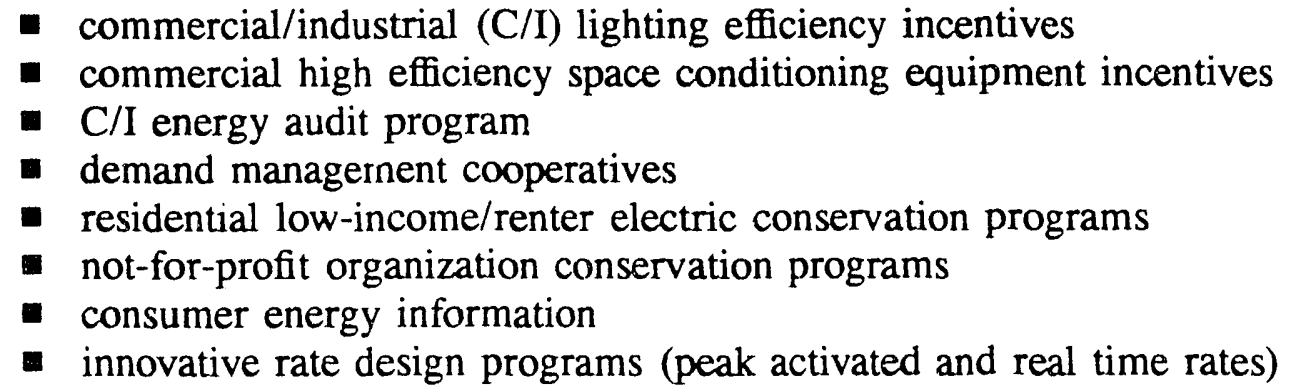

The PSC acknowledged the potential conflict in ordering utilities to implement full-scale DSM and bidding programs:

\footnotetext{
We are proceeding to require these new statewide DSM programs recognizing that there may be a conflict between this initiative and our simultaneous steps to acquire new service capacity by means of all source bidding systems. While the all source bidding systems include provisions for acquiring DSM resources, we recognized at the outset that we do not yet know the extent to which bidding systems can effectively deliver DSM services. Accordingly, we intend to proceed with plans for utilities to design and administer the delivery of DSM services. We will observe the interplay of the two approaches and change our approach if lessons of experience indicate change makes sense (NYPSC 1988b).
}

Utilities were given the challenge of resolving and defining the relationship between DSM bidder's projects and PSC-mandated utility DSM programs, without very specific guidance from the PSC. However, the Commission believed that eliminating the disincentives to DSM investment as well as providing an opportunity for shareholder incentives for successful implementation of DSM activities would provide utilities with adequate motivation to implement both types of DSM activities (NYPSC 1989a).

Con Edison filed its second long-range DSM plan and its annual DSM plans for 1991 and 1992 in July 1990, after the bidding RFP had been issued (in February 1990) and several months before the October 26 deadline for submitting bids (Con Edison 1990). In this plan, Con Edison proposed a significant expansion of company-sponsored energy efficiency programs that included higher customer rebate levels on many efficiency products. For example, Con Edison proposed to increase DSM spending to $\$ 74$ and $\$ 87$ million in 1991 and 1992 respectively, compared to 1990 expenditures of $\$ 40$ million. The Company's long-range DSM plan was quite ambitious and attempted to meet energy reduction targets that had beer established in the September 1989 
New York State Energy Plan. ${ }^{7}$ Con Edison proposed to invest $\$ 4.1$ billion between 1991 and 2008 which would result in a summer peak demand reduction of about $2500 \mathrm{MW}$. The company projected that sales growth would be reduced to $0.4 \%$ year including the effects of these proposed DSM programs compared to estimated sales growth of $1.1 \%$ /year forecast by Cen Edison in its 1989 integrated resource plan. Increased financial incentives for utility shareholders were an integral element of the Company's proposal.

As we shall see, the timing of the Company's new DSM initiatives added an additional complication quite coincidentally (i.e., higher rebate levels for customers) for potential DSM bidders that were either considering or preparing bids. More fundamentally, it illustrates the practical difficulties that can arise in coordinating integrated bidding and large-scale DSM programs.

7 The State Energy Plan called on utilities to implement DSM programs that would achieve an $8-10 \%$ reduction in energy use by 2000 and a $15 \%$ reduction by 2008 , if economically justified. 


\section{Chapter 3 \\ Design of the Bidding Program}

\subsection{Overview}

This chapter describes the features of Con Edison's bidding program as background to the analytical treatment in succeeding chapters. Distinguishing features of this bidding program compared to other utilities are: (1) the direct comparison of supply and demand-side resources using an objective bid evaluation and scoring prosedure, (2) reliance on relatively stringent threshold requirements to assure reliable, acceptable resources, and (3) a price-oriented scoring system. Due to the complexity of the scoring system, bids were not self-scored, but rather scored and ranked by Con Edison evaluaters based on bidders' proposals.

\subsection{Resource Block}

Con Edison requested $200 \mathrm{MW}$ of capacity (or demand reduction) to be in service by 1 May 1994.

\subsection{Timing}

Table 3-1 summarizes the key milestones in Con Edison's bidding program (Con Edison 1990a). Following issuance of the RFP in February 1990, bidders were given eight months to complete and submit bids. Preliminary Contract Award Group members were seiected after a three month bid evaluation period. Contract negotiations were originally anticipated to take four months, but instead took substantially longer (10-18 months).
Table 3-1. Key Milestones

$\begin{array}{ll}\text { RFP\# 90-1 Issued } & 1 \text { February } 1990 \\ \text { Pre-Bid Conference } & 25 \text { April } 1990 \\ \text { Bid Submittal Deadline } & 26 \text { October } 1990 \\ \begin{array}{l}\text { Preliminary Contract } \\ \text { Award Group Notified }\end{array} & 18 \text { January } 1991 \\ \begin{array}{l}\text { Contract Negotiations } \\ \text { Completed }\end{array} & 5 \text { comipleted, } 2 \\ \text { outstanding } \\ \begin{array}{l}\text { Deadline for Project } \\ \text { Completion }\end{array} & 1 \text { May } 1994\end{array}$

May 1994 


\subsection{Eligibility and Threshold Requirements}

Table 3-2. Key Eligibility and Threshold Requirements

\begin{tabular}{|c|c|c|}
\hline & Supp/y & DSM \\
\hline Min. Contract Term & 10 yrs & - $10 \mathrm{yrs}$ \\
\hline Min. Size & none & - $100 \mathrm{~kW}$ \\
\hline Technology & none & specified in RFP \\
\hline Economic & $\begin{array}{l}\text { specified indices for fuel prices, } \\
\text { though bidners could propnse } \\
\text { alternatives } \\
\text { project cost estimated }\end{array}$ & $\begin{array}{l}\text { bid price } \leq \text { ceiling prices } \\
\text { bid price } \leq \text { total installed } \\
\text { measure cost } \\
\text { simple payback }>2 \text { yrs } \\
\text { individual measures identified and } \\
\text { their costs }\end{array}$ \\
\hline Reliability & $\begin{array}{l}\text { letters of intent for firm wheeling } \\
\text { services } \\
\text { oil or gas-fired must be dual-fuel } \\
\text { capable } \\
\text { oil or coal nin. storage } \\
\text { meet interconnection } \\
\text { requirements \& specs }\end{array}$ & $\begin{array}{l}\text { annual certification } \\
\text { pre \& post- installation verification } \\
\text { of measures } \\
\text { must meet minimum efficiency } \\
\text { standards specified in RFP }\end{array}$ \\
\hline Risk & $\begin{array}{l}\text { evidence of site control } \\
\text { - preliminary design \& engineering }\end{array}$ & $\begin{array}{l}\text { letters of intent from all } \\
\text { customers } \\
\text { identify each DSM measure and } \\
\text { one it replaces }\end{array}$ \\
\hline Environmental & $\begin{array}{l}\text { identify all government } \\
\text { approvals, permits, licenses, and } \\
\text { data requirements } \\
\text { identify ccintrol technologies \& } \\
\text { siting issues }\end{array}$ & - none \\
\hline Source: Con Edison 1990 & & \\
\hline
\end{tabular}

The overall design philosophy of Con Edison's bidding program is influenced by the paramount importance that the utility assigned to reliability. Con Edison's minimum threshold and eligibility requirements were designed to assure that any resource passing these minimum requirements would be an acceptable resource (i.e., reliable and environmentally acceptable). Thus, compared to the solicitations of other utilities, Con Edison's eligibility and threshold requirements tend to be more stringent, particularly for DSM proposals. The key requirements set forth in the RFP for supply and DSM bids are depicted in Table 3-2. 
Both DSM and suppiy-side bidders had to propose a contract term of ten years or more. Generation projects could be proposed by either utility or non-utility providers located inside or outside of the Con Edison service territory. No minimum size was required for supply projects. ${ }^{8}$ Any bidder could index fuel prices to any of the proposed indices noted in the RFP including oil, gas, or GNP escalation rates or propose their own index (including a fixed price or fixed escalation rate). Projects fired by either oil or gas had to have dual fuel capability and those using either oil or coal had to provide minimum fuel storage facilities, both required specifications for utility-constructed projects.

Demand projects could be proposed by individual Con Edison customers, customer cooperatives, or energy service companies (ESCOs). DSM bids had to be for a minimum of $100 \mathrm{~kW}$ from one or several sites consolidated under one proposal. Only existing Con Edison customer sites were eligible; proposals targeting new customers were not eligible. Con Edison also required that ESCOs obtain a letter of intent from each participating customer, which specified measures to be installed and the estimated demand reduction. Con Edison's intent was to require ESCOs to ascertain in advance which customers would participate. Con Edison insisted that this requirement was necessary to ensure the "reliability of the size of the bid" and to minimize the possibility of "double-counting" of savings by ESCOs that were marketing the same customers (Con Edison 1989). Furthermore, a detailed list of eligible DSM measures at prescribed minimum efficiency standards was provided in the RFP from which bidders had to choose. These included the following:

\section{For residential} customers:

- compact fluorescent lamps

- timers on electric water heaters \& pool pumps

- timers on electric central $A / C$

- efficient electric central A/C

alternative-fueled waterheaters

\section{For commercial/industrial customers:}

- compact fluorescent lamps

- efficient fluorescent lamps

- efficient ballasts

- efficient ballast \& lamp combination

- high efficiency motors

- efficient electric air-conditioning (A/C) equipment

- gas $\mathrm{A} / \mathrm{C}$

\footnotetext{
${ }^{8}$ While there was no specific minimum size, sponsors of projects that were less than $2 \mathrm{MW}$ did not have to bid and could execute a contract with Con Edison at the average price of the winning bids.
} 
DSM bids were required to meet several economic criteria. First, each of the measures from the above list had individual ceiling prices below which price bids had to be offered. ${ }^{9}$ Second, the net present value of annual bid prices could not exceed the total installed cost of the measures. Third, DSM bidders were required to demonstrate that their proposed project passed the Total Resource Cost (TRC) Test. ${ }^{10}$ Finally, as a means of limiting cream-skimming opportunities, DSM bidders were required to show for each measure that total costs, net of any program administrative costs, had to exceed the customer's expected bill savings from the first two years. In other words, measures had to have a simple payback time of greater than two years from the customer's perspective in the absence of any rebate or bidding program.

DSM bidders were required to provide enforceable performance guarantees for demand reductions, including pre- and post-installation verification of the bid resource by the utility.

\subsection{Scoring System}

Bids that passed the threshold criteria were then ranked by Con Edison according to the following criteria: (1) price factor - the project sponsor's bid price which was adjusted for various factors (e.g., differences in energy output, contract term, plant availability, and transmission and distribution cost impacts) so that bids were evaluated comparably in terms of expected overall cost, and (2) several non-price factors. Non-price factors include the project's ability to diversify the utility's fuel mix, project viability and level of risk (e.g., the probability of successful development and operation throughout the term of the contract), compatibility with Con Edison's operational requirements, and the project's environmental characteristics. The non-price factors were monetized and together with the price factors were used to calculate an overall adjusted cost, which is net present valued at Con Edison's cost of capital of $9.8 \%$. Projects were then ranked by their overall adjusted costs per unit capacity on a net present value basis. This ranking criteria was the sole factor used to select among projects for the Preliminary Contract Award Group and the right to enter into contract negotiations."

The basic equation for scoring bids in the Con Edison system is as follows (all terms on $\$ / \mathrm{kW}$ basis):

\footnotetext{
${ }^{9}$ In contrast, supply projects were not subject to explicit ceiling prices; Con Edison indicated that it would compare bid prices relative to each other and would determine if bids were too costly, considering the adopted longrun avoided costs (LRACs).

10 The TRC Test compares the benefits from DSM (avoided costs) to the total costs, including measure, installation, incremental O\&M, and any program administration costs regardless of who bears the costs.

"In the RFP, Con Edison indicated that the Preliminary Contract Award Group would include projects that represented about $150 \%$ of the resource block need and the company would negotiate with projects in the order of their ranking.
} 
Adjusted Bid Price $:=$ Unadjusted Bid Price + Availability Adjustment + Make-up Energy Adjustment + Term Adjustment + Administrative Cost Adjustment + T\&D Adjustment Non-Price Factor Adjustment

Before discussing the price and non-price factors in more detail, it is useful to review the longrun avoided costs (LRACs) which were included in the solicitation because they enter into several of the adjustments to sponsor's bid price.

\subsubsection{Long-Run Avoided Costs (LRACs)}

Figure 3-1. Long-Run Avoided Costs for Con Edison (1989)

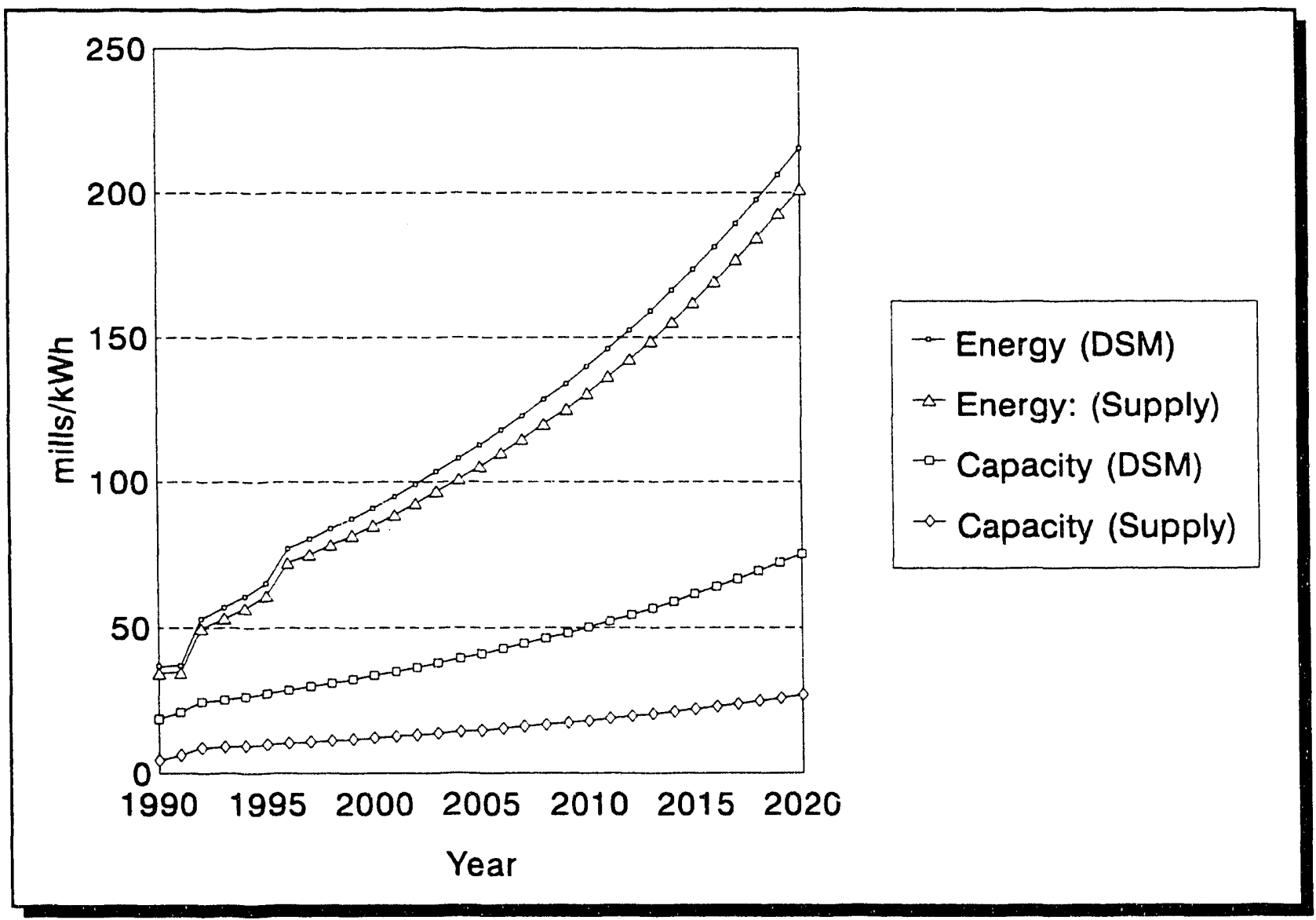

Con Edison included estimates of its long-run avoided costs (LRACs) which were developed by the PSC in 1989 in separate regulatory proceedings. In the RFP, the LRACs were expressed in terms of their capacity and energy components, segregated by interconnection level for supply projects (transmission, sub-transmission, and primary distribution) and by high- and low-tension customer for demand projects. Figure 3-1 shows the LRACs used by Con Edison in evaluating 
DSM bids (for low tension customers) and supply bids that interconnect at transmission level over a 30-year time horizon.

\subsubsection{Price Factors}

\section{Bid Price}

Bidders were requested to include a capacity-related fixed price as well as a variable component in their bid price. The variable cost for a supply-side bid consists of the variable running costs and start-up costs. The running costs are equal to the product of: the capacity bid (in $\mathrm{kW}$ ); the yearly average availability pledged by the bidder; the bid variable unit price (in $\$ / \mathrm{kWh}$ ); and, the effective hours of operation of the facility. The start-up costs are the product of the bid start-up cost (in \$/start-up) and the expected number of start-ups. The effective hours of operation and the expected number of start-ups are calculated by Con Edison based on its marginal energy cost curves, but subject to bid minimum downtime constraints and bid minimum and maximum operating hour constraints. For a DSM bid, the variable cost is the product of: the capacity bid (in $\mathrm{kW}$ ); the effective hours of operation; and, the total variable unit price (in $\$ / \mathrm{kWh}) .{ }^{12}$ The bid price is normalized by bid capacity and net present valued over the proposed contract term using a discount rate of $9.8 \%$.

\section{Make-up Energy Adjustment}

The make-up energy adjustment is designed to standardize the annual energy output of all bids. It represents the cost of energy during those hours in the year in which a supply-side option is expected not to run or a DSM option is expected not to operate. The make-up hours are equal to 8760 hours (one year) minus the effective hours of operation calculated for the project, based on its running costs. The concept of make-up hours is depicted graphically on a marginal energy cost-duration curve in Figure 3-2. A bidders' variable bid price determines the optimal hours for a project to be dispatched in the Con Edison system. Make-up hours represent the remaining hours of the year. ${ }^{13}$

For a supply-side bid, the make-up energy adjustment is equal to the product of: the capacity bid (in $\mathrm{kW}$ ); the bid yearly average availability; the make-up hours; and, the average Con Edison marginal energy cost applicable to those make-up hours, based on Con Edison's marginal energy cost curves. For DSM bids, the make-up energy is the product of: the super-peak demand reduction (i.e, the reduction in the summer weekday hours between noon and $6 \mathrm{pm}$ ) bid;

\footnotetext{
12 With the caveat that DSM proj.osals are subject to ceiling prices established for individual measures.

${ }^{13}$ A special case occurs if bidders specify minimum operating hours greater than the hours their project would operate optimally (i.e., minimum hours line to the right of the optimal hours line in Figure 3-2) in which case makeup hours would be calculated as 8760 minus the minimum hours rather than optimum hours.
} 


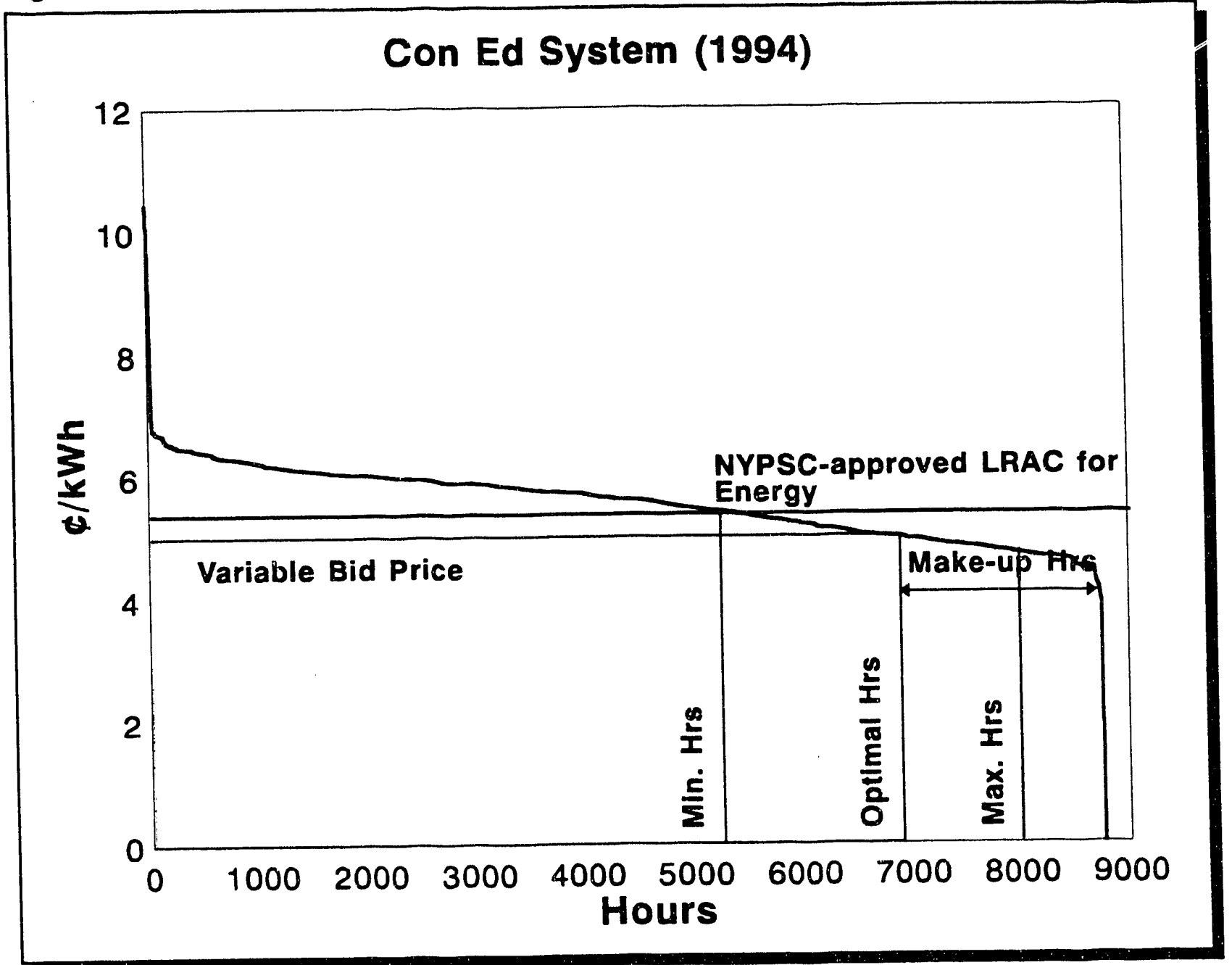

the make-up hours; and the average Con Edison marginal costs applicable to the make-up hours. The make-up adjustment is summed for each year of the contract term and converted to net present value.

\section{Term Adjustment}

The term adjustment factor normalizes bids of differing terms to the nominal contract. length of twenty years. Proposals of less than twenty years duration will have their bid cost adjusted upward by the product of: the bid capacity (in $\mathrm{kW}$ ); 8760 hours for the remaining years; and, the long-range avoided cost (in $\$ / \mathrm{kWh}$ ) for the voltage at which the project is to be interconnected. The adjustment is summed over each year less than the twenty year nominal term and expressed on a net present value basis. Proposals with contract terms that exceed twenty years will have their bid cost adjusted downwards by the product of: the bid capacity (in $\mathrm{kW}) ; 8760$ hours; and, the long-range avoided cost for the voltage at which the project is to be 
interconnected. The adjustment is summed over each year greater than the twenty year nominal term and net present valued.

\section{Availability Adjustment}

The availability adjustment normalizes supply side bids that have different guaranteed availability factors and puts them on a comparable basis. There is a capacity and energy adjustment, both of which are added to the bid price. The capacity adjustment is equal to the product of: one minus the bid availability during the peak summer period; the capacity bid (in $\mathrm{kW}$ ); 8760 hours; and, by the capacity related component of the LRAC. The adjustment is summed over each year of the contract term and net present valued. Since DSM measures are assumed to have $100 \%$ availability, there is no capacity related availability adjustment for them.

The energy adjustment is equal to the product of: one minus the bid annual availability; the capacity bid (in $\mathrm{kW}$ ); 8760 hours; and, by the energy related component of LRAC. The adjustment is summed over each year of the contract term and net present valued.

\section{Transmission and Distribution Adjustment}

This adjustment is designed to reflect the different transmission and distribution (T\&D) cost impacts of various supply and DSM bids. The factor adjusts for supply side bidders requiring interconnection at different voltage levels and for DSM bidders providing load reductions at differing voltage levels. The adjustment is necessary because capital costs and losses vary depending on the voltage level of interconnection. The adjustment is added to the bid price. The adjustment is equal to the product of the capacity bid and the penalty. The penalty is in net present $\$ / \mathrm{kW}$ and is based on an assumed twenty year contract from 1994 to 2013 . The penalty for a low-tension DSM bidder is zero, while that for a high-tension DSM bidder will be based on the secondary distribution cost. Distribution level supply side bidders will have a penalty based on primary and secondary distribution costs. Transmission supply side bidders will have a penalty based on the primary and secondary distribution costs and the transmission costs.

In addition to this direct adjustment to bid price, T\&D cost impacts enter into project evaluation in two other ways. First, the LRACs used in the other adjustments in this section depend on the interconnection voltage, with transmission LRACs higher than distribution LRACs. Second, non-price factors are monetized at rates that depend on the interconnection voltage (see section 3.5.3). 


\section{Administrative Cost Adjustment}

The administrative cost adjustment is designed to reflect varying costs that the utility is expected to incur as part of administering the contract. For supply side projects, the adjustment is independent of bid capacity ( $\$ 2000$ per year). For DSM side bids, Con Edison developed a set of rates which varied by technology and which were based primarily on estimated costs to verify installation and savings of various measures. The DSM adjustment is equal to the product of the bid capacity and the cost penalty (in $\$ / \mathrm{kW}$ ). The administrative cost adjustment is levied in each year of the project proposal duration.

\subsubsection{Non-Price Factors}

Non-price factors are divided into two categories for scoring purposes: (1) a general category which includes attributes relating to fuel diversity, reliability, level of risk, and operational issues and (2) environmental factors. Varying points are awarded for each non-price factor on the basis of answers to questions provided in the bid evaluation forms. The general category has a total of 240 possible points, while the environmental category has a total of 60 possible points.

The monetized non-price factors are subtracted from the bid price. The monetized value of the general category of non-price factors is the product of: the total number of general category points received by the bid; the bid capacity (in $\mathrm{kW}$ ); $240 / 1000 ; 8760$ hours; and, the capacity plus energy components of the LRACs. The monetized value of the environmental category of non-price factors is the product of: the total number of environmental category points received by the bid; the bid capacity (in $\mathrm{kW}$ ); 1/60; 8760 hours; and, a levelized environmental mitigation cost value of $\$ 0.01492 / \mathrm{kWh}$ (in 1990\$) which was estimated by the New York PSC.

\section{Fuel Diversity Factor}

This factor, with a maximum of 30 points, measures the degree to which the project diversifies the Con Edison system fuel mix. Zero points are awarded for oil or gas fueled projects, while renewable, coal, refuse, or nuclear bids receive 30 points. DSM projects are awarded points in proportion to their annual hours of use.

\section{Reliability Factor}

This factor, with a maximum of 70 points, measures how much the bid resource complements the Con Edison system in terms of: fuel supply and delivery; transmission system reliability and black start capability; impacts on New York Power Pool transactions; and, voltage support. 


\section{Risk Factor}

This factor, with a maximum of 110 points, measures Con Edison's risk exposure over the contract term due to: the project sponsor's experience with similar projects and, if applicable, its relationship with a thermal host; the maturity of the generation resource technology; likely licensing and other environmental requirements; the level of front-loading (evaluated with respect to the Con Edison LRACs); the level of dispatchability; and, the right of first refusal on a proposed sale of the project.

\section{Operational Factor}

This factor, with a maximum of 30 points, measures project specific operational characteristics that indicate the likelihood of reliable and economic operation of the project throughout the contract term. It depends on: willingness to install automatic generation control equipment; operating experience of the sponsor; maintenance experience of the sponsor; and, willingness to submit to audits.

\section{Environmental Factor}

This factor, with a maximum of 60 points, evaluates the environmental characteristics of projects by considering air emissions, cooling water effects and land effects (including transmission). 


\section{Chapter 4 \\ Bid Evaluation Process and Outcome}

\subsection{Response to the Solicitation}

Con Edison received 47 bids in response to its bidding RFP. There were four DSM bids and 43 supply-side bids, although eight supply bids were alternate bids for the same site. Table 4-1 profiles the 35 unique supply projects, which cumulatively offered $2976 \mathrm{MW}$ of capacity. Projects that rely on natural gas accounted for the vast majority of bids (71\%) and total capacity offered $(85 \%)$. Wood/waste projects, which tended to be small, represent about $17 \%$ of bids received, but only $5 \%$ of the total capacity. Combined-cycle projects account for roughly $50 \%$ of the supply bids and almost $70 \%$ of the capacity. A comparable n'mber of projects utilized steam turbines and gas turbines, and each of these technologies accounted for about $15 \%$ of total capacity bid. In terms of location, 15 projects were located within Con Edison's service territory, accounting for about $40 \%$ of the total capacity. Ten other proposed projects, representing about $40 \%$ of the total capacity, were located within New York State, while the remaining ten projects were located in other states.

Four DSM bids by three ESCOs and one gas utility were submitted. Two of the DSM projects offered savings from efficiency improvements for lighting and motors, one DSM project offered savings for lighting efficiency improvements only, and one project offered to substitute gas for electricity in space cooling.

The impressive market response by supply-side bidders, both in terms of capacity offered and number of bids, is consistent with the bidding experience of other utilities. However, the response of DSM bidders
Table 4-1. Profile of Supply Bids Submitted

\begin{tabular}{lrrrr} 
& $\begin{array}{c}\text { No. of } \\
\text { Bids }\end{array}$ & (\%) & (MW) & (\%) \\
\hline Fuel & & & & \\
Gas & 25 & 71 & 2520 & 85 \\
Coal & 1 & 3 & 100 & 3 \\
Oil & 2 & 7 & 160 & 5 \\
Nuclear & 1 & 3 & 60 & 2 \\
Wood/Waste & 6 & 17 & 146 & 5 \\
Technology & & & & \\
Steam Turbine & 8 & 23 & 402 & 14 \\
Gas Turbine & 6 & 17 & 444 & 15 \\
Combined-Cycle & 17 & 49 & 2052 & 69 \\
Nuclear & 1 & 3 & 50 & 2 \\
Internal & 3 & 9 & 28 & 1 \\
Combustion & & & & \\
Location & & & & \\
In Service Territory & 15 & 43 & 1160 & 39 \\
In New York State & 10 & 29 & 1168 & 39 \\
In New Jersey & 2 & 6 & 242 & 8 \\
Outside NY \& NJ & 8 & 23 & 406 & 14 \\
& & & & \\
\hline
\end{tabular}


Table 4-2. Preliminary Contract Award Group

\begin{tabular}{llll} 
& Projoct & Bid & \\
\hline Sponsor & Name & $\begin{array}{l}\text { Capacity } \\
\text { (MW) }\end{array}$ & Technology/Fuel \\
\hline $\begin{array}{l}\text { Cogeneration Technologies } \\
\text { Warbasse Cogeneration }\end{array}$ & $\begin{array}{l}\text { Brooklyn Navy Yard A } \\
\text { Bechnologies }\end{array}$ & 40 & Gas combined cycle \\
R.V. Associates, LP & Facility (Warbasse) & 16 & Gas combined cycle \\
Energy Services of Colorado & $\begin{array}{l}\text { Brooklyn Navy Yard B } \\
\text { Comm'I Lighting } \\
\text { Retrofit }\end{array}$ & 40 & Gas turbine \\
York Cogen Partners, LP & $\begin{array}{l}\text { Brooklyn Navy Yard } \\
\text { Central }\end{array}$ & 90 & DSM (lighting) \\
Bio-resources limited & $\begin{array}{l}\text { Bio-Resources Ltd } \\
\text { Enersave DSM }\end{array}$ & 17.7 & Gas turbine \\
Enersave, Inc & 7.9 & $\begin{array}{l}\text { Wood steam-turbine } \\
\text { DSM (commercial lighting } \\
\text { \& motors) }\end{array}$ \\
CESWay International & $\begin{array}{l}\text { Power Partners } \\
\text { Program }\end{array}$ & 1.6 & $\begin{array}{l}\text { DSM (commercial lighting } \\
\text { \& motors) }\end{array}$
\end{tabular}

was disappointing relative to other comparably-sized or smaller utilities that have included DSM options in their competitive bidding programs. Reasons why potential DSM bidders chose not to participate in Con Edison's bidding program are examined in Chapter 5.

\subsection{Con Edison's Bid Evaluation Process}

Projects proposals were analyzed by Con Edison and ranked in order of ascending adjusted bid price. A group of the highest ranked projects were selected to enter into contract negotiations with Con Edison. Originally this group's size was to be up to a cumulative capacity of $150 \%$ of the resource block to accommodate attrition of proposals during the contract negotiation phase (i.e., about $300 \mathrm{MW}$ ), but ultimately projects were selected totaling $214 \mathrm{MW}$.

At least two Con Edison staff reviewed each bid proposal for completeness and accuracy. In addition, an internal task force made up of members from departments throughout the company were involved in reviewing specific bid elements in their areas of expertise. These reviews resulted in several rounds of communication between Con Edison and bidders and numerous revisions to bidders' original submittals. 
Besides verifying and correcting bidders' proposals, Con Edison calculated the effective hours of operation for supply bids by determining the hours in which the total variable running cost of the plant plus any start-up cost was equal to or less than Con Edison's marginal hourly energy cost (see Figure 3-2 for an example of this procedure). This calculation was performed by utilizing the PROMOD production-cost simulation program for the proposed duration of the bid with resultant annual marginal costs scaled up to the PSC-approved LRACs used in other portions of the scoring system. While much analytical effort was expended by Con Edison to accurately depict the effective hours of operation for supply bids, it was noted that most of these projects were fully dispatched up to the maximum specified by bidders due to their generally low variable bid prices relative to the LRACs utilized at the time of the bid evaluations (Keating 1993). For DSM proposals, the effective hours of operation were taken directly by Con Edison as specified by bidders after review by members of Con Edison's energy services department. The effective hours of operation were used primarily in the make-up energy adjustment calculation.

\subsection{Preliminary Contract Award Group}

Con Edison selected nine projects for its Preliminary Contract Award Group (see Table 4-2) representing a total of $214 \mathrm{MW}$ of capacity or equivalent savings. Gas combined cycle or turbine projects accounted for almost $90 \%$ of the winning MW. One firm, York Research, sponsored all four of the winning gas-fired projects under limited partnerships. ${ }^{14}$ Three of these projects happened to be located in the Brooklyn Navy Yard. The other winning supply project was an $18 \mathrm{MW}$ wood steam turbine project sponsored by Bio Resources.

Three of four DSM projects made it to the preliminary contract award group, while the lone fuel-switching project involving gas air-conditioning failed to make the preliminary contract award group due to its high evaluated price per $\mathrm{kW}$. The winning DSM projects were sponsored by Enersave for 7.9 MW, by Energy Services of Colorado for $1 \mathrm{MW}$, and by CES/Way for 1.6 MW. ${ }^{15}$

The total capacity of the preliminary contract award group was less than Con Edison's target by $85 \mathrm{MW}$. However, if Con Edison had included the highest scoring losing bid, it would have pushed the Preliminary Contract Award Group slightly over the $300 \mathrm{MW}$ target. Given that the RFP was conceived as a pilot experiment in integrated resource bidding and not developed to meet a particular resource need, Con Edison chose to risk some attrition of projects and keep the size of the preliminary contract award group closer to $200 \mathrm{MW}$ than $300 \mathrm{MW}$ (Keating 1993).

\footnotetext{
14 York Research was involved in each project, although the name of the sponsors vary because of the limited partnership arrangements.

${ }^{15}$ During contract negotiations, Enersave reduced its demand reduction goal to $6.6 \mathrm{MW}$ and Energy Services of Colorado withdrew its proposal entirely.
} 


\subsection{Analysis of Project Bid Scores}

We calculated summary statistics on bid scoring for the entire sample of 47 bids and various subsets (e.g., supply and DSM projects, winning vs losing bids), using information provided by Con Edison (see Table 4-3). ${ }^{16}$ For each group of bids, we show the average, standard deviation, coefficient of variation (COV), minimum, and maximum values for unadjusted bid price, the various price adjustment factors, and non-price factors. The COV is defined as the ratio of the standard deviation to the mean, and is an indicator of the relative variability of a particular scoring attribute. Non-price factors are disaggregated into two categories: general and environmental (see section 3.5.3). The Adjusted Bid Price is the key figure of merit in determining the ultimate outcome and ranking of bids (shown in the far right column). Adjusted bid price is the sum of the unadjusted bid price, the individual price adjustments, and the monetized non-price factors. All values are expressed in $\$ 1990 / \mathrm{kW}$.

For completeness the unadjusted bid price is presented in Table 4-3, however readers are cautioned against making comparisons with this price because it is based on the net present value of the proposed payments to bidders over the contract term, which varies between 10 and 30 years. Thus a ten year bid will appear cheaper than a 30 year bid even if their proposed payments in the overlapping years are identical. The term adjustment corrects for this difference in contract terms by normalizing the unadjusted bid prices to a 20 -year term. Therefore, in the ensuing discussion, all references to bidder's price offers include the effects of the term adjustment and reflect a 20-year normalized price (shown in the fourth column of Table 4-3).

\subsubsection{All Bids}

Bidders in Con Edison's first solicitation offered power priced at roughly $\$ 3700 / \mathrm{kW}$ on average. The effect of non-price factors reduced bid scores by $\$ 1600 / \mathrm{kVV}$, while Con Edison's various adjustments to bid price led to increases averaging about $\$ 1800 / \mathrm{kW}$. Thus, adjusted bid prices for all bids averaged $\$ 3900 / \mathrm{kW}$. The T\&D adjustment had the largest impact on bidders prices among the price adjustments $(924 / \mathrm{kW})$. The availability adjustment was the next most influential at over $\$ 500 / \mathrm{kW}$, followed by the make-up adjustment at $\$ 350 / \mathrm{kW}$. The administrative adjustment had an inconsequential effect on bid price.

The variability within scoring categories (as measured by the COV) was greatest for the term adjustment, reflecting varying contract terms by bidders. Make-up adjustment showed the next most variation among the price adjustments, reflecting differences in expected duty cycle of

\footnotetext{
${ }^{16}$ Con Edison provided us with detailed information on the scoring and evaluation of individual bids (on a confidential basis), which has been aggregated in order to assure confidentiality. The data provided consisted ol 48 bids in which one of the DSM sponsors offered two proposals that were later consolidated into one. Therefore the summary statistics contain one more data point than indicated in the accompan ying discussion of these results.
} 


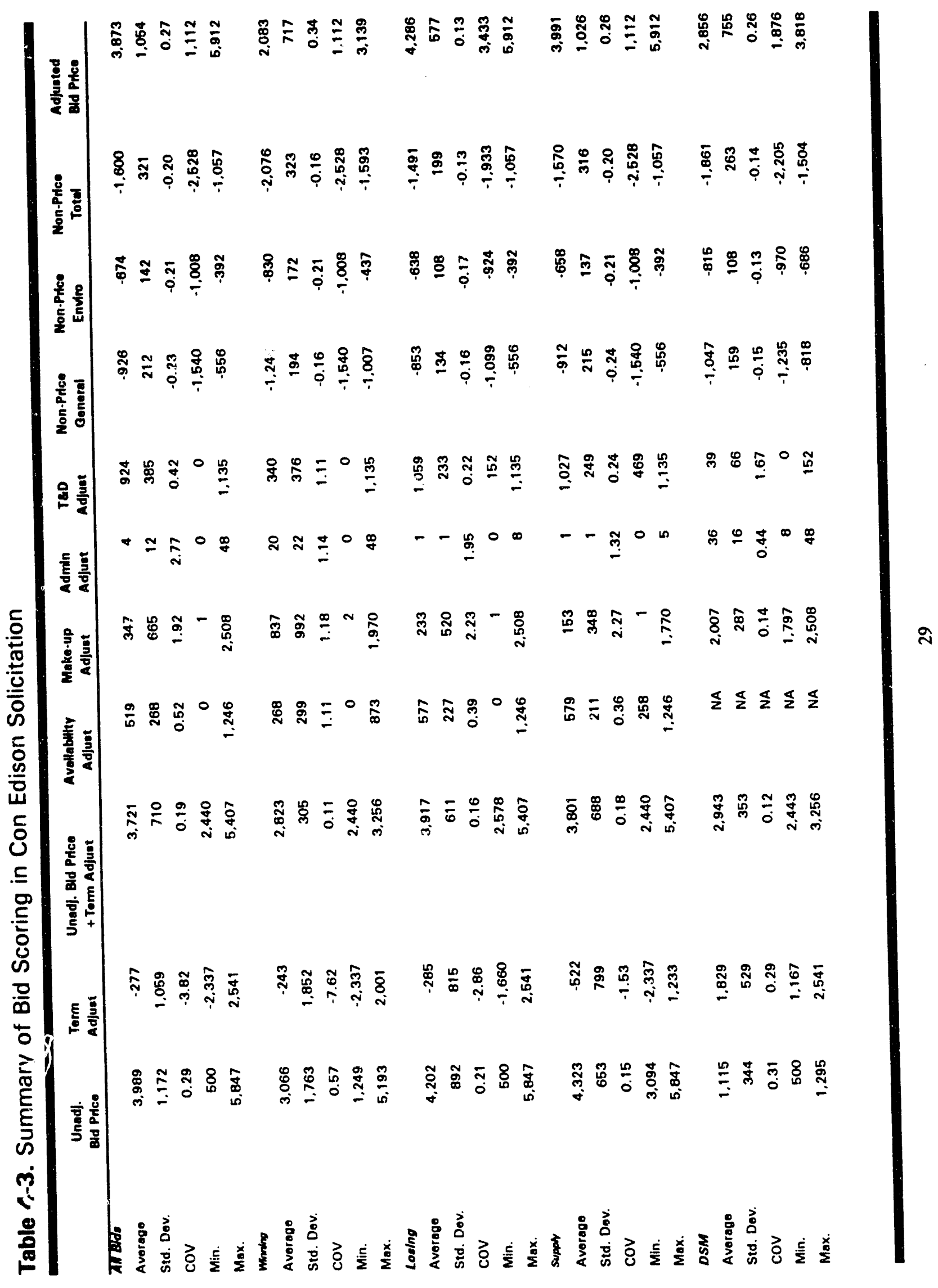


projects submitted by bidders. Other price adjustment categories exhibited much less variation. ${ }^{17}$

\subsubsection{Supply vs. DSM Bids}

The bid prices of DSM projects were considerably lower than supply projects $(\$ 2900 / \mathrm{kW}$ vs. $\$ 3800 / \mathrm{kW}$ ). The various adjustments made by Con Edison to normalize and compare different types of projects had little net effect on bidders' price proposals, slightly raising supply prices and slightly reducing DSM prices. Following all of the bid price adjustments, the spread in price between DSM and supply projects increased by about $\$ 200 / \mathrm{kW}$.

Compared to supply-side projects, DSM bids were hit hard by the make-up energy adjustment, suffering a differential impact of $\$ 1800 / \mathrm{kW}$. This result was driven by the fact that DSM projects were evaluated based on their assumed hours of operation. The T\&D and availability adjustments worked in the opposite direction as average bid prices increased by about $\$ 1000 / \mathrm{kW}$ and $\$ 600 / \mathrm{kW}$ respectively for supply projects compared to the average DSM bid. Surprisingly, DSM bids benefitted less than $\$ 200 / \mathrm{kW}$ from non-price environmental price deductions and around $\$ 100 / \mathrm{kW}$ from non-price general price deductions over supply projects. Not decisive, but worthy of note, is the fact that the administrative adjustment for DSM bids averaged $\$ 36 / \mathrm{kW}$ while that for supply projects was only $\$ 1 / \mathrm{kW}$, reflecting the additional costs of measuring and verifying DSM resources.

\subsubsection{Winning vs. Losing Bids}

Adjusted bid prices of winning bidders were over $\$ 2200 / \mathrm{kW}$ lower on average than losing bidders $(\$ 2083 / \mathrm{kW}$ vs. $\$ 4286 / \mathrm{kW})$. The 20 -year normalized bid price for losing bidders was approximutely $\$ 1100 / \mathrm{kW}$ higher than for winning bidders. In addition, price factor adjustments and non-price factors reduced bid prices of winning bidders by about $\$ 900 / \mathrm{kW}$ on average, while raising bid prices of losing bidders by $\$ 300 / \mathrm{kW}$.

Among the bid price modifiers, the T\&D adjustment showed the greatest differential between winning and losing bidders, causing on average a $\$ 700 / \mathrm{kW}$ greater increase in losir.g bid prices. Interestingly, the make-up energy adjustment worked in the op: sosite direction, as it increased winner's bid prices by over $\$ 800 / \mathrm{kW}$ on average compared to increases of only $\$ 230 / \mathrm{kW}$ for losing bidders. This result is primarily attributable to the three winning DSM bids (see section 4.4.2 for explanation). However, the availability adjustment favored winning bidders by raising their prices $\$ 300 / \mathrm{kW}$ less than losing bidders. Non-price scoring was another area where winning bidders differentiated themselves from losing bidders, capturing in total $\$ 600 / \mathrm{kW}$ more in price deductions (i.e., $\$ 400 / \mathrm{kW}$ from the general category and $\$ 200 / \mathrm{kW}$ from the environmental category).

\footnotetext{
${ }^{17}$ The exception to this is the administrative adjustment, but because its effect is an order of magnitude smaller, the variability is not particularly relevant.
} 
We also examined differences between winning bids and marginal losing bids, which we defined as the next nine highest scoring losing bids. On average, these marginal losing bids had scores that were similar to the group of all losing bids on the price factor adjustments and non-price factors. However, average bid prices of marginal losing bids were about $\$ 500 / \mathrm{kW}$ less than the larger cohort of all losing bids.

Overall, we observe a much more distinct gap in the scores of winning and losing bidders in Con Edison's bidding program compared to results reported by some other utilities that have used self-scoring bid evaluation systems. This result might be purely coincidental, driven by the particular distribution of independent power producers and ESCOs that chose to respond to the Con Edison RFP. However, our intuition is that this phenomenon is related to Con Edison's relatively unique bid scoring system and its valuation of specific attributes. In particular, the relative importance of Con Edison's T\&D adjustment helped create a larger scoring spread among projects based primarily on their location and interconnection level.

\subsection{Contract Negotiations}

As of April 1993, Con Edison had successfully negotiated contracts with five of eight projects (representing about $180 \mathrm{MW}$ ) that were included in the Preliminary Contract Award Group. Contract negotiations took much longer than expected for a variety of reasons. Contracts were signed for all three of the Brooklyn Navy Yard projects with York. The other York-sponsored project, Warbasse Cogen Facility in Brooklyn, and the wood-fired project sponsored by Bio Resources are still involved in contract negotiations with Con Edison.

On the DSM side, Con Edison completed negotiations and signed contracts with Ene: save and CES/Way. Energy Service of Colorado withdrew its bid for commercial lighting savings during contract negotiations after one of its signed customers dropped out. Winning DSM bidders reported that contract negotiations were quite protracted and difficult. A major stumbling block between the utility and ESCOs were disagreements regarding options available to ESCOs to meet their contract demand reduction goals if customers with signed letters of intent decided not to proceed with their project. ESCOs insisted that they should be able to recruit new customers to replace those that dropped out, while Con Edison opposed this provision since the terms and conditions included in the RFP specifically limited the project to the customers and measures included in each bid proposal. Con Edison felt that this requirement was necessary to assure the integrity of each bid. However, during the contract negotiations, in an effort to acquire DSM contracts, Con Edison reduced the penalty and allowed DSM project sponsors 90 days after contract execution to revise their proposed demand reduction downwards. 


\section{Chapter 5 \\ Issues in the Bidding Program}

\subsection{Overview}

In this chapter, we discuss key issues that emerge from our review of the Con Edison integrated bidding program. First, we examine reasons why few DSM bidders chose to participate in Con Edison's program. Second, we attempt to gain a deeper understanding of Con Edison's preferences regarding desirable project attributes as revealed through its bid evaluation and scoring system. One goal of this analysis is to determine whether Con Edison's bid price adjustment procedures favor certain types of projects (e.g. supply vs demand) or resources (baseload, intermediate, or peaking). Third, because Con Edison places a high value on the location of projects in its transmission and distribution network, we assess the reasonableness of their T\&D cost impact penalties. We locate our analysis quite broadly in the context of regulatory choice regarding reliance on competitive bidding for new resources versus the traditional alternatives of utility construction by a vertically-integrated firm. Transmission planning may be less efficient when independent suppliers provide generation capacity under bidding because of the loss of coordination economies. We formulate a trade-off between coordination losses in transmission planning and the gains from competition in the generation segment and link this discussion to the features of the Con Edison bidding system. Finally, we discuss project viability issues raised by the outcome of the Con Edison bidding program, specifically the difficulties experienced by one supply-side firm, whose winning bids accounted for almost $90 \%$ of the total capacity awarded by the utility.

\subsection{Lack of Participation by DSM Providers}

Con Edison received only four DSM bids for $12 \mathrm{MW}$. This response was disappointing compared to the bidding programs of other utilities and in light of Con Edison having received 36 Notices of Intent from potential demand-side bidders. As part of this study, LBL conducted a telephone survey of a sample of prospective and actual bidders in the Con Edison and Niagara Mohawk bidding programs (see Appendix A for survey results and Appendices B and C for bidder and non-bidder questionnaires).

Our interviews with staff at 24 of the 33 companies that filed Notices of Intent with Con Edison (and did not bid) suggest that interest among prospective DSM bidders was quite high initially. Many firms indicated that they were serious about participating in the auction, however, they were discouraged after examining the RFP. The principal reasons given by non-bidders as factors that affected their decision to participate are summarized in Table 5-1.18

\footnotetext{
${ }^{18}$ Some respondents offered more than one reason for not participating.
} 
Table 5-1. Principal Reasons for Non-Participation

\begin{tabular}{lc}
\hline Reason & Frequency \\
\hline $\begin{array}{l}\text { Requirement that ESCOs have signed letters of intent from all } \\
\text { customers }\end{array}$ & 14 \\
Expense of operating in New York City & 4 \\
Contract term length & 3 \\
Complexity of the RFP & 3 \\
Limited number of eligible measures & 2 \\
Ceiling prices changed; not enough time to revise bid & 7 \\
High rebate levels in utility DSM programs or heard that rebates were \\
increasing
\end{tabular}

The principal barriers to participation vary somewhat among customers and ESCOs. Among large customers, the major barriers appear to be: (1) high upfront bid preparation costs because of the "complexity of the RFP" and (2) reluctance to enter into a long- term contractual relationship with the utility in which customers guarantee the energy and demand savings. Customers felt that the upfront effort (and associated cost) required to prepare a bid was not worth the risk. Some large end-use customers noted that the risks and rewards of Con Edison's bidding program were not particularly attractive compared to the utility's existing rebate programs.

The major barriers to participation among! ESCOs are attributable largely to the utility's threshold and eligibility requirements. Energy service companies were particularly critical of Con Edison's requirement of a signed letter of intent from each participating customer, the inability of an ESCO to replace or substitute a project after the contract was signed if one of the customers with a letter of intent withdrew, and the limited list of eligible measures. Many ESCOs claimed that a signed letter of intent required a significant upfront expenditure on engineering and legal fees, which was difficult to justify given the risks of the bidding process. Moreover, many customers were unwilling to lock themselves into that type of relationship, given that there was no guarantee that the ESCO would win the auction. Two of the three ESCOs that bid already had customer lined up before the auction and consequently had minimal marketing expenses. Thus, these ESCOs had an inherent advantage in the auction over ESCOs with no experience in the service territory. Ironically, these restrictive eligibility requirements may have resulted in high numbers of "free riders", which was certainiy not Con Edison's intent. 


\begin{tabular}{|c|c|c|}
\hline & $\begin{array}{l}\text { Con Ed } \\
\text { RFP } \\
(2 / 15 / 90)\end{array}$ & $\begin{array}{l}\text { Con Ed } \\
\text { Rovisions } \\
\text { (9/28/90) }\end{array}$ \\
\hline \multicolumn{3}{|l|}{ Commercial \& Industrial Customers } \\
\hline Replace Incandescent Lamps w/Fluorescent Lamps & 750 & 1475 \\
\hline Relamp Fluorescent $\ldots \ldots \ldots \ldots \ldots \ldots \ldots \ldots \ldots$ & 500 & 725 \\
\hline Install High Efficiency Ballasts $\ldots \ldots \ldots \ldots \ldots \ldots \ldots \ldots$ & 850 & 1800 \\
\hline Replace Fluorescent Fixtures. & 700. & 1900 \\
\hline Install High Efficiency Motors & $1920 \ldots$ & 2700 \\
\hline Install Thermal Storage . . . . . & 1575 & 1575 \\
\hline Replace Electric A/C . . . . . . . . . . . . . . . . & $850 \ldots$ & 1050 \\
\hline Install Gas A/C ..... & $500 \ldots$ & 825 \\
\hline \multicolumn{3}{|l|}{ Residential Electric Customers } \\
\hline Replace Incandescent w/Fluorescent Lamps . . . . . . . . & 1075 & 1400 \\
\hline Timers on Electric Water Heaters \& Pool Pumps $\ldots \ldots \ldots \ldots$ & 650 & 650 \\
\hline Timers on Central $A / C, \ldots \ldots \ldots \ldots \ldots \ldots \ldots \ldots \ldots$ & 325 & 325 \\
\hline Replace Central A/C $\ldots \ldots \ldots \ldots \ldots \ldots \ldots \ldots \ldots$ & $3100 \ldots$ & 3100 \\
\hline Replace Electric Water Heaters $\ldots \ldots \ldots$. & $2150 \ldots$ & 2150 \\
\hline
\end{tabular}

The list of allowable measures was highly restricted in the Con Edison auction. Only eight measures were eligibie, the majority of which were covered by utility rebates. ${ }^{19}$ Consequently, ESCOs were unable to tid comprehensive packages of measures. Lighting and motors accounted for most of the proposed savings. Thus, one of the main advantages that ESCOs offer -- comprehensive ietrofits -- was not used to advantage.

Finally, a number of energy service companies indicated that (1) the utility rebates were high and the ESCO would have a difficult time marketing their program, (2) that they had heard that rebate levels were increasing and didn't want to bid given the uncertainty, and (3) that ESCOs did not have enough time to respond when Con Edison increased its rebate levels and ceiling prices about one month before the deadline. This last set of factors illustrates the problems that arise for potential bidders as well as coordination issues that the utility and PSC must address in defining the relationship between utility DSM programs and DSM bidding programs. Con Edison established the ceiling prices for individual DSM measures $(\$ / \mathrm{kW})$ by increasing utility program costs (i.e., customer rebates plus administrative costs) by $50 \%$. After the bidding RFP had been issued, Con Edison proposed significant increases in customer rebates for many efficiency measures. The Company then decided to revise its ceiling prices upward in order to

19 Con Edison wanted to limit the number of measures to those where it had the most experience, in order to make it easier to evaluate results from the pilot. 
maintain the established relationship (see Table 5-2). This decision was made in late September 1990 , approximately one month before the deadline for submitting final bids. Given the Company's threshold requirements (e.g., signed letters of intent for all participating customers), most ESCOs concluded that they could not respond in terms of renewed marketing efforts.

We also interviewed Con Edison staff that were involved with the integrated resource bidding program to obtain their perspective on the program and issues raised by prospective DSM participants. Con Edison staff indicated that they were surprised at the relatively poor response by DSM bidders. For Con Edison, a primary objective of the integrated bidding pilot was to test whether it was possible to evaluate supply and DSM resources similarly using an objective scoring system. They viewed the DSM threshold requirements as essential in order to assure that supply and DSM projects could be evaluated on a comparable basis. Con Edison staff were satisfied with the overall results both in terms of total number of bids received and quality of projects, and maintained that it was worth testing their approach and requirements for DSM projects (despite the criticisms of prospective DSM bidders). During contract negotiations with ESCOs, Con Edison staff also felt an obligation to stay as close as possible to the intent of the RFP" and thus were unwilling to relax the requirements and penalties if customers with signed letters of intent decided not to go ahead with their project.

To summarize, some of the problems that arose at Con Edison are endemic to DSM bidding. Specifically, the possibility that utility rebate leve's might change either after an RFP is issued or during contract negotiations has occurred at other utilities. Con Edison's changes to its DSM programs were driven by regulatory requirements for filing long-range DSM plans and the timing was coincidental with the integrated bidding program. However, Con Edison's program design exacerbated the problem because the threshold requirements were so burdensome to ESCOs and because ceiling prices were specifically linked to utility DSM rebate levels. More importantly, the program's threshold and eligibility requirements were the key factor that led to poor participation by ESCOs. In one sense, the Con Edison bidding program demonstrates that threshold requirements which force ESCOs to have signed letters of intent from all customers and severely limit an ESCOs ability to meet contract demand reduction goals if customers change their decisions are inappropriate for DSM bidding. For Con Edison, the DSM threshold requirements were driven by its attempt to "level the playing field" as part of an integrated, allsource nature of the bidding program. In practice, this approach negatively affected the market response by third-party DSM providers.

\subsection{Incentives in the Scoring System}

In this section we examine three pairs of stylized bids in order to analyze the effects of Con Edison's bid adjustment procedures on various types of projects. Each pair of bids is designed to accentuate a particular aspect of the bidding scheme so as to clarify the incentives in the actual auction. The members of each pair are polar opposites with respect to some feature of the bid scheme. We assume values for important bid parameters and for utility production costs. 
The assumptions are subject to debate; however, our examples are chosen so that the qualitative conclusions remain valid over a wide range of parameter values.

The first pair of bids illustrate the effects of the make-up energy adjustment. In this example, it is relatively straightforward to compare the net benefits that the bid and utility production would provide to the Con Edison system which enables us to rank this pair of bids on a normative basis. We show that the Con Edison bid scheme ranks these bids in the opposite order under certain conditions. A normative comparison is more difficult for the second and third pair of bids. Instead, we discuss the implications of the utility ranking. The term adjustment and the transmission and distribution adjustments appear reasonable.

\subsubsection{Make-up Energy Adjustment}

Con Edison developed the make-up energy adjustment to compare bids of differing capacity factor or, in the case of DSM, load factor. Con Edison's bidding RFP suggests that the utility was not predisposed (nor held any intended bias) towards acquiring either baseload or peaking capacity. To evaluate the incentives implied by the bid scheme, we consider two bids:

a one MW peaking or intermediate bid (I) and

- a one MW baseload bid (B).

To simplify the comparison, we assume that there are no maximum and minimum operation constraints, no start-up costs, and assume that both bids are $100 \%$ reliable. Any of these assumptions can be removed without invalidating the analysis. For clarity, a single year of the contract term is analyzed and the contribution of that year to the total bid cost is calculated. A net present value analysis could be carried out to calculate the value of a stream of bid costs, but the qualitative effect on the bid ranking will be clear from analysis of a single typical year.

Let the bid variable cost be $v_{I}$ for the intermediate bid and $v_{B}$ for the baseload bid. Let the optimal hours calculated for these bids be $d_{I}$ and $d_{B}$, respectively: that is, $\left(v_{I}, d_{I}\right)$ and $\left(v_{B}, d_{B}\right)$ are points on the utility price-duration curve derived from production cost modeling (see Figure 3-2 for example). By our assumption, if successful, these bids would be dispatched to operate for the optimal hours and would displace utility generation for these hours. Let the yearly bid fixed costs be $c_{I}$ and $c_{B}$, respectively.

In the absence of the bids, the one MW slice of the load-duration curve at durationd, corresponding to a variable cost $v_{l}$, is assumed to be supplied by a new utility plant of annualized fixed cost $u_{I}$. Similarly, assume that the slice at duration $d_{B}$ would be supplied by a new utility plant of annualized fixed $\cos t u_{B}$. That is, the utility baseload and intermediate generation is considered to have the same variable costs as the bid baseload and intermediate generation, respectively so that the comparison of the bid and utility construction hinges on the comparison between the fixed costs of new utility and bid generation. 
A reasonable normative criterion for ranking the bids in a solicitation is the net benefits they provide ratepayers compared to utility construction. The plant with the greater net benefits should be ranked higher. The normative criterion for ranking the bids is therefore the sign of:

$$
\delta=\left(c_{B}-u_{B}\right)-\left(c_{I}-u_{I}\right) .
$$

If $\delta>0$, then the intermediate bid should be ranked ahead of the baseload bid on a normative basis, otherwise the baseload bid should be ranked ahead of the intermediate bid.

To see how the Con Edison bidding scheme actually ranks projects, the sum of each bids' fixed plus variable costs are compared along with the make-up energy cost for that bid. Thus, the intermediate bid's costs include: $d_{I} v_{I}+c_{I}+\left(8760-d_{I}\right) v_{\text {avI }}$, where $v_{\text {ovI }}$ is the weighted average marginal energy cost over the duration between $d_{I}$ and 8760 hours. The $\left(8760-d_{I}\right) v_{\text {ovI }}$ term is the make-up energy component (see Fig. 3-2). Similarly, the baseload bid's costs are: $d_{B} v_{B}+c_{B}+\left(8760-d_{B}\right) v_{a v B}$, where $v_{a v B}$ is the weighted average marginal energy cost over the duration between $d_{B}$ and 8760 hours. The difference between these bid prices is:

$$
\Delta=d_{B} v_{B}+c_{B}-d_{I} v_{I}-c_{I}-\left(d_{B}-d_{I}\right) v_{a v},
$$

where the $\left(d_{B}-d_{1}\right) v_{a v}$ term is the difference between the make-up energy components for the two bids.

There are various combinations of possibilities that can arise with respect to the relative costs of the bid and utility construction. We investigated one of the possibilities that illustrate potential biases in this bidding scheme.

- $u_{I}>c_{I}$, that is, the intermediate bid is cheaper than the utility intermediate plant of the same variable cost, while,

- $u_{B}<c_{B}$, that is, the baseload bid is more expensive than the utility baseload plant of the same variable cost.

Given these assumptions, an optimal resource plan would incorporate the utility baseload plant and the intermediate bid plant. Therefore, under these assumptions, the intermediate bid should be ranked ahead of the baseload bid. The normative criterion of Equation $5-1,8>0$, is satisfied.

By this measure, the incentives in the bidding scheme are correct if they favor the intermediate bid over the baseload bid. For this to be true, $\Delta$ should be greater than zero. However, if $\left(d_{B}-d_{1}\right) v_{\sigma v}$ is sufficiently large, then $\Delta$ may be less than zero. This can occur if the system costs are dominated by variable costs and if two bids of significantly different optimal durations, $d_{B}$ and $d_{l}$, are being compared. The Con Edison long-run avoided costs shown in Figure 3-1 indicate that the energy costs are approximately five to ten times larger than the capacity costs. This suggests that the make-up energy term could easily dominate the comparison between 
baseload and intermediate bids. In this case, the bid scheme can rank the bids incorrectly by favoring the baseload bid over the intermediate bid.

To illustrate the effect of the make-up energy adjustment on bid choice, Table 5-3 presents two hypothetical bids matching the scenario laid out above. The baseload bid is more expensive than comparable utility construction, while the intermediate bid is cheaper. Annual capacity payments are $\$ 290 / \mathrm{kW}$-yr for the baseload plant and $\$ 104 / \mathrm{kW}-\mathrm{yr}$ for the intermediate bid using a 20-year contract term and a $9.8 \%$ discount rate. Mapping the variable bid prices to the marginal energy cost duration curve of Figure 3-2 gives estimated effective hours of operation of 8000 hours for the baseload bid and 5500 hours for the intermediate bid. ${ }^{20}$ The make-up energy adjustment is the product of the difference of the two durations and $v_{a v}$, which we estimate to be five $\mathrm{c} / \mathrm{kWh}$ (see Figure 3-2). The result is that $\Delta$ is negative; that is, the baseload bid is chosen over the intermediate bid.

A significant point is that the sign of $\Delta$, which determines which of the bids is more likely to be accepted in the auction, is not closely connected with the normative criterion for choosing between the bids. Put another way, the make-up energy concept is not linked to net benefits, but rather is cost-based. We have shown in previous work on competitive bidding scoring systems that the net benefits approach is preferable (Goldman et al. 1992; Stoft and Kahn 1991).

It is possible that non-price factor points for projects that offer dispatchability explicitly and agree to install automatic generation control (AGC) equipment offset the make-up energy penalty imposed on intermediate load bids. ${ }^{21}$ While willingness to participate in AGC is different than dispatchability, it is reasonable to assume that a project with AGC would also be dispatchable. If the make-up energy adjustment is viewed as a penalty for lack of perceived dispatchability,

\footnotetext{
${ }^{20}$ Plant availability limits baseload operation to 8000 hours per year.

${ }^{21}$ Five points are awarded for dispatchability and three points are awarded for Automatic Generation Control out of a possible 240 points for non-price factors (see Evaluation Data Sheets 8-10).
} 
then the points awarded for dispatchability and AGC should compensate for the make-up energy penalty. Hrwever, the yearly monetized value of eight points is approximately $\$ 4 / \mathrm{kW}$-year (based on an LRAC of $\$ 500 / \mathrm{kW}$-year). This amount is an order of magnitude less than the yearly value of $\left(d_{B}-d_{I}\right) v_{\alpha v}$, which is approximately $\$ 125 / \mathrm{kW}$-year, based on $v_{\alpha v}=$ five $\mathrm{c} / \mathrm{kWh}$ (a typical value from Figure 3-2) and $d_{B}-d_{I}=2500$ hours. Thus, the points awarded for these non-price factors do not overcome the cost penalty imposed by the make-up energy adjustment.

\subsubsection{Term Adjustment}

The term adjustment is used to compare bids of differing duration. It is somewhat analogous to the make-up energy term in that, for bids shorter than the nominal term of twenty years, it accounts for the cost of capacity and energy while the bid generator is not operating. The adjustment also accounts for make-up energy during such years.

We consider two bids:

- a long-term bid (L) and

- a short-term bid (S).

Because the effects of make-up energy were analyzed in the previous section, we construct the bids so that they generate in each hour of each year. Thus, for simplicity, we assume that both bids offer one MW of capacity and have zero variable costs, have availability factors of $100 \%$ and do not have any minimum or maximum operating constraints. Each bid is dispatched for 8760 hours per year over the durations of their contracts. The short-term bid proposes a ten year contract, while the long-term bid wants a 30 year contract. Con Edison's nominal contract term is 20 years.

Since the variable costs for the short-term bid (S) are zero, the adjusted bid price for $S$ consists of the bidder's capacity costs and the term adjustment:

$$
1 M W\left(\sum_{t=1}^{10} c_{S t}+\sum_{t=11}^{20} L R A C_{t}\right)
$$

where $c_{S \mathrm{~s}}$ are the net present valued bid capacity costs and $L R A C_{t}$ are the net present valued longrun average avoided costs for each year over the 11 to 20 year adjustment term.

The adjusted bid price for the long-term bid (L) is the difference between bidder's capacity costs and the term adjustment: 


$$
1 M W\left(\sum_{t=1}^{30} c_{L t}-\sum_{t=21}^{30} L R A C_{t}\right),
$$

where $c_{L}$ are the net present valued bid capacity costs and $L R A C_{t}$ are the net present valued longrun average avoided costs for each over the 21 to 30 year adjustment term.

First, to evaluate the incentives provided by the term adjustment, let us assume that the capacity costs of bid L between years 11 to 30 approximately match Con Edison's long-run average avoided costs during that period. Then the difference between the adjusted bid price for $S$ and $\mathrm{L}$ will depend solely on each tidder's costs during the first ten years. This seems to compare the two bids appropriately. Second, suppose that the bid costs for L deviate from the utility's long-run average avoided costs in the years 11 to 30 . Then, the term adjustment will also consider any net benefits or disadvantages provided by $\mathrm{L}$ compared to utility generation in those years, which is reasonable.

In summary, the term adjustment seems to compare bids fairly well, assuming that the long-run cost of utility generation is an appropriate proxy. However, a second order effect occurs because some bidders will have costs that are less than Con Edison's LRACs. Consequently, the average costs of bid capacity over all successful bidders will be somewhat lower than the utility's LRACs. Therefore, using LRACs as an adjustment will always penalize short-term and advantage long-term bids relatively more than the average bid costs. A further effect is that bids of duration less than 8760 hours will be additionally penalized by the make-up energy adjustment as described previously.

The problem of comparing bids of differing duration has not been well-solved in the theoretical literature. A key unresolved issue involves appropriate expectations regarding the outcome of future rounds of competitive solicitations and future utility construction. It is unclear whether it is more appropriate to assume that equivalent, more costly, or less costly generation should be assumed to replace a short-term bid at the end of its term and what risk trade-offs should be made between shorter term and longer term contracts. In the Con Edison bid scheme, replacement is always at the utility's long-run avoided costs. However, we expect these type of considerations will become more significant to electric utility planners as competitive bidding becomes more common.

This problem is the competitive analogue of the "end effects" problem in the engineering economics framework for evaluating projects within the setting of a vertically integrated firm. In this simpler setting, differences in project lifetime are usually small, and the normalization procedure for comparing projects involves simply extending their lives by replicating their costs out for a long period (say 50 years) so that discounting effects become insignificant. This simple replication is no longer quite so reasonable in a competitive setting, where the replacement cost is determined by a market process. 


\subsubsection{Transmission and Distribution Adjustment and Related Non-Price Factors}

The transmission and distribution adjustment is used to adjust for differences in the costs of moving power from generator to load. The LRACs that are used in the calculation of the makeup energy and term adjustments depend on the voltage levels. In addition, the non-price factors also include several attributes that are directly related to transmission requirements. Thus, we analyze the combined effect of the transmission and distribution adjustment and the relevant nonprice factors on adjusted bid prices. The non-price factors are monetized at rates that depend on transmission requirements. In Con Edison's scoring system, the transmission and distribution adjustment is added to a bidders' price, while the monetized non-price factors are subtracted from the bidder's cost.

We consider two bids that span the full spectrum of possible transmission requirements:

- a bid that connects at the primary distribution level (D) and

- a bid that is outside New York State and requires transmission construction (T).

Each bid proposes a 20 year contract from 1994 to 2013 with baseload production in all hours of the year. ${ }^{22}$ For these bids, the net present value of distribution and transmission adjustment penalties are $\$ 469 / \mathrm{kW}$ and $\$ 1135 / \mathrm{kW}$ (in $1990 \$$ ), respectively (see revised Evaluation Data Sheet 6).

We then score each bid on the transmission-related non-price factors. These scores reflect the maximum possible effect of a project's transmission-related features. We assume that bid D receives the maximum possible points on transmission-related questions, while bid $\mathrm{T}$ receives zero points. Actual bids may not reflect such a large difference. ${ }^{23}$ Each transmission-related question is paraphrased in Table 5-4.

The non-price factors are monetized as follows (see Chapter 3 for a detailed discussion of this procedure). Total points in the non-price general category (Evaluation Data Sheets 8 and 9) are multiplied by 0.001 and the summed net present value of the LRACs at the appropriate voltage. Summing the primary distribution net present value LRACS at a $9.8 \%$ discount rate to 1990 dollars over the twenty year bid from 1994 to 2013 yields $\$ 5603 / \mathrm{kW}$. This yields an adjustment for bid D of:

$$
(50+5+0) * 0.001 * \$ 5603 / k W=308 \$ / k W
$$

\footnotetext{
2 This allows us to ignore differences in make-up energy and term adjustments.

23 Actual bids could be expected to have some non-zero scores for these items. This further affects the comparison between the bids, even if the points were the same for Bids D and T, since the point scores for bids $\mathrm{D}$ and $\mathrm{T}$ are monetized at different rates. However, we will neglect this difference.
} 
Table 5-4. Non-price Points Related to T\&D for Two Hypothetical Bids

\begin{tabular}{|c|c|c|}
\hline & Bid D & Bid T \\
\hline \multicolumn{3}{|l|}{ Evaluation Data Sheet 8, Reliabihity Factor } \\
\hline 6. Overhead transmission not required? $\ldots \ldots \ldots \ldots$ & $10 \ldots \ldots$ & 0 \\
\hline 7. Additional firm capacity exists? . . . . . . . . . & $10 \ldots \ldots$ & 0 \\
\hline 9. Project in New York State? . . . . . . . . . . . . & $13 \ldots \ldots$ & 0 \\
\hline 10. Project is East of the West-Central Interface? . . . . & $12 \ldots \ldots$ & 0 \\
\hline $\begin{array}{l}\text { 11. Project is in Con Edison service area? } \ldots \ldots \ldots \\
\text { Evaluation Data Shoet 9, Risk Factor }\end{array}$ & $5 \ldots \ldots$ & 0 \\
\hline $\begin{array}{l}\text { 8. Transmission doesn't require Article VII Certification . } \\
\text { Evaluation Dats Sheot 11, Environmental Benefits }\end{array}$ & 5 & 0 \\
\hline (Under Land Effects) Uses existing transmission? ... & 8 & 0 \\
\hline
\end{tabular}

For transmission, the summed LRACs are $\$ 5030 / \mathrm{kW}$, leaving the adjustment for $\mathrm{T}$ as:

$$
0 * 0.001 * \$ 5030 / k W=0 \$ / k W \text {. }
$$

These adjustments are subtracted from the bid cost.

For environmental factors, the point : core is divided by 60 , and multiplied by the summed net present valued environmental mitigation cost. Summing the environmental mitigation cost at a $9.8 \%$ discount rate to 1990 dollars over the twenty year bid from 1994 to 2013 yields $\$ 770 / \mathrm{kW}$.

For $\mathrm{D}$, th:e adjustment is:

$$
8 / 60 * \$ 770 / k W=103 \$ / k W
$$

For $\mathrm{T}$, the adjustment is:

$$
0 / 60 * \$ 770 / k W=0 \$ / k W
$$

These adjustments are also subtracted from the bid cost.

Therefore, the net adjustment to the cost of the distribution-level bid (D) is:

$$
469-308-103=58 \$ / k W \text {. }
$$

The net adjustment to the bid cost for the transmission-level bid $(\mathrm{T})^{6}$ is:

$$
1135-0-0=1135 \$ / k W .
$$


Thus, the cost difference between bids that connect at transmission and distribution levels (with associated transmission requirements) is $1077 \$ / \mathrm{kW}$. This is quite expensive for transmission capacity, noting that the bid capacity and energy are intended to be the values at the point of connection to the Con Edison system. The Con Edison system has a diameter of less than 50 miles, so that the amount of transmission construction in the Con Edison system to support this generation could have a length of no more than 50 miles. This implies that the difference in costs for projects that interconnect at traismicsion vs. distribution level is valued at about $\$ 21.5 / \mathrm{kW}$-mile. By comparison, the cost for new overhead transmission capacity ranges between $\$ 1-2 / \mathrm{kW}$-mile where right-of-way is not particularly expensive (Baldick and Kahn, 1992). The high costs may be due to the predominantly underground transmission capacity in the Con Edison service territory. We explore this question in more detail in the next section.

\subsection{The Importance of Transmission and Distribution Impacts}

Con Edison's scoring system places a high value on the location of projects in its T\&D network. Bidders with projects located at the primary distribution level are penalized $\$ 469 / \mathrm{kW}$, while projects located at transmission level are penalized $\$ 1135 / \mathrm{kW}$. These penalties are designed to reflect incremental costs of additional T\&D capacity and had a significant impact in determining the outcome of the auction. In this section we discuss several questions:

(1) Are these transmission cost impacts reasonable given the characteristics of the Con Edison system?

(2) What do these penalties represent?

(3) What do these valuations imply about the bid evaluation system more broadly?

First, we examine transmission cost data for Con Edison and other utilities as a way of assessing the reasonableness of the transmission cost impacts implied by these penalties. The question of what the penalties represent is addressed from the general perspective of regulatory choice between competitive bidding for new supply versus the traditional alternatives. We argue that transmission planning is less efficient when independent suppliers provide generation capacity, because co-ordination economies are typically lost. We then formulate a trade-off between this loss and the gains from competition. Finally we link this discussion with other features of the bid evaluation system.

\subsubsection{How Large Are Con Edison's Transmission Costs?}

Con Edison's estimates of the cost impazts of T\&D expansion in its bid scoring system appear relatively high. Thus, it is useful to assess the plausibility of these values. In reviewing aggregate data on transmission investments among investor-owned utilities, it is clear that there is substantial variation in the share of total assets devoted to transmission. Table 5-5 shows data on the share of transmission assets in the total of underpreciated electric utility plant for a selected group of large investor-owned utilities (EIA 1992). Transmission assets represent about 
$12 \%$ of the total asset base for all investor-owned utilities. However, utilities that have been large scale-wholesale purchasers historically (Con Edison, San Diego Gas \& Electric, and Southern California Edison) have about $20 \%$ of their asset base in transmission.

Table 5-5. Share of Transmission in Total Assets of Selected Investor-Owned Electric Utilities

\begin{tabular}{lrrc} 
Utility & $\begin{array}{r}\text { Net Eloctric } \\
\text { Utility Plant } \\
\text { (million \$) }\end{array}$ & $\begin{array}{r}\text { Total Transmission } \\
\text { Plant } \\
\text { (million \$) }\end{array}$ & $\begin{array}{c}\text { Transmission/ } \\
\text { Total Plant } \\
\%\end{array}$ \\
\hline Consolidated Edison & 7054 & 1558 & 22 \\
San Diego Gas \& Electric & 2554 & 501 & 20 \\
Southern California Edison & 12379 & 2405 & 19 \\
Duke Power & 8450 & 1223 & 14 \\
Pacific Gas \& Electric & 13504 & 1851 & 14 \\
Detroit Edison & 8879 & 1024 & 11 \\
Cleveland Electric Illuminating & 5317 & 547 & 10 \\
Houston Lighting \& Power & 8705 & 764 & 9 \\
Texas Utilities & 16655 & 1388 & 8 \\
Philadelphia Electric & 10089 & 685 & 7 \\
Investor-Owned Utilities Total & 455061 & 52630 & 12
\end{tabular}

If we normalize the transmission plant investment of each utility to its peak demand, then Con Edison's average transmission costs are roughly double those of Pacific Gas \& Electric (about $\$ 200 / \mathrm{kW}$ to $\$ 100 / \mathrm{kW}$ ). ${ }^{24}$ These differences (on average) are small, yet on the margin, Con Edison appears to have substantially greater costs. The most likely explanation of this difference is that Con Edison's costs arise from high density, whereas PG\&E's arise from long distances.

We test this conjecture by examining the balance between overhead T\&D circuit miles and underground T\&D circuit miles for a subset of these utilities (see Table 5-5). Undergrounding is substantially more expensive than overhead capacity. By one estimate it is 7-8 times more for transmission and 2-3 times more for distribution capacity (Baughman and Botaro 1976).

The share of underground T\&D capacity is sizeable for three utilities: Con Edison, Detroit Edison (Ddt Ed) and Cleveland Electric Illuminating (CEI) (see Table 5-6). These utilities are all urban-based with small geographic service territories. Within this group, Con Edison has by far the smallest total number of miles. Even without normalizing for peak load, Con Edison's density cost is still apparent. Measured simply by $\$ /$ mile, Con Edison's cost is $\$ 1.5$

\footnotetext{
24 We divide the $\$ 1.56$ billion Con Edison transmission plant cost by its summer peak demand of about 9000 MW and the PG\&E $\$ 1.85$ billion PG\&E transmission plant cost by its summer peak demand of about $17000 \mathrm{MW}$ peak.
} 


\begin{tabular}{lrrrrrr} 
& Con Ed & SDG\&E & SCE & PG\&E & CEI & Ddt Ed \\
\hline Overhead & 440 & 774 & 4668 & 6572 & 1262 & 1003 \\
Under-ground & 589 & 0 & 182 & 69 & 1050 & 1764 \\
& & & & & & \\
\hline
\end{tabular}

million/mile, compared to roughly $\$ 400,000 /$ mile for Detroit Edison and about $\$ 200,000 / \mathrm{mile}$ for CEI.

While these type of comparisons are not definitive, collectively, they suggest that Con Edison's true incremental interconnection cost at the transmission level is indeed quite high, and that the RFP penalties are not unreasonable.

\subsubsection{Integrating Private Power into the Network}

When private producers interconnect, integrating their transmission needs into the long-term transmission plans of the utility can be costly. If generation additions occur at multiple sites, the utility may not be able to plan optimally and take advantage of coordination economies. In contrast, utility plans for generation will be available to utility transmission planners at a much earlier stage of development. Large transmission projects typically must be certified at a public utility commission, necessitating lead times for transmission projects that are as long or longer than the lead times for generation projects. Therefore, gains from competition in the generation segment may be offset by coordination losses in transmission planning.

To attempt to eliminate the coordination loss, the regulator might require the utility to investigate and disclose all possible transmission expansion plans involving multiple site locations. At a minimum, this task is computationally challenging. Even if some limited approximation to disclosure of all possible transmission plans were available, the regulatory outcome might still not be desirable. Suppose the utility does disclose information on the potential economies of joint citing and interconnection. Two bidders might then coordinate their proposals to capture these economies. The net social economy would not necessarily be reflected in lower prices paid by utility ratepayers, since collusion between bidders could capture most of the rent through higher bids for generation.

Competition in the generation segment creates the opportunity to drive down prices to ratepayers. Because the cost of generation is typically significantly greater than the cost of transmission, small economies in generation may outweigh coordination losses in transmission planning. There is a balance between the gains from competition in the generation segment and the potential coordination losses in transmission planning. We can formalize this trade-off to determine the conditions under which the gains from competition in generation exceed the 
coordination losses in transmission. Trade-offs of this kind lie at the heart of the unbundling process in regulated and vertically integrated industries (Gilbert and Riordan 1992).

\section{Formulating the Trade-off}

Over a wide range of choices of generation expansion, losses from uncoordinated planning are relatively large as a fraction of the transmission expansion costs. Baldick and Kahn (1992) have attempted to make estimates of these losses. These losses occur regardless of what type of generation capacity is installed. We can express the transmission coordination losses as the product of the percentage coordination loss $(C L)$ and the total transmission expansion cost (TC).

In contrast, the benefits of competition in generation depend partly on the type of generation capacity installed. Benefits are typically greater for baseload generation, which operates for most hours of the year, compared to peaking generation, which operates for brief periods of time. We parametrize the costs and benefits of competition in the generation segment to illustrate the importance of this effect.

The gains from competition in the generation sector can be expressed as the product of a percentage competitive benefit $(\alpha)$ and the cost of generation $(G C)$. Generation costs are the sum of fixed costs $(F C)$ and total variable costs (TVC).

$$
\text { Gains from competition }=\alpha \cdot G C=\alpha[F C+T V C] .
$$

Total variable costs for a particular dispatchable project are approximately proportional to the number of hours per year that it is optimal to operate a particular generator. This optimal operating profile is determined by simulation of the power system dispatch (Stoft and Kahn 1991). We describe the operating profile as a capacity factor (CF). Finally, as a mathematical convenience, we define a proportional relationship between variable generation cost and $T C$, parametrized by a multiplier $\beta$. Therefore, the gains from competition are $\alpha[F C+\beta \cdot C F \cdot T C]$. These gains exceed coordination losses when:

$$
\alpha[F C+\beta C F \cdot T C]>C L \cdot T C .
$$


Rearranging terms, this can be expressed in terms of those capacity factors that satisfy:

$$
C F>\frac{C L}{\alpha \beta}-\frac{F C}{(\beta \cdot T C)}
$$

By estimating the parameter values in the right hand side of this expression, we can gain some insight into the conditions that are likely to make competition the desirable regulatory strategy. This also helps illuminate the particular circumstances faced by Con Edison.

\section{Numerical Estimates}

Rough estimates of the value of $\alpha$ (i.e., percent benefits from competition) range between 0.1 (Kahn 1991) and 0.2 (Lieberman 1992). Baldick and Kahn (1992) suggest that a typical value for coordination losses $(C L)$ is $25 \%$. Based on these estimates, $C L / \alpha$ is between one and three. We then express generation costs $(G C)$ as a function of capacity factor $(C F)$ in present-value $\$ / \mathrm{kW}$, and use values that are consistent with Con Edison's avoided cost information in the RFP:

$$
G C(C F)=600 \$ / k W+C F 4700 \$ / k W .
$$

On the basis of this parameterization, $\frac{F C}{(\beta \cdot T c)}=13 \%$.

To determine $\beta$, we use estimates of transmission costs (TC) and the relationship between variable generation costs and transmission costs: $\beta \cdot T C=4700 \$ / \mathrm{kW}$. TC can be quite variable, depending upon local conditions. A typical range for transmission costs (TC) is $\$ 200-300 / \mathrm{kW}$ (Pacific Gas \& Electric 1991). A high cost case, such as Con Edison, would be TC $=1135$ $\$ / \mathrm{kW}$ (taking transmission and distribution impacts together). Using this range of values, we get $20>\beta>4$.

The implication of these estimates is the following. For most cases where transmission costs are small compared to generation costs, competition is beneficial for capacity factors $(C F)$ that are greater than $10 \%$. This means that only the 'peaking' technology segment of the market should be excluded from competition. In areas where transmission system costs are high, competition should be confined to high capacity factor (baseload) market segments. For $\beta=$ 4 and $C L / \alpha=3$, the critical capacity factor is more than $60 \%$. In this case, the intermediate load segment of the market may or may not be a beneficial arena for competition. The high transmission cost case may arise either in areas of high urban density or because interconnection distances are long. This latter case is likely for renewable energy projects, which are often located in remote areas relative to the main transmission corridors. 


\subsubsection{Implications}

\section{Baseload Orientation}

Given the high interconnection costs, the trade-off analysis developed in Section 5.4.2 suggests that Con Edison should seek baseload capacity in its RFP. The magnitude of the incentive for baseload power depends strongly on the parameter $\alpha$, the gain from competition. The smaller the estimate of this gain, the greater the incentive should be for baseload resources. Conversely, the larger $\alpha$ is, the less the T\&D impacts should matter.

In retrospect, Con Edison appears to have reaped substantial benefits from the solicitation. Measured simply on the price factor alone, winning supply bids were all less than $65 \%$ of avoided cost. Among losing supply bids, only 14 of 37 projects had bid prices that exceeded $90 \%$ of the utility's estimated avoided costs. However, these results may be less significant than they first appear. The main reason is that the avoided cost estimates turned out to be too high. ${ }^{25}$ In the time between when the RFP was released and when contracts with winning bidders were signed, the consensus estimate of avoided costs for New York utilities decreased significantly (20-30\%) (NYPP 1991; NYPSC 1991). Therefore, the true gain from competition in this case must be substantially smaller than the percentages of avoided cost as calculated by Con Edison.

The effect of high estimated avoided costs on the structure of the bidding system is mixed. On the one hand, it may well have been understood by Con Edison to be high, and therefore to overstate the benefits of competition. By the previous logic this would lead to encouraging a baseload-oriented bid evaluation system. The T\&D penalties should be sufficient to achieve this, if they do, in fact, reflect incremental cost. In addition, our analysis suggests that the make-up energy feature can also be biased in the direction of baseload resources (see section 5.3.1). However, Con Edison's high estimated avoided costs meant that, in practice, most bids ended up being evaluated as if they were baseload. This is because the assumed marginal cost curve is so high compared to the bidders' variable price that very little make-up energy penalties are assigned. For example, the average make-up energy adjustment for supply bids is only $\$ 153 / \mathrm{kW}$ compared to unadjusted prices for supply bids averaging $\$ 4323 / \mathrm{kW}$, and adjusted prices averaging $\$ 3991 / \mathrm{kW}$ (see Table 4-2). The few DSM projects were the only bids that incurred substantial penalties from the make-up energy adjustment: the average penalty was $\$ 2007 / \mathrm{kW}$ compared to unadjusted prices of $\$ 1115 / \mathrm{kW}$ and adjusted prices of $\$ 2856 / \mathrm{kW}$.

\footnotetext{
${ }^{25}$ In 1989, the PSC's adopted LRACs assumed that gas prices would escalate at a real rate of $5.5 \%$ per year between 1990 and 2000 .
} 


\section{Remote Projects Acquired Outside of Bidding}

If T\&D cost impacts are such a serious matter that they are responsible for Con Edison structuring its bid evaluation criteria toward baseload projects, questions arise about large-scale projects acquired outside of bidding. Con Edison has a contract with a large QF project located outside of its service territory: the Sithe/Energies project located in Oswego, New York. The Sithe project has a contract (dated May 1991) for approximately 700 MW with Con Edison, and may sell as much as $200 \mathrm{MW}$ to Niagara Mohawk Power Corporation, in whose service territory the project is located. To interconnect with the Con Edison system, the Sithe project requires wheeling and should have to incur transmission costs at approximately the level indicated in the RFP. It is unclear whether such fees have been charged to developers.

\subsection{Project Viability Issues}

Perhaps the most unusual result of the Con Edison RFP on the supply side was the near collapse and subsequent resuscitation of the development firm which was awarded the vast majority of the contractual capacity rights. York Research, a New York based firm whose stock is traded on the over-the-counter market, was the managing partner or responsible agent for four separate projects that were in the Preliminary Contract Award Group. These four projects had a combined capacity of $186 \mathrm{MW}$ (out of the award group total of $214 \mathrm{MW}$ ). York ran into a number of difficulties with vendors and financial backers that called the viability of its projects into doubt (Kleinbard 1991). Subsequently, York entered into an agreement with Mission Energy to develop the Con Edison projects (Independent Power Report, 1992).

The York problems might have been identified if the RFP had included requirements regarding the financial viability of proposals. One kind of indicator would be minimum debt service coverage ratios. Con Edison proposed such a measure in its Draft RFP, but several parties, including the PSC staff objected, and the Company withdrew this requirement in favor of a statement from a reputable financial institution that a project is financeable (NYPSC Staff 1989).

The York projects had several features in common. Three of the four projects were based at the Brooklyn Navy Yard, and therefore scored well on the T\&D factor. ${ }^{26}$ Furthermore, although each project used natural gas, they proposed a pricing arrangement in which the variable costs of production escalated over time at the rate of the GNP deflator rather than at a rate tied to natural gas prices. This kind of indexation mechanism is relatively unusual in the private power industry, where it is fairly typical to match the change in costs with the change in revenues (Kahn 1991; Kahn et al. 1992). It is difficult to tell whether the unusual fuel pricing arrangements were an indicator of the subsequent problems experienced by York. Nonetheless, discussions in the trade literature suggest that the proposed pricing arrangements were too low to pay a sufficient return (Gadomski 1992). Furthermore, the financial community strongly

\footnotetext{
${ }^{26}$ One project interconnected at transmission level and thus suffered the full T\&D penalty.
} 
encourages project structures which match variable costs to variable revenues. In cases where this does not occur, financial analysts will assess the impacts of a worst case fuel price scenario on debt service (Standard \& Poor 1991). We will outline how such assertions are related to the particular terms of the contracts between York and Con Edison. The purpose of this discussion is to highlight the nature of the project viability problem, which is generic to competitive bidding.

While the typical terms of natural gas fuel supply pricing involve indexation to the future market price of gas, there are exceptions to this norm. The fuel supply arrangements for the Midland Cogeneration Venture (MCV) and the contract terms of the Holtsville project sponsored by the New York Power Authority for sale to Long Island Lighting (LILCO) are two prominent exceptions. MCV is a well-known private power project located in Michigan, that was converted from a failed nuclear power project. Its pricing terms include variable cost payments that are tied to a coal-based escalation index. To match these terms while still using natural gas for fuel, MCV arranged for a fuel supply mix with non-standard pricing terms. Details of these arrangements are described in a feasibility study (Stone and Webster 1991) that was included in a bond prospectus issued by MCV in November 1991.

In both the MCV and the Holtsville projects, gas suppliers appear to require a cost premium above the current spot market commodity price in exchange for the non-standard escalation. Presumably the reason for the premium is that the non-gas escalator is expected to increase less rapidly than the gas escalation index. Another key feature of these gas contracts is that the seller limits his risk by limiting the term of his commitment. In the MCV gas supply portfolio, the average contract term is 14 years (contract terms range between 10-20 years). In the Holtsville contract, the gas commodity cost is fixed for five years (i.e. no escalation), and then subsequently shifts and adjusts in future years with a gas spot market index.

The York Research contracts are for thirty years or more, and include the GNP deflator indexation feature for fuel costs over the entire term. To assess the risk premium embedded in the initial price, we translate the 1990 bid price for three of these projects into implied gas commodity costs by assuming a net electric heat rate for each project. We then calculate the cost premium relative to 1990 spot gas prices (see Table 5-7).

Table 5-7. Implied Gas Premium

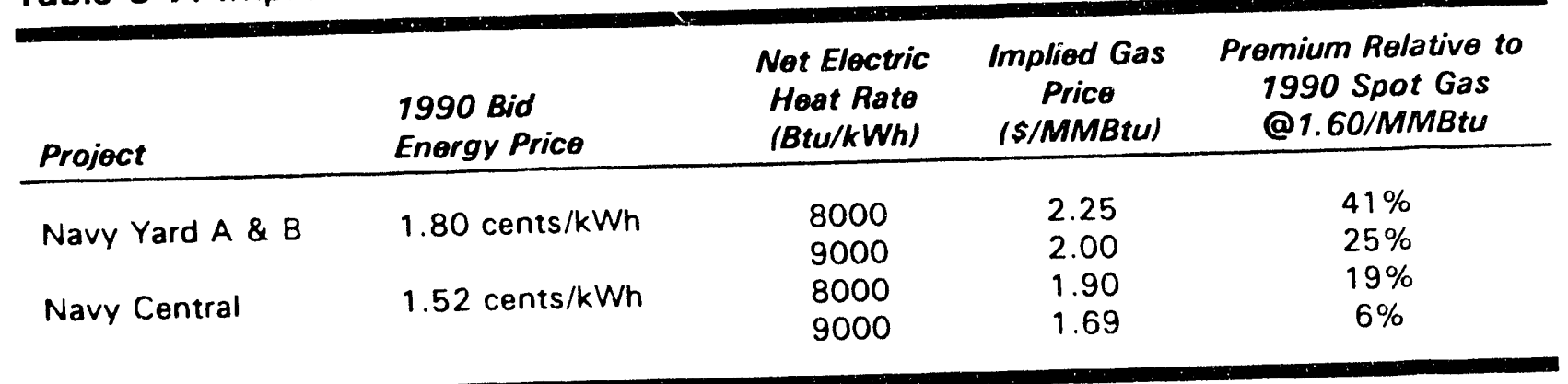


The 40 MW Brooklyn Navy Yard A and B contracts specify a 1990 energy bid price of 1.8 $\mathrm{c} / \mathrm{kWh}$. Small-scale cogeneration projects seldom operate with a net electric heat rate less than $8000 \mathrm{Btu} / \mathrm{kWh}$, while in many cases, they operate closer to $9000 \mathrm{Btu} / \mathrm{kWh}$. For these two heat rates, Table 5-7 shows that the corresponding gas commodity cost would be $\$ 2.25 / \mathrm{MMBtu}$ and $\$ 2 / M M B t u$ respectively. The 1990 spot price for gas was approximately $\$ 1.60$ (Natural Gas Clearinghouse 1992). The implied premium is then the ratio of the implied gas price to the spot market price, which for this project ranges between $25 \%-41 \%$. The $90 \mathrm{MW}$ Brooklyn Navy Yard Central project specified a 1990 energy bid price of $1.52 \mathrm{c} / \mathrm{kWh}$. The implied premium for this project ranges from $6 \%$ to $19 \%$.

The MCV gas contracts provide one standard of comparison against which these estimates of the premium can be assessed. Most of the MCV gas contracts with fixed escalation rates of $4 \%$ annually were negotiated during 1988 . Their average base price is $\$ 2.20 / \mathrm{MMBtu}$. The average spot price in 1988 was $\$ 1.60 / \mathrm{MMBtu}$. This implies a premium of $38 \%(=2.2 / 1.6)$, although there is no reason to assume that these premia are stable or unstable over time. Nonetheless, the MCV premium suggests either that the York projects are very efficient (i.e. have very low heat rates) or that the pricing terms are unrealistic. This is particularly true of the Brooklyn Navy Yard-Central project.

These calculations are only suggestive and certainly not definitive because of other complicating factors. For example, the York contracts include payments for variable O\&M costs. It is possible that this is just a mechanism for covering fuel costs under another name. Moreover, any calculation of the implied gas premium made in 1991, when the contracts with York were being negotiated would be reassuring in one sense. Spot gas prices averaged \$1.40/MMBtu in 1991, making any estimate of the implied premium look bigger and therefore more consistent with the MCV gas contracts than the estimates we used based on 1990 prices at the time developers were preparing their proposals (see Table 5-7). On the other hand, the thirty year commitment in the York contracts is unprecedented. Conceptually, a longer commitment would have to imply a larger premium than in the MCV case. The Holtsville contract, which incorporates no escalation over a six year period, specifies a fixed price of $\$ 3.53 / \mathrm{MMBtu}$ starting in 1994. By any estimate this is a larger premium than the MCV contracts.

These details of the fuel pricing arrangements in the York bids and resulting contracts illustrate one of the fundamental dilemmas of competitive bidding. When is an innovative and attractive offer too good to be true, and when is it a good deal? It is a generally recognized phenomenon in many markets where competitive bidding is practiced that winning bids will sometimes (often) turn out to be too aggressive. This is called the "winner's curse," and seems to pose a conceptual problem only for economists, who cannot believe that irrational behavior can occur (Thaler 1988). But the persistence of the winner's curse shows that even sophisticated economic agents cannot always tell when 100 much of a good thing is being proposed.

It is useful to ask what might have been done to minimize the potential project viability problems encountered by the York projects. The fuel pricing issues raised by the York projects did confer a competitive advantage for these bids. Using the pricing data from these contracts, we estimate 
that the scores of the York bids would have increased by $\$ 800-900 / \mathrm{kW}$ if they had been evaluated using the Con Edison oil and gas price escalators (see Appendix E). While this is a sizable increase, it would not have been enough to change the list of winning bids (see Table 42). Moreover, it is also possible that if York had known that it would be required to bid its variable costs in terms of an oil and gas price index, then the developer might have been able to offer a lower variable energy bid price.

The York bid might have been interpreted as a signal of "non-viability" based on the unusually long term over which fuel price stability was being offered. However, without some criteria for making such a determination, bidders in general might have felt that there was bias in the bid evaluation procedure. For example, if York owned gas reserves that it was committing to fuel these projects over the contract term, then the pricing may have been perceived to be more viable. The important point is that Con Edison had no procedure for evaluating non-standard offers in the fuel pricing area. Without a mechanism to verify the bidder's offer, Con Edison was vulnerable to relying on assertions that may not have been supportable.

Another approach to the viability problem is to rely on portfolio diversification criteria. In its 1988 RFP, Virginia Power indicated that it would seek to avoid a concentration of ownership among the set of winning bidders (Virginia Power 1988). It is not obvious how one applies such a criterion. Presumably it would be done with some kind of threshold on the amount of capacity any one entity could offer. Enforcing such threshold limits in the face of creative entrepreneurs may not be easy.

In summary, the financial distress of the York Research projects may or may not be related to the unusual fuel pricing terms proposed by the bidder. To the degree that these terms signalled a "too good to be true" proposition, they may have foreshadowed the subsequent problems the developer experienced. 


\section{Chapter 6 \\ Discussion}

\subsection{Overview}

In this chapter, we discuss methods that can be used to assess the relative merits of bidding programs. In our discussion, we draw upon our review and case studies of the bidding programs of both Con Edison and Niagara Mohawk (see Goldman et al. 1992). Several "indicators of success" are identified which provide a framework for comparative analysis. Because there have been few detailed case studies of utility bidding programs, well-established evaluation criteria do not exist, nor are there many systematic summaries of the experiences of other utilities. Thus, by definition, this analysis will not be definitive, but will be illustrative of the types of issues that PUCs and utilities should consider as they review results from the firstgeneration of bidding programs.

\subsection{Indicators of Success}

The creation of competitive markets and processes in regulated industries can be a challenging and even painful process. Despite the widespread belief in the virtues of competition, success is not necessarily guaranteed. Competitive resource acquisition programs can encounter problems at various stages: failure to bid, difficulty in designing a system for choosing the best projects fairly, an inability of utilities and private parties to negotiate contracts successfully, failures or substantial delays in project development, and inability to maintain firm capacity or demand reductions over the contract lifetime.

Given these challenges, the following factors provide some useful indicators against which to measure the outcomes of competitive bidding processes:

(1) market response;

(2) project viability - the percentage of projects (and MW) with signed contracts that

successfully develop and come on-line

(3) economic benefits to ratepayers compared to alternatives; and

(4) processes that are administratively tractable, workable and perceived to be fair.

The first three indicators focus on assessing quantifiable impacts associated with a utility's bidding program, while the fourth indicator is more subjective and process-oriented. There are some clear linkages among the first three indicators; they track the project development process. 


\subsubsection{Market Response}

Assessing the market response by private producers and DSM providers to a utility's solicitation is often viewed as the "front page" test of a utility's bidding program. The typical figure of merit for this indicator is total capacity offered by private producers relative to the utility's resource block need. Attention also focuses on the number of bids received. Table 6-1 summarizes market response from utilities that have included both supply and DSM resources in a bidding solicitation. Private producers have proposed projects that represent 3-20 times the capacity put out to bid by utilities. On the demand-side, the ESCO industry is relatively immature compared to the private power industry and individual bids tend to be quite small ( $<$ than $5 \mathrm{MW}$ ). Thus, in analyzing market response by DSM providers, it is useful to examine participant response as measured by the number of bids, rather than focusing only on demand reduction quantities.

The market response by private power producers to the Niagara Mohawk and Con Edison bidding programs was substantial, and closely parallels national trends. On the demand-side, the initial market response by energy service companies (ESCOs) and customers was particularly noteworthy in Niagara Mohawk's bidding program: 33 bids representing $163 \mathrm{MW}$. At the time, the magnitude of this response was viewed by many observers of the energy services industry as a breakthrough in terms of industry maturity. Compared to other utilities, the market response by DSM providers to Con Edison's bidding program (i.e., four bids for $12 \mathrm{MWs}$ ) can only be characterized as poor. As discussed in Section 5.2, the threshold and eligibility requirements established by Con Edison discouraged many prospective DSM bidders.

There are several reasons why even this simple indicator should be interpreted with caution. First, there are significant accounting differences among utilities in reporting offers made by private producers. For example, some utilities allow developers to submit more than one bid per supply-side site. Niagara Mohawk received 75 supply-side bic's offering $7115 \mathrm{MW}$ of capacity. However 26 projects were multiple bids at the same site (which varied principally by contract term), which meant that there were only 49 unique supply projects representing about $4700 \mathrm{MW}$. On the supply-side, it is probably more meaningful to report the cumulative capacity represented by projects at unique sites.

Second, the DSM resource can be "mined" either by utility-sponsored DSM programs or by energy service companies via bidding or performance contracting programs. Thus, the scope and comprehensiveness of a utility's existing DSM programs plays a key role in defining remaining market opportunities for ESCOs. For example, at the time Public Service of Colorado issued a DSM-only bidding solicitation for $50 \mathrm{MW}$, the utility had only minimal DSM program offerings. Public Service Colorado received 64 bids representing $131 \mathrm{MW}$, even though the DSM ceiling price was quite low compared to other utilities $(\$ 240 / \mathrm{kW})$. 
Table 6-1. Market Response in Smail vs. Large Bidding Programs

\begin{tabular}{|c|c|c|c|c|c|c|}
\hline \multirow[b]{2}{*}{ Utility } & \multirow[b]{2}{*}{$\begin{array}{l}\text { RFP } \\
\text { Issued }\end{array}$} & \multirow[b]{2}{*}{$\begin{array}{l}\text { Hesourco } \\
\text { Block Size }\end{array}$} & \multirow{2}{*}{$\begin{array}{l}\text { Supply } \\
\text { Resource } \\
\text { No. of } \\
\text { Bids }\end{array}$} & \multirow[b]{2}{*}{ MWs } & \multicolumn{2}{|c|}{ DSA Resource } \\
\hline & & & & & $\begin{array}{l}\text { No. of } \\
\text { Bids }\end{array}$ & $M W$ \\
\hline Con Ed & $2 / 90$ & 200 & 35 & 2976 & 4 & 11.9 \\
\hline Miagara Mohawk & $11 / 89$ & 350 & 75 & 7115 & 32 & 162 \\
\hline \multicolumn{7}{|l|}{ Small Program } \\
\hline CMP \#1 & $12 / 87$ & 100 & 45 & 666 & 13 & 36 \\
\hline Puget & $6 / 89$ & 100 & 34 & 1251 & 8 & 28 \\
\hline RG\&E & $9 / 90$ & $50 / 20$ & 3 & 59 & 19 & 67 \\
\hline Central Hudson & $11 / 90$ & $50 / 20$ & 15 & 680 & 7 & 40 \\
\hline Pacific Power \& Light & $10 / 91$ & 50 & 30 & 1288 & 19 & 91 \\
\hline $\begin{array}{l}\text { Washington Water } \\
\text { Power }\end{array}$ & & 30 & 10 & 280 & 5 & 15 \\
\hline \multicolumn{7}{|l|}{ Large Program } \\
\hline ORU & $6 / 89$ & 200 & 25 & 1395 & 12 & 29 \\
\hline LILCO & $11 / 89$ & $150 / 15$ & 21 & 1765 & 14 & 23 \\
\hline CMP \#2 & $5 / 89$ & $150-300$ & 41 & 2338 & 9 & 30 \\
\hline JCP\&L & $8 / 89$ & 270 & 11 & 712 & 8 & 56 \\
\hline PSE\&G & $8 / 89$ & 200 & 8 & 654 & 8 & 53 \\
\hline P:-: Energy & $12 / 88$ & 550 & 12 & 1800 & 9 & 78 \\
\hline NYSEG & $7 / 90$ & $100 / 30$ & 11 & 595 & 31 & 98 \\
\hline NCPA & $7 / 91$ & 200 & 58 & 9866 & 12 & 139 \\
\hline $\begin{array}{c}\text { Notes: (1) Some utilities estal } \\
\text { goal). }\end{array}$ & hod separa & pply \& DSM & ource block si & targets is & n by suppl & joal/DSM \\
\hline
\end{tabular}


Third, a quantitative assessment of capacity offered relative to resource block need provides policymakers with little information regarding the quality of bids. Threshold and eligibility requirements vary significantly among utilities and it appears that market response is correlated to some extent with the stringency of these requirements. Some utilities that defined minimal threshold requirements have reported that many of their bids were not serious offers and were quickly eliminated during the utility's initial bid evaluation. These projects may not have even been proposed by developers in solicitations with more stringent requirements. At a minimum, it would be useful to gauge market response by comparing offers from projects which can be characterized as "serious bids," defined as the subset of bids which at least pass the utility's threshold and eligibility requirements. But these requirements vary and the relevant statistics are not known.

\subsubsection{Successful Developinent of Projects with Signed Contracts}

Because competitive bidding is a relatively new phenomenon, a key indicator of success is the extent to which projects with signed contracts ultimately come on-line and deveiop successfully. There are two over-arching issues which complicate any analysis of project viability. First, there is the so-called "winners curse" phenomenon, which was discussed briefly in Section 5.5. The utility buyer is obligated to look for the best deal for ratepayers, however there is always the possibility that the sellers' project is unrealistic, and therefore not truly viable. The utility's bid evaluation and selection process must distinguish between bids that are too good to be true and projects that are truly innovative. Second, there is a potential problem if the utility's underlying strategic motives are at odds with the stated objectives of the solicitation. In a situation in which the utility's role is defined as the "supplier of last resort" and the utility would like to build a favored generation option, then the perception may exist among some parties that the utility would prefer that winning bids to fail.

Several approaches have been used by utilities to manage risks associated with project viability. For example, some utilities explicitly factor the expectation that a certain fraction of projects will fail to develop and thus sign contracts for a quantity of capacity which exceeds their resource need requirements. Various policy options have been proposed to make the utility financially indifferent to the "buy vs. build" choice. Private power industry representatives have suggested that utility shareholders should have the opportunity to earn some type of financial incentive based on their relative success in acquiring low-cost purchased power.

According to a recent study, $2842 \mathrm{MW}$ or about $13 \%$ or the projects with signed contracts awarded through bidding processes at U.S. utilities have been cancelled and/or failed to develop (Current Competition 1993). Interestingly, the decision to cancel was initiated by developers for over $1060 \mathrm{MW}$ while utilities cancelled contracts representing over $1100 \mathrm{MWs}$. Because the vast majority of capacity has been won by supply-side bidders and because these projects tend to be significantly larger than DSM bids, failures of individual supply-side projects are particularly important. The principal reasons for cancelled projects include environmental permitting problems, public opposition, local zoning problems and loss of steam host. These 
failure rates should be viewed as providing preliminary evidence because only about $24 \%$ of projects with contracts awarded through bidding have come on-line (see Figure 6-1). Most projects are either still under construction, under development, or have not yet signed contracts. Of the 92 projects that are currently operational, about $75 \%$ met their original on-line date.

Figure 6-1. Status of Projects Awarded Through Bidding

\section{Total $=21,284 \mathrm{MW}$}

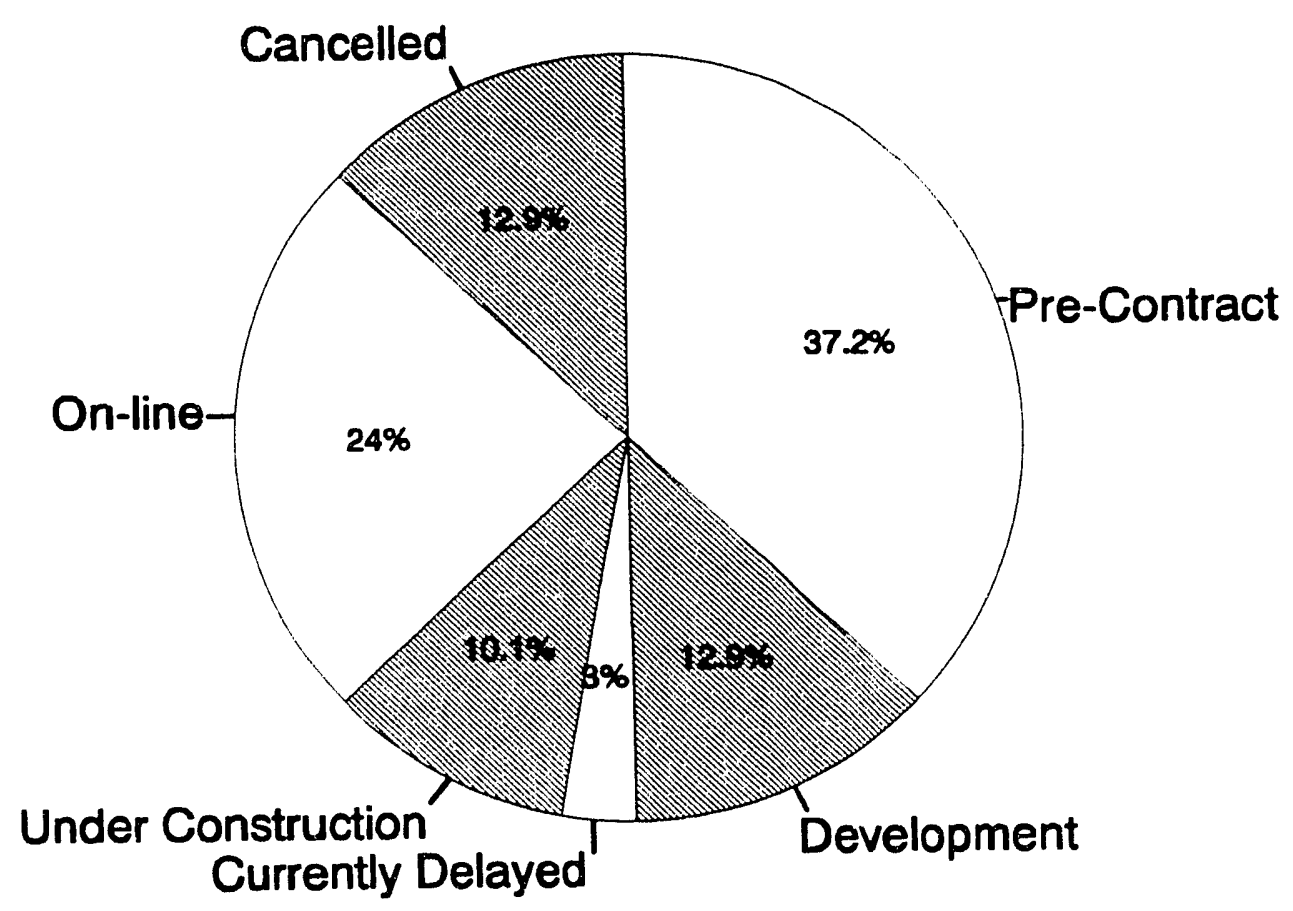

We make the following observations with respect to project viability issues that emerged from the Con Edison and Niagara Mohawk bidding programs.

- For a variety of reasons, the amount of capacity and number of projects that will successfully develop from Niagara Mohawk's bidding program will be significantly less than the utility's resource need as indicated in the RFPs (see Table 6-2). Niagara Mohawk (NMPC) has cancelled both of its winning supply-side bids (Huntley 67, a refurbishment of an existing coal-fired plant, and Guilderland, a gas-fired project) which represent $405 \mathrm{MWs}$ out of $441 \mathrm{MW}$ in the Final Award Group. According to the utility, the primary reason for cancellation was that the projects were no longer cost-effective, given the utility's most recent estimates of long-run avoided costs 
Table 6-2. Development Status of Winning Projects in Niagara Mohawk and Con Edison Bidding Programs

\begin{tabular}{|c|c|c|c|}
\hline Projoct & Capacity & $\begin{array}{l}\text { Type of } \\
\text { Resource }\end{array}$ & $\begin{array}{l}\text { Dovelopment } \\
\text { Status } \\
\end{array}$ \\
\hline \multicolumn{4}{|l|}{ Niagara Mohawk } \\
\hline Huntley 67 & 189 & Life extension & Cancelled by utility \\
\hline Guilderland & 216 & Gas combined-cycle & Cancelled by utility \\
\hline CESMay & 7.7 & DSM & Partially completed \\
\hline Syresco & 5.8 & DSM & Partially completed \\
\hline Planergy & 5.1 & DSM & Completed \\
\hline General Motors & 1.4 & DSM & Partial completion \\
\hline SESCO & 16.0 & DSM & Cancelled by utility \\
\hline Total & 441 & & \\
\hline \multicolumn{4}{|l|}{ Con Ed } \\
\hline Brooklyn Navy Yard A & 40 & Gas & Under development \\
\hline Brooklyn Navy Yard B & 40 & Gas & Under development \\
\hline $\begin{array}{l}\text { Brooklyn Navy Yard } \\
\text { Central }\end{array}$ & 90 & Gas & Under development \\
\hline Brooklyn Warbasse Cogen & 16 & Gas & In contract negotiations \\
\hline Brooklyn Bio Resources & 17.7 & Wood & In contract negotiations \\
\hline Enersave Inc & 6.6 & DSM & Partial completion \\
\hline CES/Way & 1.6 & DSM & partial completion \\
\hline Energy Service of Colorado & 1.0 & DSM & $\begin{array}{l}\text { Withdrew during } \\
\text { negotiations }\end{array}$ \\
\hline Total & 215 & & \\
\hline
\end{tabular}


which are substantially lower than those in effect at the time the RFP was issued (and when projects were evaluated). The situation is less clear for the Con Edison bidding program because the bulk of supply-side projects are under development. In Section 5.5 , we reviewed the financial difficulties experienced by York Research, the developer of four winning bids representing $186 \mathrm{MW}$ out of a total award group of $215 \mathrm{MW}$. With the re-organization of these projects and York's formation of a partnership with Mission Energy, staff at Con Edison believe that the prospects are good that these projects will ultimately develop. However, their prospects remain uncertain. Contract negotiations have not been completed for two of the projects, representing about $34 \mathrm{MW}$. The process has taken far longer than anticipated and has been extended by mutual agreement between Con Edison and the project developers. ${ }^{27}$

- Looking at the status of winning DSM bidders at Con Edison and Niagara Mohawk, it appears that the six signed contracts will ultimately yield about $28 \mathrm{MW}$ of demand reductions as compared to $46 \mathrm{MW}$ of savings comprising the Final Award Groups for each utility. ${ }^{28}$ There was some attrition among winning DSM bidders as two projects dropped out or were cancelled during contract negotiations. Energy Services of Colorado withdrew their one MW project during contract negotiations with Con Edison, while NMPC recently announced that it would not complete negotiations with SESCO. NMPC claimed that the project was no longer cost-effective, given decreasing avoided costs, although SESCO has filed a protest with the NYPSC. These DSM projects got sidetracked in the initial stages of the development process (i.e., contract negotiations); similar patterns have been observed at other utilities. According to staff at both utilities, all DSM bidders with signed contracts are likely to achieve their contract demand goals, although in one or two cases, ESCOs have encountered some minor problems. Most DSM bidders have received partial payments as they have successfully completed installations representing a portion of their contract demand.

- Using the categories described in Figure 6-1, the status of winning projects at these two utilities can be summarized as follows. At Con Edison, about $80 \%$ of the capacity of winning projects is under development and $16 \%$ is pre-contract phase because of delays (sce Table 6-2). At Niagara Mohawk, about $95 \%$ of the capacity of winning projects was cancelled by the utility. It appears that the failure of winning bidding projects to develop successfully will have only a minimal impact on system reliability and economic losses to the utility should be small. The economic recession and increased utility DSM activity have reduced load growth while, at the

27 Con Edison's willingness to extend contract negotiations is influenced by the fact that they perceive no pressing need for new capacity.

28 NMPC's Final Award Group for DSM bidders was $36 \mathrm{MWs,} \mathrm{while} \mathrm{the} \mathrm{original} \mathrm{size} \mathrm{of} \mathrm{the} \mathrm{three} \mathrm{winning}$ DSM bids in Con Edison's program was about 10.5 MWs. 
same time, a glut of private power projects from the pre-bidding era are coming online. Thus, NMPC's sharply reduced need for new resources makes comparisons with other U.S. utilities more problematic because the underlying economic incentives to pursue these purchases are muted. Although the bidding programs in New York were regarded by regulators as a pilot for gaining experience with competitive resource acquisition, high failure rates among winning bids are not a particularly desirable uuticome. This is because perceptions of the integrity of the bidding process cain be adversely affected (and questions raised regarding the utility's underlying motives).

\subsubsection{Economic Benefits to Ratepayers}

Ultimately, the merits of competitive bidding will be judged on whether the process yields projects that offer economic benefits to ratepayers compared to the relevant alternatives. At present, several factors make this issue difficult to analyze: (1) data limitations, (2) disagreements over the appropriate yardstick to use in assessing economic benefits to ratepayers, (3) analytic complexities involved in valuing and pricing various contract terms and provisions and (4) changing market conditions.

First, in order to analyze economic benefits to ratepayers from competitive bidding, it is essential that the products of the process (i.e., contracts) be publicly available. However, some commissions (e.g., Texas) and utilities (e.g., Niagara Mohawk) regard all or some of the provisions of private power contracts as confidential. Moreover, some cost components (e.g., estimated and actual customer cost contributions) are not typically included in the contract between the utility and winning DSM bidder. This information along with utility administrative costs are necessary to calculate the societal cost-effectiveness of DSM projects.

Second, in evaluating the economic benefits of supply-side projects to ratepayers, a utility's avoided supply costs provide a convenient and relatively well-established metric. However, on the demand-side, the value of a DSM bid depends to some extent on what it is replacing. The DSM bid could be compared to the utility's avoided supply-side costs, but the utility might also believe that it is important to evaluate the cost of the DSM bid relative to "comparable" planned or existing utility DSM programs. Significant disagreements exist regarding the appropriate metric to use in evaluating the value of DSM bids, and this issue figured quite prominently in Niagara Mohawk's bid evaluation process (Hamilton and Flaim 1992). We would suggest that the costs of a "comparable" utility DSM program adjusted for additional risks and services provided by an ESCO provides a lower bound for comparing the economic benefits to ratepayers of DSM projects, while the utility's avoided supply costs (including environmental externalities) provides an upper bound.

Third, contract terms and provisions are often quite complex, particularly those relating to the pricing and performance of supply-side projects. This makes it difficult to reduce contract features to standardized formats that allows various projects to be analyzed on a comparable 
basis. Contracts that provide for dispatchability are more valuable than must run projects, all else being equal. Measuring the value difference can be complex (Kahn et al. 1992).

Figure 6-2. Effect of Changed Market Conditions on Estimating Benefits of Competition

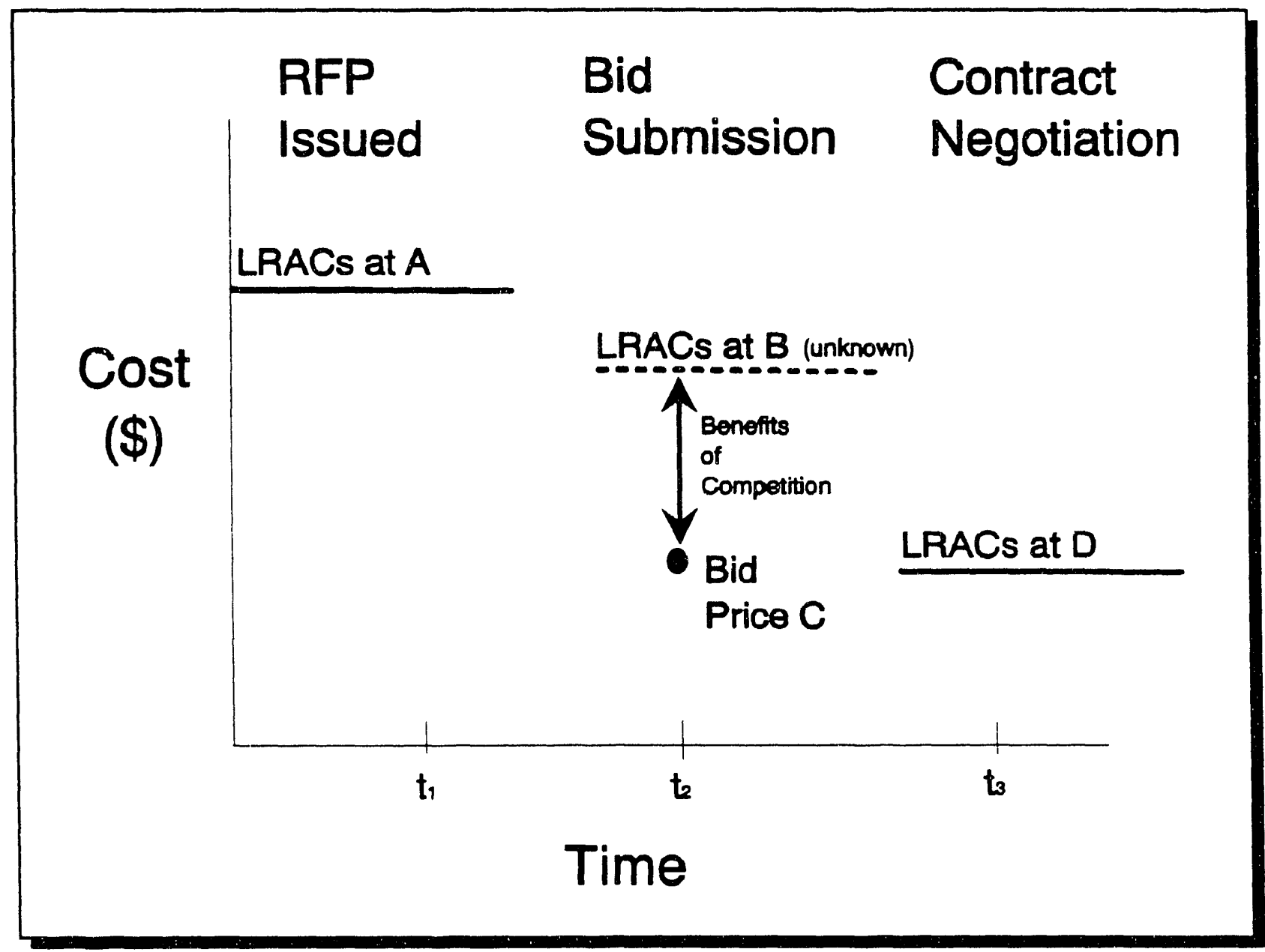

Fourth, the time period between formulation of a utility RFP, bid submission, evaluation and contract negotiation can be long. During this period market conditions may change. New York's utilities experienced considerable changes during the various phases of competitive bidding. Figure 6-2 shows these changes in market conditions in a stylized fashion. The utility's long-run avoided costs (LRACs) vary during three distinct phases. At $t_{1}$, the bidding RFP is formulated and LRAC values (i.e., level A) to be used in the RFP are negotiated with the PSC. At $t_{2}$, bidders submit proposals based on a market assessment, which may reflect lower costs than those estimated at $t_{1}$ (i.e., level B). By $t_{3}$, market costs have fallen further than at $t_{2}$, possibly because the long-term forecast of gas prices has dropped (LRAC level D). Compared to the LRACs at $t_{1}$, the winning bid price $C$ is quite low. But the competitive benefit of a project with bid price $C$ is really best measured relative to the period contemporaneous with bid 
submission (i.e., LRAC level B). During contract negotiations, which occur at $t_{3}$, the LRACs at level $\mathrm{D}$ are lower than when bids were submitted. On the one hand, if the market response to the utility's bidding RFP is impressive, then winning projects might have a substantial price cushion relative to administratively determined LRACs that have become outdated. However, the economic benefits of winning projects are more tenuous when LRACs are at level D, and in this situation, the utility may want to consider deferring the project priced at $\mathrm{C}$ or consider negotiations regarding payment for contract termination (if a contract has already been signed).

Figure 6-3. Utility Payments to DSM Bidders

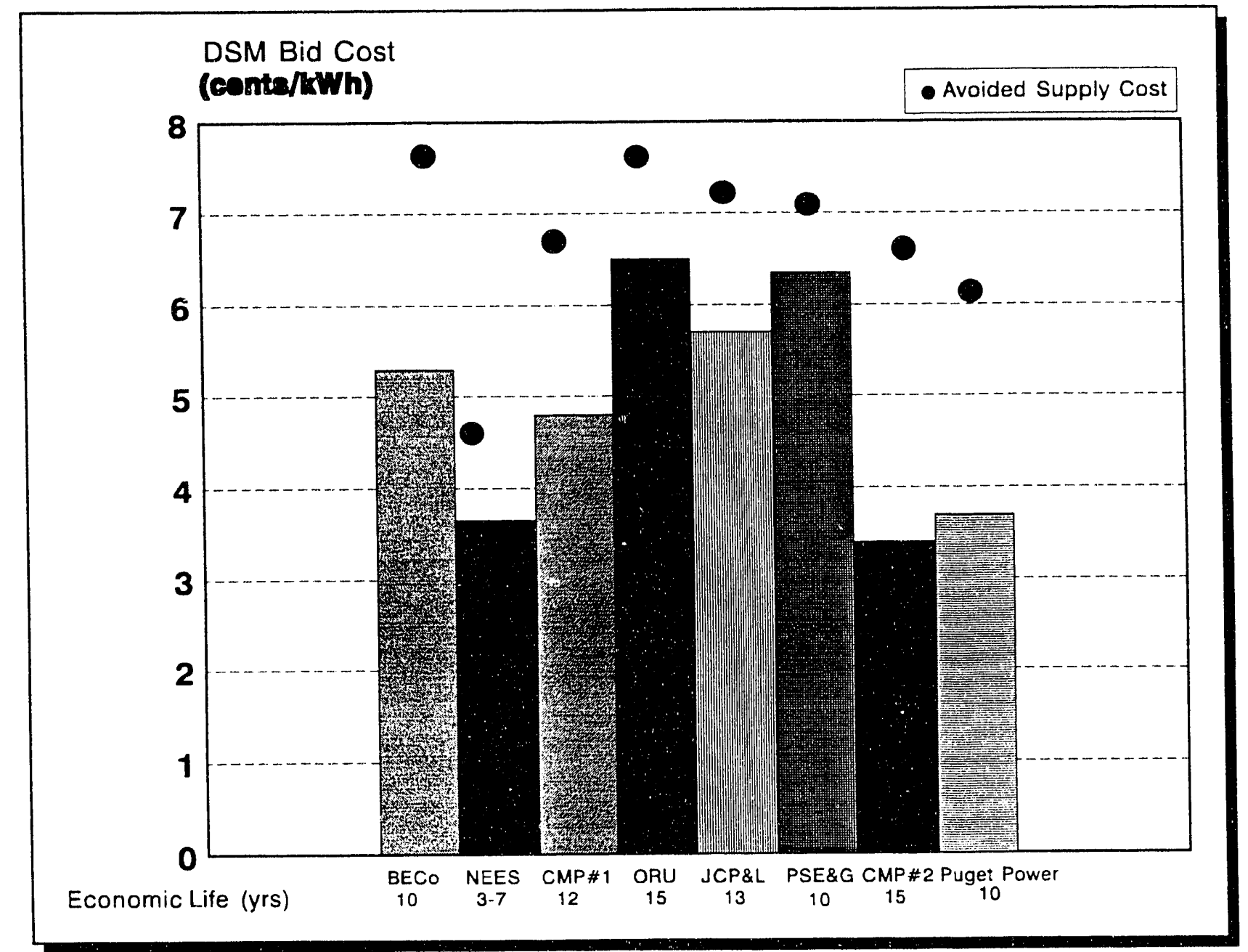

Several analysts have conducted scoping studies that include small samples of contracts signed under competitive bidding and attempt to estimate the benefits compared to contracts that were signed under the PURPA standard offer regime or compared to utility avoided supply costs (Kahn 1991; Lieberman 1992). Goldman and Busch (1992) have also collecied information on the costs of various utility DSM bidding programs based on signed contracts, evaluation reports, and interviews with program managers (see Figure 6-3). 
For comparison, we aggregated information on the costs of nine individual DSM and supply-side projects with signed contracts in the Niagara Mohawk and Con Edison bidding programs, summarized in Table 6-3. ${ }^{29}$

Table 6-3. Cost-Effectiveness of NMPC and Con Edison Bids with Signed Contracts

\begin{tabular}{|c|c|c|c|c|c|c|c|c|}
\hline Bid & MW & $\begin{array}{l}\text { Bid Price } \\
(6 / \mathbf{k W h})\end{array}$ & $\begin{array}{c}\text { Estimatod } \\
\text { Customer } \\
\text { Contribution } \\
(C / \mathrm{kWh}) \\
\end{array}$ & $\begin{array}{c}\text { Program } \\
\text { Admin } \\
\text { Coet } \\
(c / \mathrm{kWh}) \\
\end{array}$ & $\begin{array}{l}\text { Lovelized } \\
\text { Unility Coste } \\
\text { (c/kWh) }\end{array}$ & $\begin{array}{l}\text { Lovolized } \\
\text { TRC Costs } \\
\text { (6/kWh) }\end{array}$ & $\begin{array}{c}\text { Bid Prices } \\
\text { as \% of } \\
\text { Coiling } \\
\text { Price }\end{array}$ & $\begin{array}{l}\text { Bid Price } \\
\text { as } \% \text { of } \\
1989 \\
\text { LRACs }\end{array}$ \\
\hline $\begin{array}{l}\text { Con } \\
\text { Ed } \\
\text { DSM }\end{array}$ & 7.4 & 4.3 & 1.0 & 0.3 & 4.7 & 5.6 & $86 \%$ & $30 \%$ \\
\hline $\begin{array}{l}\text { Con } \\
\text { Ed } \\
\text { Supply }\end{array}$ & 170 & 7.0 & NP & NA & 7.0 & 7.0 & NA & $63 \%$ \\
\hline $\begin{array}{l}\text { NMPC } \\
\text { DSM }\end{array}$ & 20 & 3.7 & 1.1 & 0.3 & 4.0 & 5.1 & $48 \%$ & $48 \%$ \\
\hline
\end{tabular}

- Levelized costs for the three supply-side projects average 7.0 cents $/ \mathrm{kWh}$ and are about $37 \%$ lower than the utility's avoided supply cost. At first glance, the winning supply-side bids offered Con Edison a more substantial discount from the utility's avoided supply cost than what has typically occurred at othei utilities (10-20\%). However, estimates of the LRACs values that appear in Con Edison's RFP (which were approved in 1989) decreased significantly during this period. Using the stylized example shown in Figure 6-3, the competitive benefit would be estimated at $37 \%$ based on bid price $C$ and LRAC level $A$ values during $t_{1}$, but information on LRAC values (level B) is not available during $t_{2}$. Thus, dramatic changes in market conditions make it much more difficult to estimate the competitive benefit of these projects. The levelized cost data is informative, but this type of information is not widely available from other utilities that have conducted bidding programs.

\footnotetext{
29 There are four DSM contracts from the Niagara Mohawk bidding program (CES/Way, Syresco, Planergy, and General Motors), and two DSM contracts (CES/Way and Enersave) and three supply-side contracts (York Research projects at Brooklyn Navy Yard) from the Con Edison bidding program.
} 
- Levelized total resource costs for DSM bidders in Con Edison and Niagara Mohawk bidding programs average 5.6 and 5.1 cents/ $\mathrm{kWh}$ respectively. ${ }^{30}$ These levelized costs are likely to be within the range observed in the bidding programs of other utilities. However, our ability to make definitive comparisons of these costs to those of other utilities' bidding programs is limited because of differences in data quality and the fact that not all of the relevant costs are available for each utility. ${ }^{31}$ Moreover, utility payments to winning bidders are determined by a number of factors including: (1) the allowed ceiling price for DSM bids, (2) the relative cost and mix of DSM options, (3) comprehensiveness of energy services being provided by bidders, (4) perceived competitors, (5) degree to which performance risks and marketing and measurement costs are borne exclusively by ESCOs, and (6) flexibility in payment streams. For example, Con Edison established ceiling prices for incividual DSM measures paid by the utility. For the mix of measures offered by winning bidders, the ceiling prices were about 5 cents $/ \mathrm{kWh}$, which was much lower than the utility's avoided supply costs. Prices of winning bids averaged $86 \%$ of Con Edison's ceiling price. In this situation, it is not particularly meaningful to compare DSM bid prices as a percentage of avoided supply costs across the two utilities. Prices of winning bids averaged $48 \%$ of NMPC's ceiling price (which was the utility's avoided supply cost). Thus, it does appear that NMPC, which received over 30 DSM bids, was able to select somewhat lower cost projects compared to Con Edison, whose DSM bid choices were quite limited.

- A much more detailed and disaggregated analysis would be required to compare the costs of these DSM bids to "comparable" utility DSM programs. This type of comparison would provide a lower bound benchmark estimate to use in valuing economic benefits to ratepayers. In some cases, this type of analysis could be problematic. For example, two of NMPC's four winning DSM bids were directed at residential customers, proposing measures (e.g., second refrigerator pick-up) and targeting sectors (i.e., multifamily) that were not part of the utility's current DSM program offerings. Although Con Edison offered similar lighting and motor measures in its commercial rebate program, the two ESCOs are bearing additional performance risk in their contracts. Thus, in comparing the economic benefits to ratepayers of the two program delivery approaches, one must account for differences in risk allocation and assign some monetary value to the risk bearing.

30 These costs include levelized bid prices, estimated customer cost contribution, and utility program administration costs (including measurement and evaluation costs).

31 Note that levelized cost data from other utilities includes only levelized contract bid prices. Utility administrative costs and estimated customer cost contribution are excluded (because they are often not available). In most cases, customer contributions are minimal, while inclusion of program administrative costs would raise levelized costs by 5-20\%, depending on the utility. Data quality varies significantly: in New Jersey, bid prices are based on analysis of signed contracts, while, for Puget Power and NEES, information on payments to winning bidders are based on rough estimates provided by utility program managers (and hence are more uncertain). 


\subsubsection{Process-related Issues: Workable, Reasonable and "Fair"}

This last indicator encompasses several process-related issues and is clearly the most subjective. In one sense, reliance on competitive procurement involves a trade-off between the expected economic gains from competition with the costs of managing the potential conflicts associated with this type of process. It is unlikely that utilities will receive many kudos for managing competitive processes in part because a significant market response means that there will be many losing bidders almost by definition. About the best outcome one can expect on processrelated issues is that most parties view the utility's bidding process (including the design and implementation of the RFP) to be reasonable and that the utility's evaluation and selection process is perceived as "fair".

A poor market response, or failure to bid, is one indication that a utility's bidding program was not administratively tractable. In addition, several utilities have conducted process evaluations of their DSM bidding programs (ERCE 1990; ERCE 1991; Peters et al. 1992). ${ }^{32}$ These evaluations can also be very helpful in assessing barriers to participation and providing information on the workability of a bidding program from bidders' perspective. However, process evaluations of DSM bidding programs need to be viewed critically because the win/lose situation created by a bidding program, which may produce disgruntled losing bidders, is so different from the typical dynamics faced by customers considering participating in a utility rebate program.

In assessing "fairness", we consider several dimensions. First, are there systematic biases in the utility's bidding RFP, particularly its bid evaluation and scoring system? Second, are there serious problems in the way that the utility implemented the provisions of the bidding RFP which significantly disadvantaged certain types of resources or providers? In reviewing Con Edison's bidding program, we focused more on the first dimension, in part because the utility relied exclusively on an objective scoring system (see Section 5.3). In contrast, NMPC's twophase bid evaluation process necessarily involved more judgment on the part of utility management. Thus, our analysis focused on the decision criteria and resource choices made by NMPC in implementing their bidding scheme because the process was much less transparent.

Issues related to assessing the "fairness" of each utility's RFP design or bid evaluation and selection process with respect to various types of resources (supply vs. DSM) and providers (non-utility vs. utility) are obviously more subjective and open to varying interpretation. For example, it may be quite reasonable for the utility to place some restrictions on the types of entities or resources that are eligible to bid, often because this will make bid evaluation a more tractable process. We reject the notion that because certain types of resources or providers are excluded from a particular bidding RFP, then the utility's bidding program is unfair. This

\footnotetext{
32 Formal evaluations that are publicly available are rare for supply-side procurements. Comparisons of subsequent supply-side RFPs over time suggests that many utilities have made significant changes to their bidding programs based on internal management review, which in some cases are influenced by new regulatory requirements or preferences.
} 
question is perhaps best addressed in the context of reviewing the consistency and linkages between the utility's integrated resource plan and its competitive resource acquisition strategy.

The design of the Con Edison bidding system discouraged many third-party DSM providers from even participating. Con Edison over-reacted in its concerns about potential project viability problems among third-party DSM bidders by establishing overly stringent threshold requirements. While DSM bidders responded quite favorably to Niagara Mohawk's RFP, the Company's decision criteria used in the phase two bid evaluation of projects in the Preliminary Award Group were too restrictive in managing competition among ESCOs and between ESCO and utility DSM programs (Goldman et al. 1992). After grouping bids into similar customer classes and targeted end uses, NMPC rejected all but the least cost ESCO bid in a particular category. The negative impacts of this decision were most pronounced in the heterogenous commercial/industrial sector where NMPC received a number of attractive ESCO bids.

Bid evaluation and selection processes are further complicated when utility subsidiaries participate directly as a seller in the parent utility's own auction. A few PUCs (e.g., New Jersey) have deemed the potential threat posed by anti-competitive practices to be so great as to exclude a host utility from participating as a seller in its own bidding program. Other PUCs, like New York, have allowed the utility to propose its preferred resource options but have imposed additional requirements and procedural safeguards (e.g., sealed bids, use of independent third party to open bids) plus the threat of financial sanctions if unfair or abusive practices are discovered. In New York, Con Edison did not participate as a seller but Niagara Mohawk proposed two life extension projects, one of which (Huntley 67) was selected for the Final Award Group.

NMPC utilized a two-stage bid evaluation process which featured an independent contractor (hired by NMPC) who ranked bids based on an objective self-scoring system in phase one. NMPC then analyzed projects in the Initial Award Group in more detail in a second stage using modeling and analysis methods established by the utility. NMPC's use of a third-party evaluator in Phase one was not sufficient protection against the appearance of self-dealing. This is particularly true in light of the limited exploration of alternatives in the Phase 2 subjective bid evaluation and concerns about asymmetric and more lenient treatment of refurbishment projects compared to new projects in the Phase 1 environmental scoring (Goldman et al. 1992). The Huntley 67 project illustrates the generic issue of the treatment of utility repowering and life extension options in competitive bidding: the difficulty of comparing refurbishments of existing resources with new projects. Utility subsidiaries can be expected to play an even more prominent role in competitive bidding programs with the passage of the Energy Policy Act of 1992 and the creation of a new class of independent power producers (i.e., Exempt Wholesale Generators).

Finally, in thinking about process-related issues, compared to PUCs and utilities in many other states, the New York commission and utilities have placed greater emphasis on formal 
evaluations of these programs. ${ }^{33}$ Thus the process and outcomes have been subject to more public scrutiny and review by third parties such as this study. We believe that regulators and utilities have an ongoing need to assess the relative benefits and risks of competitive procurement, given its emergence as the dominant mechanism to acquire non-utility resources. To meet this challenge, the interested parties will be required to develop a more comprehensive evaluation framework, refine analytic methods, and assure the increased availability and consistent reporting of cost and performance data.

\footnotetext{
${ }^{33}$ Niagara Mohawk hired a third party contractor to conduct a formal process evaluation of the DSM component of the integrated bidding component (ERCE 1992). There has not been a formal process evaluation among supplyside participants, although many issues/problems that arose in the state's bidding program have been discussed at meetings of the Supply-side Bidding Working Group, under the direction of the NYPSC's Office of Research. LBL's review of the bidding progiams of two utilities was supported by the NYPSC and NYSERDA.
} 


\section{Acknowledgements}

The authors acknowledge the support offered by the New York State Energy Research and Development Authority project managers, Marsha Walton and David Wolcott.

We thank Sam Swanson, Jim Gallagher, Bill Mills, Mark Reeder, Harvey Arnett, Sury Putta, and Neil Rosenstrauch c. he Department of Pubiic Service, and Jim Keating of Con Edison for their helpful comments on a draft of this report. We also thank Bill Machold, Dennis Wilson and Andrew Glace for their helpful comments on a draft of this report. Finally, we thank Ellen Hodges for technical editing and report preparation.

The work described in this report was funded by the Assistant Secretary for Conservation and Renewable Energy, Office of Utility Technologies, Office of Energy Management of the U.S. Department of Energy under Contract No. DE-ACCj-76SF00098 and by New York State Energy Rescarch and Development Authority under Contract No. 1515-EEED-BES-91. 


\section{References}

Baldick, R. and E. P. Kahn 1992. "Transmission Planning in the Era of Integrated Resource Planning." LBL32231, Lawrence Berkeley Laboratory, Berkeley CA. September.

Barakat \& Chamberlin 1992. "Process Evaluation of Public Service of Colorado's 50-MW Bidding Program." April 15.

Baughman, M. and D. Bottaro 1976. "Electric Power Transmission and Distribution Systems: Costs and Their Allocation." IEEE Transactions on Power Apparatus and Systems PAS-95.

Consolidated Edison Company of New York (Con Edison) 1989. "Response of Consolidated Edison Company of New York Inc. to Parties' Comments on its Bidding Plan." New York NY. Case 88-E-246. February 21.

Consolidated Edison Company of New York (Con Edison) 1990a. "Request for Proposals for Supply Side and Demand Side Resources RFP \#90-1." New York NY, February 15.

Consolidated Edison Company of New York (Con Edison) 1990b. "Demand Side Management 1991-1992 Annual Plan and Long Range Plan." New York NY, July 23.

Current Competition 1993. "On-Line, On Time and Doing Just Fine," Stockton NJ, February.

Electric Power Research Institute (EPRI) 1986. "TAG-Technical Assessment Guide." Volume 1: Electricity Supply. EPRI: Palo Alto CA. December.

Energy Information Administration (EIA) 1992. "Financial Statistics of Selected Investor-Owned Electric Utilities 1990." DOE/EIA-0437(90)/1.

Environmental and Energy Services Co. (ERCE) 1990. "Evaluation of the Orange and Rockland Utilities Competitive Bidding Program for Demand-side Resources." ERCE/DSM-66. December.

Environmental and Energy Services Co. (ERCE) 1991. "Evaluation of Central Maine Power's Pilot Power Partners Program, Pilot Efficiency Buy-Back Program, and Pilot Commercial and Industrial Shared Savings Program." ERCE/PO-52.

Gadomski, C. 1992. "Trouble at York." Independent Energy. 22:7.

Goldman, C.A., J.F. Busch, E.P. Kahn, S. Stoft, and S. Cohen 1992. "Review of Integrated Resource Bidding at Niagara Mohawk," LBL-31667, Lawrence Berkeley Laboratory, Beikeley CA. May.

Goldman, C.A. and J.F. Busch 1992, "DSM Bidding - The Next Generation," The Electricity Journal. 5:4, p. 34-43. May.

Gilbert, R. and M. Riordan 1992. "Regulating Complementary Products: A Problem of Institutional Choice." working paper. University of California: Berkeley, CA.

Independent Power Report 1992. "Mission Inks Pact with York Research For 280-MW Unit at Brooklyn Navy Yard," April 10, pg. 6. 
Kahn, E. 1991. "Risks in Independent Power Contracts: An Empirical Survey." The Electricity Journal. 4:9, p. 30-45. November.

Kahn, E., M. Meal, S. Doerrer, et al. 1992. "Debt Leveraging in Private Power Projects." LBL-32487, Lawrence Berkeley Laboratory, Berkeley CA. August.

Kleinbard, D. 1991. "York Research, a Con Edison Contractor, Under SEC Investigation." Bloomberg Business News. November 26.

Lieberman, L. 1992. "The Impact of Procurement Regime on the Price Paid for Independent Generation." working paper. Stanford University, Department of Economics: Palo Alto CA.

Natural Gas Clearinghouse 1992. "Survey of Domestic Spot Natural Gas Prices."

New York Power Pool (NYPP) 1988. "Load and Capacity Data 1988-2004." April.

New York Power Pool (NYPP) 1991. "Report of the Member Electric Corporations of the New York Power Pool Concerning 1991 Long-Run Avoided Cost Estimates.” New York Public Service Commission Case 91-E-0237.

New York Public Service Commission (NYPSC) 1988a. "Proceeding on Motion of the Commission to Examine the plans for Meeting Future Electricity Needs in New York State." Opinion and Order Concerning Bidding, Avoided Cost Pricing, and Wheeling Issues. Opinion 88-15, Albany NY. June 3.

New York Public Service Commission (NYPSC) 1988b. "Case 28223, Order Concerning Long Range Demand-side Management Plans." Albany NY. October 13.

New York Public Service Commission (NYPSC) 1989a. "Opinion and Order Approving Demand-side Management Incentives and Establishing Further Proceedings." Opinion 89-29. Albany NY. September 12.

New York Public Service Commission 1989b. "Opinion and Order Establishing Guidelines for Bidding Program." Proceeding on Motion of the Commission (established in Opinion No. 88-15) as to the guidelines for bidding to meet future electric capacity needs of Consolidated Edison Company of New York Inc. Case 88-E-246, Opinion No. 89-30. September 13.

New York Public Service Commission (NYPSC) 1989c. "Order resolving Issues presented in petition for rehearing." Case 88-E-246. Albany NY. December 12.

New York Public Service Commission (NYPSC) 1991. Staff Position Paper in Case 91-E-0237.

New York Public Service Commission Staff (NYPSC Staff) 1989. "Staff's Comments to Consolidated Edison Company of New York Inc.'s Bidding Plan.” Albany NY. Cases 29409 and 88-E-246. January 20.

New York State Energy Office (NYSEO) and New York Departments of Environmental Conservation and Public Service 1989. "New York State Energy Plan." Albany NY. September.

New York State Energy Office (NYSEO) and New York Departments of Environmental Conservation and Public Service 1991. "Draft New York State Energy Plan 1991 Biennial Update." Volumes I-IV. Albany NY. July. 
Pacific Gas and Electric (PG\&E) 1991. "LOCATION: Incremental Transmission Impact Evaluation Program." Proceedings. California Public Utilities Commission Workshop.

Peters, J.S., M. R. McRae, and K. Seiden 1992. "Process Evaluation of Public Service of Colorado's 50-MW Bidding Program," April.

Standard \& Poor's 1991. "Indepenủent Power Project Finance Rating Criteria," October 17.

Stoft, S. and E. Kahn 1991. "Auction Markets for Dispatchable Power: How to Score the Bids." Journal of Regulatory Economics 3:3, p. 275-286.

Stone and Webster Management Consultants Inc. 1991. "Feasibility Report for the Midland Cogeneration Venture." Prospectus \$999,905,607 Midland Funding Secured Lease Obligation Bonds. Midland Cogeneration Venture Limited Partnership.

Thaler, R. 1988. "Anomalies: The Winner's Curse." Journal of Economic Perspectives. 2:1. p. 191-202.

Virginia Power 1988. "Request for Proposal for Power Purchases 1988 Solicitation." 


\section{Appendix A \\ Reactions to Consolidated Edison's DSM Bidding Program}

LBL conducted a telephone survey of a sample of prospective and actual DSM bidders in the Con Edison and Niagara Mohawk bidding programs during May-June 1991. The selected sample of non-bidders was drawn from companies that requested Con Edison's (and Niagara Mohawk's) RFP but did not submit a bid. We also had follow-up discussions with winning DSM bidders in the Con Edison program in February 1993 on the status of their projects. We also interviewed Con Edison staff involved in the bidding program.

The objective and scope of the LBL survey was rather limited, in part because the Bidding Working Group, led by the Department of Public Service, had plans to survey supply-side and DSM bidders. We developed separate surveys for bidders and non-bidders, which relied heavily on open-ended questions and covered selected topics (see Appendix B and C for bidder and nonbidder survey). Because there were relatively few DSM bidders and because responses were generally consistent among bidders and non-bidders, results from each survey are discussed together. Major factors that were explored with prospective bidders included:

(1) factors that affected decision on participation

(2) assessment of program design features and bid evaluation and selection process

(3) key issues that arose in contract negotiations with winning DSM bidders

(4) overall assessment of Con Edison's program compared to other utility DSM bidding programs

\section{Factors That Affected Bidder Participation}

Con Edison indicated that it received 36 Notices of Intent from potential demand-side bidders. We conducted interviews with staff at 26 of these companies. At eight companies, either the relevant person had left or the company was no longer in business, while in several cases, the person that filed the Notice of Intent represented more than one client. Among the sample, eight non-bidders in Con Edison's program were energy service companies that did submit bids in the Niagara Mohawk auction. Most of the remaining non-bidders were engineering, architecture, or real estate management companies.

Participation by DSM bidders was quite limited in Con Edison's bidding program. Con Edison received five DSM bids (from four different entities), and thus only about $10 \%$ of those that filed a Notice of Intent ultimately bid. Our interviews suggest that interest was quite high and that most firms were initially serious about participating in the auction. However, after examining the RFP, many firms were discouraged. A typical comment was, "We were quite excited about the bidding program until we analyzed the RFP." 
Table A-1. Principal Reasons for Non-Participation

\begin{tabular}{lc} 
Reason & Frequency \\
\hline $\begin{array}{l}\text { Requirement that ESCOs have signed letters of intent from all } \\
\text { customers }\end{array}$ & 14 \\
Expense of operating in New York City & 4 \\
Contract term length & 3 \\
Complexity of the RFP & 3 \\
Limited number of eligible measures & 2 \\
Ceiling prices changed; not enough time to revise bid & 7 \\
High rebate levels in utility DSM programs or heard that rebates were \\
increasing
\end{tabular}

The principal reasons given by non-bidders as factors that affected their decision to participate are summarized in Table A-1.

Con Edison's threshold requirement that bidders have signed letters of intent from customers for the entire contractual demand reduction was the primary reason given by most firms that chose not to participate. Prospective bidders reacted quite negatively to this program design feature:

- "You've got to be nuts to spend the money for marketing and engineering analysis that signed letters of intent require without a guarantee of signing a contract."

- "The requirement was ridiculous and unreasonable and a totally contrived mechanism to prevent DSM companies from bidding."

Four respondents mentioned the hassle and expense of doing business in New York City as a contributing factor in their decision not to submit bids. Several companies that did not have an office or contacts in the area indicated that the marketing expenses were likely to be prohibitive. Several companies cited potentially high labor costs and restrictive union work rules as barriers to participation (e.g., the electrical union requires people to work in pairs and thus the hourly labor rate is $\$ 120 / \mathrm{hr}$ for the pair, even if it is only a one-person job).

The complexity of the RFP was also cited as a barrier to participation by three firms. Many firms felt that the upfront effort (and associated cost) required to prepare a bid was not worth the risk. According to these firms, they might have participated, despite other misgivings, if bid preparation were less time consuming. 
Two firms indicated that it would too difficult to compete successfully against Con Edison's attractive rebates for its own utility-sponsored programs. Others indicated that they had heard rumors that rebate levels were going to increase before the deadline for the submission of bids, which made them reluctant to incur bid preparation costs. Seven prospective bidders complained that ceiling prices for individual DSM measures were initially too low to be profitable given the risks and that not enough time was given to prepare new bids after Con Edison revised and raised ceiling prices after the RFP was first issued. Several firms mentioned felt that the list of eligible measures was too limited.

\section{Assessment of Program Design Features}

Many firms indicated that the Con Edison bidding process was too restrictive. Energy service companies were particularly critical of several key threshold and eligibility requirements: Con Edison's requirement of a letter of intent from each participating customer, the inability of an ESCO to replace or substitute a project after the contract was signed if one of the customers with a letter of intent withdrew, and the limited list of eligible measures.

Many ESCOs claimed that a signed letter of intent required a significant upfront expenditure on engineering and legal fees, which was difficult to justify given the risks of the bidding process. Moreover, many customers were unwilling to lock themselves into that type of relationship, given that utility rebate levels were likely to change (and increase) and that there was no guarantee that the ESCO would win the auction. Two of the three ESCOs that bid already had customers lined up before the auction and consequently had minimal marketing expenses. Thus, these ESCOs had an inherent advantage in the auction over ESCOs with no experience in the service territory. Ironically, these restrictive eligibility requirements may have resulted in high numbers of "free riders", which was certainly not Con Edison's intent.

The list of allowable measures was highly restricted in the Con Edison auction. Only eight measures were eligible, all of which were covered by utility rebates. Consequently, ESCOs were unable to bid comprehensive packages of measures. Lighting and motors accounted for most of the proposed savings. Thus, one of the main advantages that ESCOs offer -- comprehensive retrofits -- was not used to advantage.

Several respondents commented that the RFP design seemed to be tailored primarily to supplyside resources, with relatively little thought given to which factors deserve the most weight when evaluating DSM bids.

\section{Bid Evaluation and Selection Process}

Many prospective DSM bidders commented that there interactions with the utility during the bid preparation process were problematic. The major issue mentioned was Con Edison's decision to increase customer rebates for its own core DSM programs about six weeks before the deadline 
for the submission of bids. Con Edison also raised the DSM ceiling prices for individual measures. However, several ESCOs mentioned that there was insufficient time to modify their bids or prepare new one, given the upfront marketing and engineering analysis required in this bidding process. Moreover, these firms were miffed because they had already invested significant resources on marketing and engineering analysis based on competing with the previous utility rebate levels.

Several prospective bidders questioned utility management's overall support for the bidding program and the degree to which customer service representatives were prepared for inquiries from customers regarding the bidding program. For example, one ESCO claimed that when a customer called for verification of the bidding program, the Con Edison representative that the customer had dealt with for years was unaware of the bidding program, which damaged the ESCOs credibility with this client. Another firm indicated that utility marketing reps were targeting customers already signed up by ESCOs and trying to sign them up for utility rebates.

\section{Contract Negotiation Process}

Winning bidders reported that contract negotiations were quite protracted and difficult. The Preliminary Contract Award Group was announced in January 1991, but it took between 10-20 months to negotiate the two DSM contracts. One DSM bidder withdrew very early during the contract negotiations.

Winning bidders indicated that a major stumbling block during contract negotiations were disagreements regarding options available to ESCOs to meet their contract demand reduction goal if customers that signed letters of intent decided not to go ahead with the project. ESCOs insisted that they should be able to recruit new customers to replace those that dropped out, while Con Edison opposed this provision.

Con Edison staff maintained that the provision that third party bidders must have signed letters of intent from all customers was clearly specified in the RFP. Thus, to assure the overall integrity of the bidding process (and those DSM bidders that chose not to submit bids), Con Edison felt compelled to maintain its position in negotiations.

\section{Overall Impressions}

Compared to their experiences with other utility bidding programs, several respondents indicated that Con Edison was relatively inflexible and uncommunicative. Overall, the survey indicates that prospective bidders would not give Con Edison high marks on any aspect of the bidding program: RFP design, bid evaluation and selection process, or contract negotiations. The level of dissatisfaction among DSM bidders is reflected primarily in the poor market response to the RFP both in te:ms of the number of DSM bids and the quantity of demand reductions offered. One respondent's comment captures the feelings of many prospective bidders and suggests that 
Con Edison should consider significant changes in program design philosophy if DSM bidding is to be utilized in the future: "the whole process was a real bear." 


\section{Appendix B Survey of DSM Bidders}

Firm

Respondent

Title

Date

Interviewer
NMPC $1^{\text {tt }}$ Stage Winner ( $Y / N$ )

NMPC $2^{\text {nd }}$ Stage Winner ( $\left.Y / N\right)$

Con Edison Winner ( $\mathrm{Y} / \mathrm{N})$

Customer (C), Nat'l (N) or Local (L) E

My name is and I am calling from the Lawrence Berkeley Laboratory in California. We are conducting a study of the integrated resource bidding programs of Niagara Mohawk and Con Edison companies under the sponsorship of NYSERDA, NYPSC, and DOE and as part of that study we are surveying the views of prospective and actual bidders in these programs.

We appreciate your taking the time to answer a few prepared questions. The interview should take approximately 30 to 45 minutes and all responses will be kept in strict confidence.

\section{NIAGARA MOHAWK BIDDING PROGRAM}

1. Did you submit a DSM bid in Niagara Mohawk's competitive bidding solicitation? yes no (If no, skip to question 18)

2. What in particular motivated you to participate in this bidding program?

3. What market sectors (commercial, industrial, residential) did you intend to approach?

4. What types of measures did you bid (lighting, HVAC etc.)? Was the choice of measures a reflection of your specialty, dictated by the list of eligible measures in the RFP, deterinined by the posted ceiling price, or due to other factors?

\section{Potential Impact of "Integrated" Bidding Program}

5. What affect, if any, did the fact that the bidding program was integrated and included "all-sources", both supply and demand-side resource options, have on your decision to bid or the iontent of your bid?

\section{Assessment of Procram Design Features}

6. Were there any elements of the RFP that you founa to be particularly well thought out? (PROBE: specific areas in table below)

7. Were there any elements of the RFP that you found to be particularly problematic or generally in need of improvement:

(PROBE: specific areas in table below) 
Threshold criteria

- 15 year minimum contract length

- $100 \mathrm{~kW}$ minimum capacity bid

- contract deposit of $\$ 15 / \mathrm{kW}$

Self-scoring criteria

- price score

- front-loaded payments \& security

- technical and market feasibility

- impact of customer behavior

- project viability (level of development, financing)

- qualifications \& experience

- performance monitoring and verification of savings

- basis for payment (estimated vs. measured savings)

- project location

- environmental score

Time for response to RFP Other

Bid Evaluation and Selection Process

8. Did the RFP adequately explain the bid evaluation and contractor selection process for

Phase One?

9. Did the company provide an explanation for their decision in selecting the Final Award Group (Phase Two)?

10. Were you satisfied with the way Niagara Mohawk's two-stage bid evaluation and contractor selection process worked in practice?

11. Do you have any comments on your interactions with the independent third party firm that conducted the evaluation and verification of bids in Phase One?

\section{Coordination and Relationship to Other Utility DSM Programs}

12. Niagara Mohawk has indicated that DSM bids were evaluated in relation to the company's own core DSM progr:ms. Do you have an opinion about whether, or how, this consideration should be treated in a bidding program?

\section{Comparison of Bidding to Other Utility DSM Programs}

13. Are you now, or have you in the past, participated in other Niagara Mohawk DSM programs? If so, what advantages or disadvantages does the bidding program have in comparison to those other programs? 


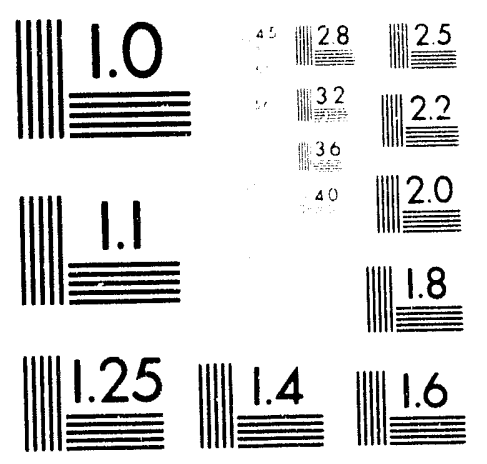



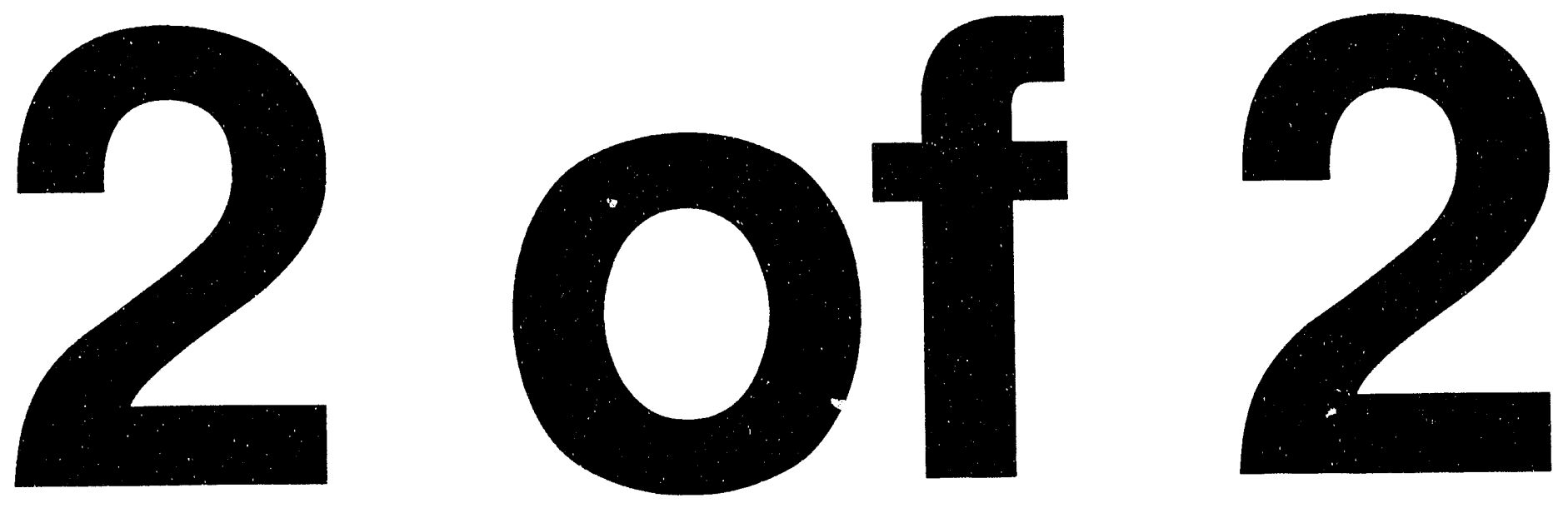


\section{Conclusions}

14. What is your overall assessment of the bidding program?

15. How could the bidding program be improved?

(Final Award Group Unly)

16. What were the major issues in the contract negotiation process?

17. Have you begun to instali measures in field? What is your timetable?

\section{CONSOLIDATED EDISON BIDDING PROGRAM}

18. Did you submit a DSM bid in Con Edison's bidding program? yes no

(If yes, skip to question 21; if no, go to questions 19-20)

19. Were there any aspects in particular of Con Ed's program that led you to decide against participation?

20. Were there reasons other than those directly related to the program that led to your decision not to participate (e.g., not enough time, too much of a hassle doing business in New York state or city, etc.l?

(If 18 = no and national ESCO, skip to 34 ; if customer, skip to 36 ; if local ESCO terminate interview)

21. What motivated you to participate in this bidding program?

22. What market sectors (commercial, industrial, residential) do you intend to approach?

23. What types of measures did you bid (lighting, HVAC etc.)? Was the choice of measures a reflection of your specialty, dictated by the list of eligible measures in the RFP, determined by the posted ceiling price, or due to other factors?

Potential Impact of "Integrated" Bidding Program

24. What affect, if any, did the fact that the bidding program was integrated and included "all-sources", both supply and demand-side resource options, have on your decision to bid or the content of your bid?

\section{Assessment of Program Design Features}

25. Were there any elements of the program that you found to be particularly well thought out?

(PROBE: specific areas in table below)

26. Were there any elements of the program that you found to be particularly in need of improvement?

(PROBE: specific areas in table below) 
Threshold criteria

- list of eligible measures

- $100 \mathrm{~kW}$. minimum capacity bid

- ceiling price for measures

- letter proving that bid is financeable

- verification of installation

- signned letter of intent with DSM client

- security arrangements $(\$ 15 / \mathrm{kW}$ deposit)

- front loading security

- ten year minimum contract

Self-scoring criteria

- make-up energy for hours not operating

- term adjustment (penalties for short lifetimes)

- availability adjustment

- front loading adjustment

Time for response to RFP

Other

Bid Evaluation and Selection Process

27. Did the RFP adequately explain the bid evaluation and contractor selection process?

28. Were you satisfied with Consolidate Edison's implementation of the bid evaluation and contractor selection process?

29. Do you feel the company gave an adequate explanation for their final selections?

\section{Comparison of Bidding to Other Utility DSM Programs}

30. Are you now, or have you in the past, participated in other Con Edison DSM programs? If so, what advantages or disadvantages does the bidding program have in comparison to those other programs?

\section{Conclusions}

31. What is your overall assessment of the bidding program?

32. How could the bidding program be improved?

\section{(Con Edison Winners Only)}

33. What were the major issues in the contract negotiation process?

(If customer, skip to 37; if local ESCO, terminate interview)

\section{Comparison of NMPC and Con Edison Bidding Programs (National ESCOs only)}

34. How would you compare the bidding programs of Con Edison and Niagara Mohawk? 
35. Have you had experience with other DSM bidding programs besides Niagara Mohawk or Con Edison? If so, how would you characterize that experience vis a vis the NMPC and Con Edison programs?

[terminate interview]

\section{(Customers Only)}

36. Have you been aware of, or participated in, other utility DSM programs? (PROBE: Which ones, and how?)

37. Were you approached by any ESCOs as a possible client during this bidding program?

38. Do you feel that the bidding program is adequately geared to the needs of customers? [terminate interview] 


\title{
Appendix C Survey of DSM Non-bidders
}

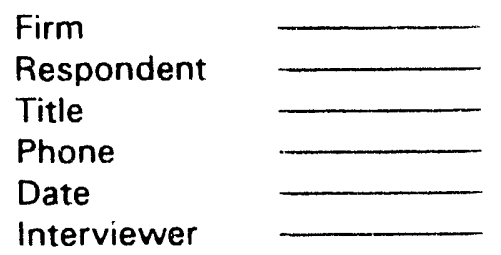

\author{
Customer (C), Nat'l (N) or Local (L) ESCO \\ Con Edison Non-respondent \\ NMPC non-respondent
}

This survey will be used for those firms/customers that received RFPs from either NMPC or Con Edison and chose not to respond.

My name is __and I am calling from the Lawrence Berkeley Laboratory in California. We are conducting a study of the integrated resource bidding programs of Niagara Mohawk and Con - tison companies under the sponsorship of NYSERDA, NYPSC, and DOE. As part of that study we are surveying views of firms/customers that received a copy of the Request for Proposals.

In 1989, [choose 1 Niagara Mohawk, Con Edison] requested demand and supply bids in their Competitive Bidding Program.

It is our understanding that you received a cupy of the RFP. We appreciate your taking the time to answer a few prepared questions. The interview should take approximately 20 minutes and all responses will be kept in strict confidence.

The first questions I have are about your firm.

\section{Non-respondents}

1. Were you the person responsible for reviewing the RFP?

Yes

No

2. Which of the following best describes your firms' major type of business? [check box]

a. Industrial Manufacturing firm

b. Commercial business

c. Government/Health Care/Education

d. Energy Service Company

e. Architecture/Engineering firm

f. Other Describe:

\section{Customer Perspective on Bidding Programs}

(Customers only: If $\mathbf{2}=\mathbf{a}$ or $\mathrm{b}$ or $\mathrm{c}$ )

3. Have you been aware of, or participated in, other utility DSM programs? (PROBE: Which ones, and how?) 
4. Were you approached by any ESCOs as a possible client during this solicitation?

5. Do you feel that the bidding program is adequately geared to the needs of customers?

[Skip to 9]

\section{Perspectives of Non-participating Energy Service Firm}

6. (For Energy service firms; $2=e$ or $f$ ) Which of the following DSM energy services does your firm provide?

a. Energy auditing

b. Design of ECMs

c. Installation of ECMs (specify technologies)

d. ECMs installation/design

7. Have you worked with the utility on other DSM programs? Have you done any work in INMPC or Con Edison service territories? (PROBE: Which ones, and how?)

8. Did your experience affect your decision to not submit a bid?
a. Yes
b. No
(Probe: In what ways?)

Overall Reactions of Non-respondents

9. What statement best explains your initial response to solicitation?

a. Received RFP for information only, no intention to apply

(Terminate Interview)

b. Interested in responding to supply-side RFP

(Terminate Interview)

c. Interested in program but had no time to prepare a proposal

d. Interested in program and tried to prepare a proposal

e. Other

10. What was the single factor that most influenced your decision not to respond to the solicitation?

11. (If appropriate ask:) Is there anything which could be changed in DSM bidding program which would lead you to willing to submit a proposal?

12. Were there reasons other than those directly related to the program that led to your decision not to participate (e.g., not enough time, too much of a hassle doing business in NYC, etc.)?

13. Do you have any final comments?

Thanks again for your cooperation. [Terminate interview] 


\section{Appendix D \\ Questionnaire to Con Edison Staff Involved in Bidding Program}

Respondent

Date
Title

Interviewer

\section{Bidding Program Design}

2) How well did the integrated auction work in practice? Was this approach well suited to evaluate DSM bids (Y/N)? Supply-side projects $(Y / N)$ ?

3) In general, how satisfied were you with the ability of the threshold requirements to screen out inadequate projects?

4) Were there any elements of the RFP (threshold requirements or evaluation criteria) that turned out to be particularly confusing, troublesome, or in need of improvement? Would you make any major changes in the relative weights for evaluation criteria?

\section{Bid Evaluation}

5) To what extent were people from the company DSM program area involved in the evaluation of bids?

6) In your view, has the company formulated and applied a policy (implicit or otherwise) in the bid evaluation process for determining how the DSM bidding and company-sponsored DSM programs are to co-exist?

\section{Contract Negotiations:}

7) What were the major issues that emerged in contract negotiations?

8) Do you see any role for negotiations in resolving outstanding issues that might otherwise result in bids being rejected outright?

9) Could you discuss the measurement/evaluation/verification plans of bidders? Were you satisfied with the plans proposed by bidders?

\section{Overall Impressions and Directions for Future:}

10) Based on the experience of RFP No. 1, is Con Edison prepared to pursue integrated bidding in the future or separate auctions for supply and demand, or some other approach? 
11) Were there any unanticipated results in terms of the scale of response, types of projects/rneasures bid, or other things?

12) Turning back the clock, what would you do differently if you were given a chance to issue RFP No. 1 all over again? 


\section{Appendix E Impact of Fuel Escalation Rate on Bid Price}

In this appendix, we illustrate the effect that a bidders' choice of gas price escalation rate would have on their adjusted price score. The calculations shown in Tables E-2 and E-3 show the effect on the bid price $(\$ / \mathrm{kW})$ of two different fuel price escalation assumptions for the Brooklyn Navy Yard A project. In Table E-2, the bid price is determined with the price of fuel escalating with the Implicit Price Deflator. This is how the project was bid and was subsequently contracted with Con Ed. ${ }^{34}$ In Table E-3, the fuel price escalates instead with the forecast for oil and gas prices given by Con Edison in their Request for Proposals. The two calculations are identical in all other respects.

Table E-1. Comparison of Different Gas Price Escalation Assumptions on the Bid Prices for the Brooklyn Navy Yard Projects

\begin{tabular}{lllll}
\hline & $\begin{array}{l}\text { Proposed } \\
\text { Start Date }\end{array}$ & $\begin{array}{l}\text { Contract } \\
\text { Capacity }\end{array}$ & $\begin{array}{l}\text { Contract Price } \\
\text { (uses iPD for fuel } \\
\text { escalation) }\end{array}$ & $\begin{array}{l}\text { Price using Con } \\
\text { Ed fuel price } \\
\text { forecast }\end{array}$ \\
\hline Navy Yard A & May 1992 & $40 \mathrm{MW}$ & $\$ 5,085 / \mathrm{kW}$ & $\$ 5,971 / \mathrm{kW}$ \\
Navy Yard B & May 1994 & $40 \mathrm{MW}$ & $\$ 4,464 / \mathrm{kW}$ & $\$ 5,419 / \mathrm{kW}$ \\
Navy Yard Central & May 1994 & $90 \mathrm{MW}$ & $\$ 3,959 / \mathrm{kW}$ & $\$ 4,770 / \mathrm{kW}$ \\
\end{tabular}

The payment stream is discounted back to mid-1990 using a discount rate of $9.8 \%$. All prices are given in nominal dollars. The rate of increase in the Implicit Price Deflator is assumed to be a constant $4.1 \%$ per annum. The annual price increase for gas in the Con Edison forecast varies from $5.1 \%$ to $10.35 \%$ (and the average annual price increase from 1990 to 2024 is $6.1 \%$ ). The calculations assume a capacity factor of $95 \%$ which, for a $40 \mathrm{MW}$ contract capacity, results in annual sales of 332,880 MWh of electricity. Start up charges (which are very small) are neglected in the calculation shown for the Brooklyn Navy Yard A project. Results of similar calculations for the Navy Yard B and Navy Yard Central projects are shown in Table E-1.

34 Contract No. 412, Power Purchase Agreement, by and between Con Edison Company of New York, Inc. and Cogeneration Technologies, Inc. (Brooklyn Navy Yard A), executed October 22, 1991. 
Table E-2. Brooklyn Navy Yard A as Bid

Assumptions:

Annual energy purchased $=332,880 \mathrm{MWh}$

Costs associated with start-ups are negligibie and have been neglected

Discount rate $=9.8 \%$

Annual inflation escalator $=4.1 \%$

Capacity Payment Components

Energy Payment Components

Total Cost

\begin{tabular}{|c|c|c|c|c|c|c|c|c|c|c|c|}
\hline Year & $\begin{array}{c}\text { Operating } \\
\text { Time }\end{array}$ & $\begin{array}{l}\text { Fixed } \\
\text { Capacity } \\
\$ / k W\end{array}$ & $\begin{array}{l}\text { Fixed } \\
O \& M \\
\$ / k W\end{array}$ & $\begin{array}{l}\text { Fixed } \\
\text { Fuel } \\
\text { Transp } \\
\$ / \mathbf{k W}\end{array}$ & $\begin{array}{c}\text { Total } \\
\text { Fixed } \\
\text { Paymt } \\
\$ / \mathbf{k W}\end{array}$ & \begin{tabular}{|c|} 
Price \\
Escalator \\
as Bid \\
$\%$ \\
\end{tabular} & $\begin{array}{l}\text { Var. } \\
\text { Fuel } \\
\text { c/kWh }\end{array}$ & $\begin{array}{l}\text { Var. } \\
\text { O\&M } \\
\text { c/kWh }\end{array}$ & $\begin{array}{l}\text { Var. } \\
\text { Fuel } \\
\text { Transp } \\
\text { c/kWh }\end{array}$ & $\begin{array}{c}\text { Total } \\
\text { Energy } \\
\text { Paymt } \\
\$ / \mathrm{kW}\end{array}$ & $\begin{array}{c}\text { Capacity } \\
+ \\
\text { Energy } \\
\$ / k W\end{array}$ \\
\hline 1990 & 0 & & 50 & 50 & & 4.1 & 1.80 & 0.40 & 0.20 & 0 & 0 \\
\hline 1991 & 0 & & 52 & 51 & & 4.1 & 1.87 & 0.42 & 0.20 & 0 & 0 \\
\hline 1992 & $8 \mathrm{mo}$. & 166 & 54 & 52 & 182 & 4.1 & 1.95 & 0.43 & 0.21 & 144 & 326 \\
\hline 1993 & all year & 166 & 56 & 53 & 276 & 4.1 & 2.03 & 0.45 & 0.21 & 224 & 500 \\
\hline 1994 & all year & 155 & 59 & 54 & 279 & 4.1 & 2.11 & 0.47 & 0.22 & 233 & 512 \\
\hline 1995 & all year & 166 & 61 & 55 & 283 & 4.1 & 2.20 & 0.49 & 0.22 & 242 & 525 \\
\hline 1996 & all year & 166 & 64 & 56 & 286 & 4.1 & 2.29 & 0.51 & 0.23 & 252 & 538 \\
\hline 1997 & all year & 166 & 66 & 58 & 290 & 4.1 & 2.38 & 0.53 & 0.23 & 262 & 552 \\
\hline 1998 & all year & 166 & 69 & 59 & 294 & 4.1 & 2.48 & 0.55 & 0.24 & 272 & 566 \\
\hline 1999 & all year & 166 & 72 & 60 & 298 & 4.1 & 2.58 & 0.57 & 0.24 & 283 & 581 \\
\hline 2000 & all year & 166 & 75 & 61 & 302 & 4.1 & 2.69 & 0.60 & 0.24 & 294 & 596 \\
\hline 2001 & all year & 166 & 78 & 62 & 307 & 4.1 & 2.80 & 0.62 & 0.25 & 306 & 612 \\
\hline 2002 & all year & 166 & 81 & 64 & 311 & 4.1 & 2.92 & 0.65 & 0.26 & 318 & 629 \\
\hline 2003 & all year & 166 & 84 & 65 & 316 & 4.1 & 3.03 & 0.67 & 0.26 & 330 & 646 \\
\hline 2004 & all year & 166 & 88 & 66 & 320 & 4.1 & 3.16 & 0.70 & 0.27 & 343 & 664 \\
\hline 2005 & all year & 166 & 91 & 68 & 325 & 4.1 & 3.29 & 0.73 & 0.27 & 357 & 682 \\
\hline 2006 & all year & 166 & 95 & 69 & 330 & 4.1 & 3.42 & 0.76 & 0.28 & 371 & 702 \\
\hline 2007 & all year & 119 & 99 & 71 & 288 & 4.1 & 3.56 & 0.79 & 0.28 & 386 & 674 \\
\hline 2008 & all year & 119 & 103 & 72 & 294 & 4.1 & 3.71 & 0.82 & 0.29 & 401 & 695 \\
\hline 2009 & all year & 119 & 107 & 73 & 299 & 4.1 & 3.86 & 0.86 & 0.29 & 417 & 717 \\
\hline 2010 & all year & 119 & 112 & 75 & 305 & 4.1 & 4.02 & 0.89 & 0.30 & 434 & 739 \\
\hline 2011 & all year & 119 & 116 & 76 & 311 & 4.1 & 4.19 & 0.93 & 0.31 & 451 & 763 \\
\hline 2012 & all year & 119 & 121 & 78 & 318 & 4.1 & 4.36 & 0.97 & 0.31 & 469 & 787 \\
\hline 2013 & all year & 119 & 126 & 80 & 324 & 4.1 & 4.54 & 1.01 & 0.32 & 488 & 812 \\
\hline 2014 & all year & 119 & 131 & 81 & 331 & 4.1 & 4.72 & 1.05 & 0.33 & 507 & 838 \\
\hline 2015 & all year & 119 & 136 & 83 & $33 \varepsilon$ & 4.1 & 4.92 & 1.09 & 0.33 & 528 & 866 \\
\hline 2016 & all year & 119 & 142 & 85 & 345 & 4.1 & 5.12 & 1.14 & 0.34 & 549 & 894 \\
\hline 2017 & all year & 119 & 148 & 86 & 353 & 4.1 & 5.33 & 1.18 & 0.35 & 571 & 924 \\
\hline 2018 & all year & 119 & 154 & 88 & 361 & 4.1 & 5.54 & 1.23 & 0.35 & 593 & 954 \\
\hline 2019 & all year & 119 & 160 & 90 & 369 & 4.1 & 5.77 & 1.28 & 0.36 & 617 & 986 \\
\hline 2020 & all year & 119 & 167 & 92 & 377 & 4.1 & 6.01 & 1.34 & 0.37 & 642 & 1,019 \\
\hline 2021 & all year & 119 & 174 & 94 & 386 & 4.1 & 6.26 & 1.39 & 0.38 & 667 & 1,054 \\
\hline 2022 & all year & 119 & 181 & 96 & 395 & 4.1 & 6.51 & 1.45 & 0.38 & 694 & 1,089 \\
\hline 2023 & all year & 119 & 188 & 98 & 404 & 4.1 & 6.78 & 1.51 & 0.39 & 722 & 1,126 \\
\hline 2024 & all year & 119 & 196 & 100 & 414 & 4.1 & 7.06 & 1.57 & 0.40 & 751 & 1,165 \\
\hline
\end{tabular}

Net Present Value in mid-1990 dollars $\$ 5,085$ 
Table E-3. Brooklyn Navy Yard A Using Con Edison Fuel Price Escalator

Assumptions:
Annual energy purchased $=332,880 \mathrm{MWh}$
Costs associated with start-ups are negligible and have been neglected
Discount rate $=9.8 \%$
Annual inflation escalator $=4.1 \%$

Capacity Payment Components

\begin{tabular}{|c|c|c|c|c|c|c|c|c|c|c|c|}
\hline Year & $\begin{array}{c}\text { Operating } \\
\text { Time }\end{array}$ & $\begin{array}{c}\text { Fixed } \\
\text { Capacity } \\
\$ / \mathbf{k W}\end{array}$ & $\begin{array}{l}\text { Fixed } \\
\text { O\&M } \\
\$ / k W \\
\end{array}$ & $\begin{array}{c}\text { Fixed } \\
\text { Fuel } \\
\text { Transp } \\
\mathbf{\$} / \mathbf{k W} \\
\end{array}$ & $\begin{array}{c}\text { Total } \\
\text { Fixed } \\
\text { Pymnt } \\
\$ / \mathrm{kW} \\
\end{array}$ & $\begin{array}{c}\text { Con Ed } \\
\text { Price } \\
\text { Escalator } \\
(\%)\end{array}$ & $\begin{array}{c}\text { Var. } \\
\text { Fuel } \\
\text { cikWh }\end{array}$ & $\begin{array}{c}\text { Var. } \\
\text { O\&M } \\
\text { c/kWh } \\
\end{array}$ & $\begin{array}{l}\text { Var. } \\
\text { Fuel } \\
\text { Transp } \\
\text { c/kWh } \\
\end{array}$ & $\begin{array}{c}\text { Total } \\
\text { Energy } \\
\text { Pymnt } \\
\$ / \mathrm{kW} \\
\end{array}$ & $\begin{array}{c}\text { Capacity } \\
+ \\
\text { Energy } \\
\$ / \mathrm{kW} \\
\end{array}$ \\
\hline 1990 & 0 & & 50 & 50 & & 5.14 & 1.80 & 0.40 & 0.20 & 0 & 0 \\
\hline 1991 & 0 & & 52 & 51 & & 5.14 & 1.89 & 0.42 & 0.20 & 0 & 0 \\
\hline 1992 & $8 \mathrm{mo}$. & 166 & 54 & 52 & 182 & 5.14 & 1.99 & 0.43 & 0.21 & 37 & 218 \\
\hline 1993 & all year & 166 & 56 & 53 & 276 & 10.35 & 2.20 & 0.45 & 0.21 & 238 & 514 \\
\hline 1994 & all year & 166 & 59 & 54 & 279 & 10.35 & 2.42 & 0.47 & 0.22 & 259 & 538 \\
\hline 1995 & all year & 166 & 61 & 55 & 283 & 10.35 & 2.67 & 0.49 & 0.22 & 282 & 564 \\
\hline 1996 & all year & 166 & 64 & 56 & 286 & 10.35 & 2.95 & 0.51 & 0.23 & 307 & 593 \\
\hline 1997 & all year & 166 & 66 & 58 & 290 & 8.26 & 3.19 & 0.53 & 0.23 & 329 & 619 \\
\hline 1998 & all year & 166 & 69 & 59 & 294 & 8.26 & 3.46 & 0.55 & 0.24 & 353 & 647 \\
\hline 1999 & all year & 166 & 72 & 60 & 298 & 8.26 & 3.74 & 0.57 & 0.24 & 379 & 677 \\
\hline 2000 & all year & 166 & 75 & 61 & 302 & 8.26 & 4.05 & 0.60 & 0.24 & 407 & 710 \\
\hline 2001 & all year & 166 & 78 & 62 & 307 & 5.14 & 4.26 & 0.62 & 0.25 & 427 & 734 \\
\hline 2002 & all year & 166 & 81 & 64 & 311 & 5.14 & 4.48 & 0.65 & 0.26 & 448 & 759 \\
\hline 2003 & all year & 166 & 84 & 65 & 316 & 5.14 & 4.71 & 0.67 & 0.26 & 470 & 785 \\
\hline 2004 & all year & 166 & 88 & 66 & 320 & 5.14 & 4.95 & 0.70 & 0.27 & 493 & 813 \\
\hline 2005 & all year & 166 & 91 & 68 & 325 & 5.14 & 5.21 & 0.73 & 0.27 & 517 & 842 \\
\hline 2006 & all year & 166 & 95 & 69 & 330 & 5.14 & 5.48 & 0.76 & 0.28 & 542 & 872 \\
\hline 2007 & all year & 119 & 99 & 71 & 288 & 5.14 & 5.76 & 0.79 & 0.28 & 568 & 857 \\
\hline 2008 & all year & 119 & 103 & 72 & 294 & 5.14 & 6.05 & 0.82 & 0.29 & 596 & 890 \\
\hline 2009 & $a^{\prime} i$ year & 119 & 107 & 73 & 299 & 5.14 & 6.36 & 0.86 & 0.29 & 626 & 925 \\
\hline 2010 & all year & 119 & 112 & 75 & 305 & 5.14 & 6.69 & 0.89 & 0.30 & 656 & 962 \\
\hline 2011 & all year & 119 & 116 & 76 & 311 & 5.14 & 7.04 & 0.93 & 0.31 & 688 & 1,000 \\
\hline 2012 & all year & 119 & 121 & 78 & 318 & 5.14 & 7.40 & 0.97 & 0.31 & 722 & 1.040 \\
\hline 2013 & all year & 119 & 126 & 80 & 324 & 5.14 & 7.78 & 1.01 & 0.32 & 758 & 1,082 \\
\hline 2014 & all year & 119 & 131 & 81 & 331 & 5.14 & 8.18 & 1.05 & 0.33 & 795 & 1.126 \\
\hline 2015 & all year & 119 & 136 & 83 & 338 & 5.14 & 8.60 & 1.09 & 0.33 & 8.34 & 1,172 \\
\hline 2016 & all year & 119 & 142 & 85 & 345 & 5.14 & 9.04 & 1.14 & 0.34 & 875 & 1,221 \\
\hline 2017 & all year & 119 & 148 & 86 & 353 & 5.14 & 9.50 & 1.18 & 0.35 & 918 & 1,271 \\
\hline 2018 & all year & 119 & 154 & 88 & 361 & 5.14 & 9.99 & 1.23 & 0.35 & 964 & 1,324 \\
\hline 2019 & all year & 119 & 160 & 90 & 369 & 5.14 & 10.51 & 1.28 & 0.36 & 1,011 & 1,380 \\
\hline 2020 & all year & 119 & 167 & 92 & 377 & 5.14 & 11.05 & 1.34 & 0.37 & 1,061 & 1,438 \\
\hline 2021 & all year & 119 & 174 & 94 & 386 & 5.14 & 11.61 & 1.39 & 0.38 & 1,113 & 1,500 \\
\hline 2022 & all year & 119 & 181 & 96 & 395 & 5.14 & 12.21 & 1.45 & 0.38 & 1,169 & 1,564 \\
\hline 2023 & all year & 119 & 188 & 98 & 404 & 5.14 & 12.84 & 1.51 & 0.39 & 1,226 & 1,631 \\
\hline 2024 & all year & 119 & 196 & 100 & 414 & 5.14 & 13.50 & 1.57 & 0.40 & 1,287 & 1,701 \\
\hline
\end{tabular}

Net Present Value in mid-1990 dollars $\$ 5,971$ 

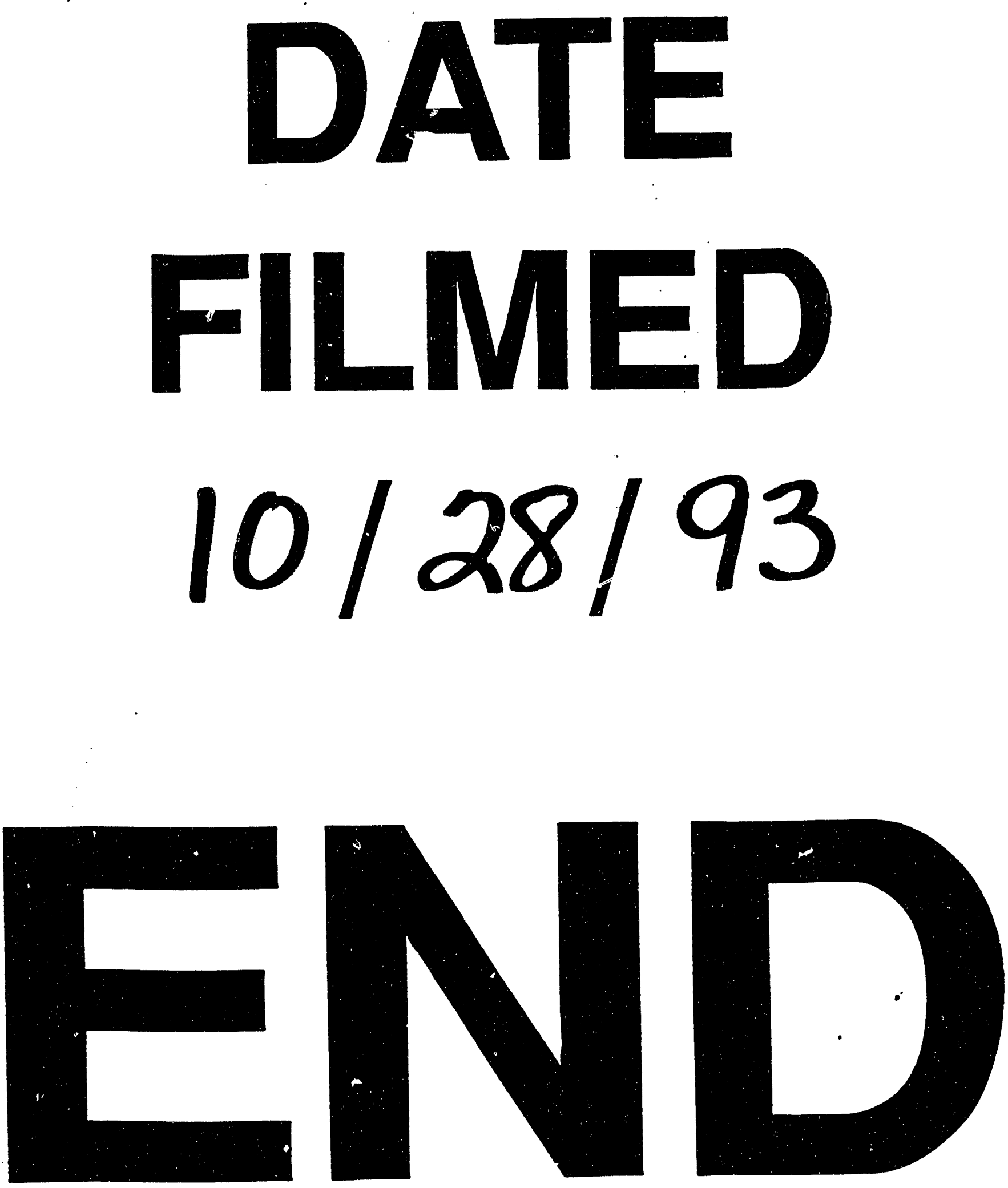
